\title{
A MODULAÇÃO DA LIPASE DE TRIACILGLICEROL DO ADIPÓCITO (ATGL) E DA PERILIPINA 1 CONTRIBUI PARA O AUMENTO DA LIPÓLISE EM PACIENTES CAQUÉTICOS
}

Tese apresentada ao Departamento de Biologia Celular e do Desenvolvimento do Instituto de Ciências Biomédicas da Universidade de São Paulo para obtenção do Título de Doutor em Ciências.

São Paulo

2011 
RENATA SILVÉRIO

\section{A MODULAÇÃO DA LIPASE DE TRIACILGLICEROL DO ADIPÓCITO (ATGL) E DA PERILIPINA 1 CONTRIBUI PARA O AUMENTO DA LIPÓLISE EM PACIENTES CAQUÉTICOS}

Tese apresentada ao Departamento de Biologia Celular e do Desenvolvimento do Instituto de Ciências Biomédicas da Universidade de São Paulo para obtenção do Título de Doutor em Ciências.

Área de concentração: Biologia Celular e Tecidual

Orientadora: Prof $^{\mathrm{a}}$ Dr $^{\mathrm{a}}$ Marília Cerqueira Leite Seelaender

Versão original

São Paulo

2011 
DADOS DE CATALOGAÇÃO NA PUBLICAÇÃO (CIP)

Serviço de Biblioteca e Informação Biomédica do

Instituto de Ciências Biomédicas da Universidade de São Paulo

reprodução não autorizada pelo autor

\section{Silvério, Renata.}

A modulação da lipase de triacilglicerol do adipócito (ATGL) e da perilipina 1 contribui para o aumento da lipólise em pacientes caquéticos / Renata Silvério. -- São Paulo, 2011.

Orientador: Marília Cerqueira Leite Seelaender.

Tese (Doutorado) - Universidade de São Paulo. Instituto de Ciências Biomédicas. Departamento de Biologia Celular e do Desenvolvimento. Área de concentração: Biologia Celular e Tecidual. Linha de pesquisa: Metabolismo lipídico na caquexia associada ao câncer.

Versão do título para o inglês: Modulation of adipose triglyceride lipase (ATGL) and perilipin 1 contributes to increased lipolysis in cachectic patients

Descritores: 1. Tecido adiposo 2. Metabolismo de gordura 3. Lipase 4. Câncer I. Seelaender, Marília Cerqueira Leite II. Universidade de São Paulo. Instituto de Ciências Biomédicas. Programa de Pós-Graduação em Biologia Celular e Tecidual III. Título. 


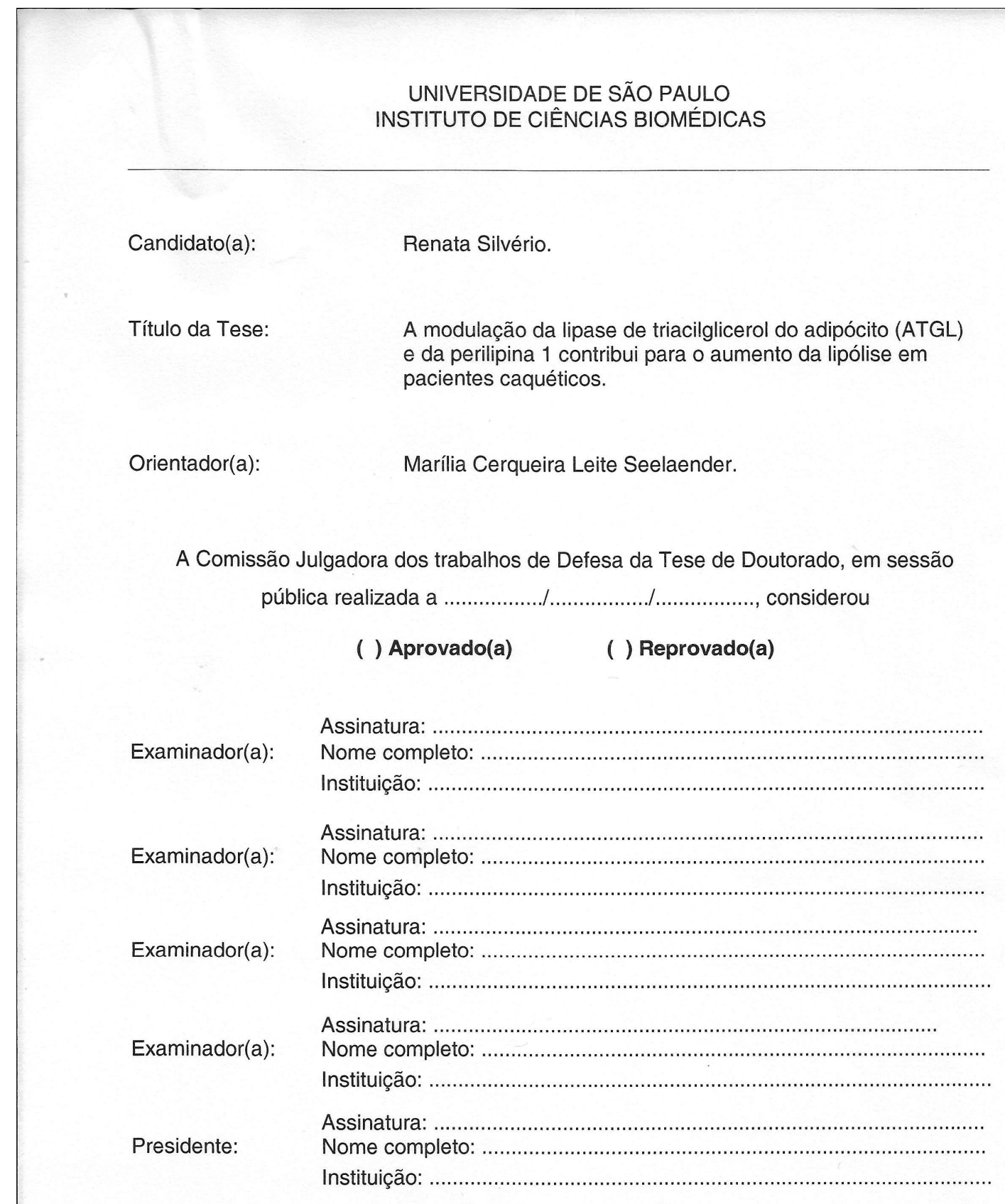




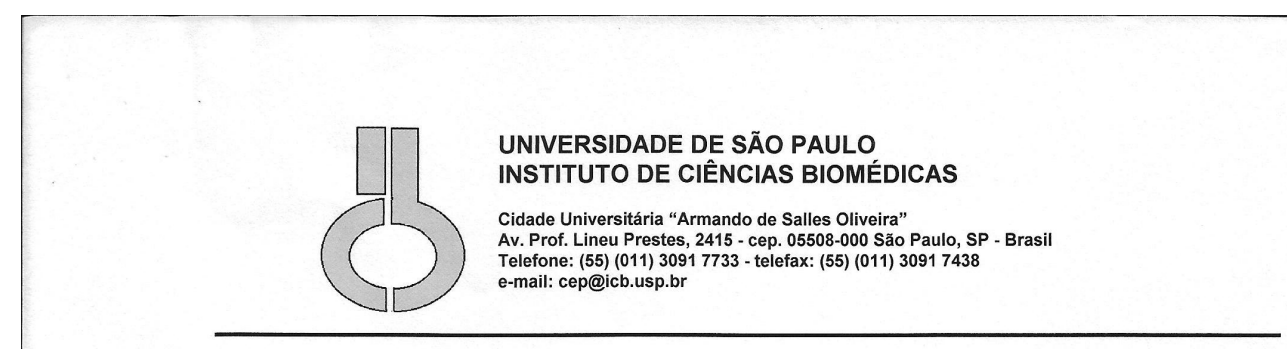

Decl. CEPSH.042/2011

\section{E C L A R A Ç Ã O}

Em adendo ao Parecer PARECER 788/CEP, datado de 13.06.07, por solicitação da Profa. Dra. Marilia Cerqueira Leite Seelaender, responsável pelo Projeto: "Influência das citocinas pró- e antiinflamatórias no tecido adiposo branco. Possível interação adipócito e infiltrado mononuclear", informo que a aluna Renata Silvério faz parte do referido projeto.

São Paulo, 10 de agosto de 2011.

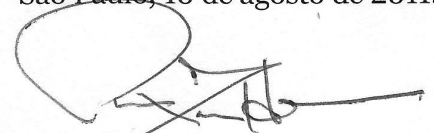

Prof Dr. Paolo M.A Zanotto

Coordenador da Comissão de Ética em

Pesquisas com Seres Humanos - ICB/USP

Comissão de Ética em Pesquisa com Seres Humanos do Instituto de Ciências Biomédicas - USP

Aprovada pela Comissão Nacional de Ética em Pesquisa - CONEP, em 10 de fevereiro de 1998. 


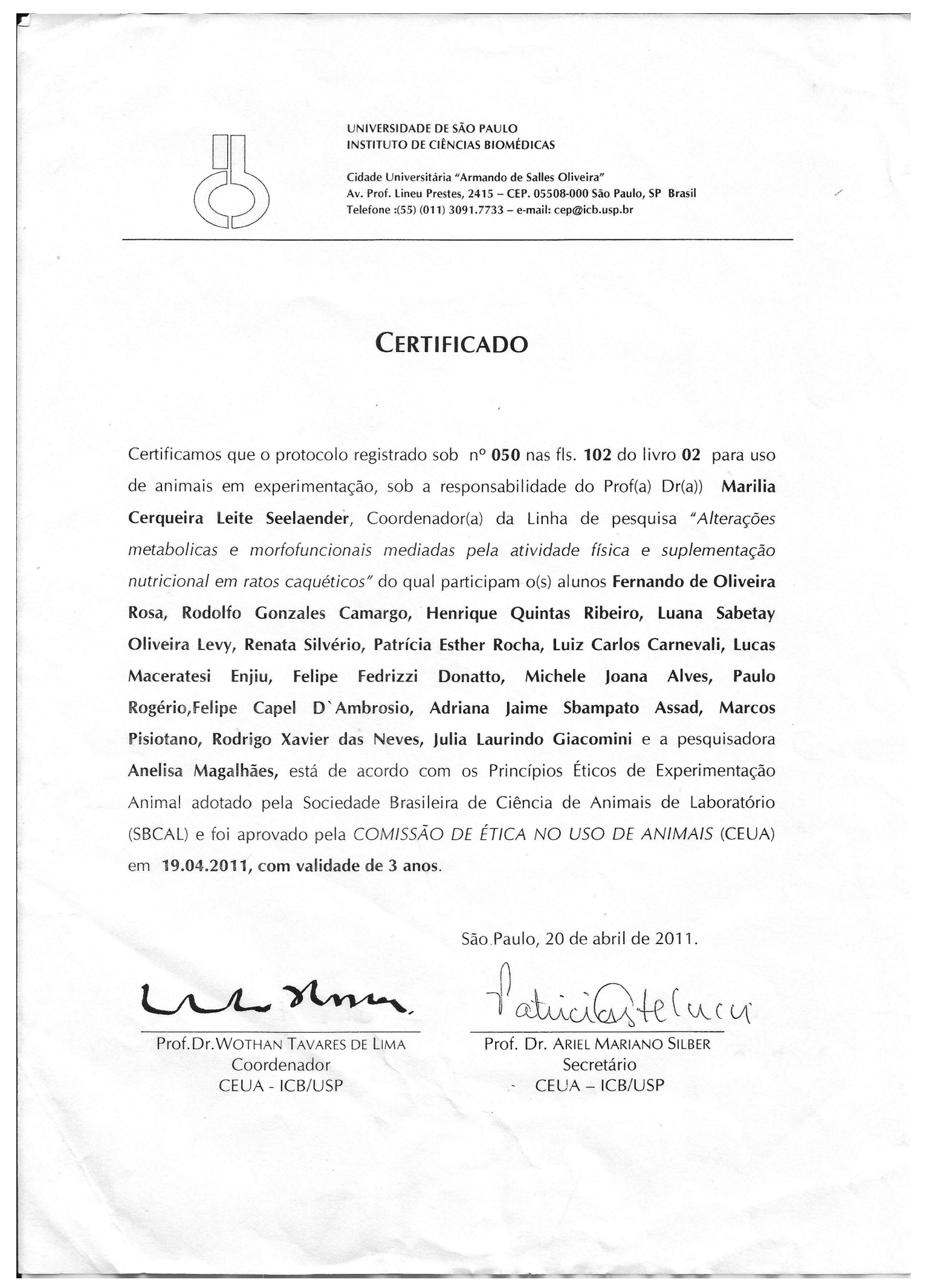


Ao meu pai... 


\section{RESUMO}

Silvério R. A modulação da lipase de triacilglicerol do adipócito (ATGL) e da perilipina 1 contribui para o aumento da lipólise em pacientes caquéticos. [tese (Doutorado em Biologia Celular e Tecidual)]. São Paulo: Instituto de Ciências Biomédicas, Universidade de São Paulo; 2011.

A caquexia associada ao câncer é uma síndrome inflamatória crônica que apresenta como uma das principais características uma profunda perda de massa gorda. O tecido adiposo é um importante órgão endócrino, capaz de secretar uma miríade de fatores, as adipocinas. A intensa redução da massa gorda observada na caquexia, cujas bases moleculares ainda não estão estabelecidas, poderia, portanto, implicar em alterações que vão além da simples redução das reservas energéticas. Postula-se que um aumento na lipólise decorrente do aumento na expressão e na atividade da lipase hormônio-sensível (LHS) seja o fator-chave por trás da atrofia do tecido adiposo nesta síndrome. Entretanto, a contribuição das novas proteínas relacionadas à lipólise [adipose triglyceride lipase (ATGL), comparative gene identification - 58 (CGI-58) e perilipina 1] ainda é controversa. Foi objetivo deste estudo, caracterizar a expressão das proteínas relacionadas à lipólise (LHS, ATGL, CGI-58 e perilipina 1) e das adipocinas (adiponectina, leptina e visfatina) ao longo da progressão do estado caquético. Pacientes do Hospital Universitário foram divididos em três grupos: portadores de tumor com caquexia (TBC), portadores de tumor com peso estável (TB) e controles (CTR). Um modelo experimental de caquexia foi também estudado, representado pelos seguintes grupos: ratos portadores do carcinossarcoma de Walker 256 sacrificados no 70 dia (TB7) e no $14^{\circ}$ dia (TB14) após a inoculação tumoral, e ratos controle. O tecido adiposo subcutâneo dos pacientes e o tecido adiposo epididimal dos animais foram investigados quanto aos aspectos morfológicos ( $\mathrm{HE}$ ) e morfométricos (área, diâmetro e perímetro dos adipócitos). Aspectos moleculares foram também examinados através da determinação do conteúdo protéico (ELISA e Western blotting) e expressão gênica (PCR tempo real) das seguintes proteínas: LHS, ATGL, CGI-58, perilipina 1, leptina, adiponectina, visfatina e fator de necrose tumoral-alfa (TNF-a). Verificamos um aumento da lipólise nos pacientes caquéticos, não apenas pelo aumento na expressão de LHS, mas também pela aumentada expressão da ATGL (quase 2 vezes em relação ao CTR) e redução no conteúdo de perilipina 1 (51 \%). Nos animais em uma fase intermediária da síndrome, a qual se assemelha com o estágio observado em nosso modelo clínico, verificou-se ainda um desequilíbrio na secreção de fatores anti e pró-inflamatórios. No estágio final da caquexia as alterações são ainda mais profundas e houve redução na expressão de quase todas as proteínas analisadas nos 
animais. Esta marcante redução na expressão de adipocinas e proteínas relacionadas à lipólise, associada à alteração na matriz extra-celular e formato dos adipócitos, sugere que no estágio final do estado caquético há um comprometimento da função celular como um todo. Verificamos que a caquexia induz importantes alterações morfológicas, moleculares e humorais no tecido adiposo branco, cuja intensidade relaciona-se diretamente com o estágio da progressão do estado caquético.

Palavras - chave: Caquexia associada ao câncer. Tecido adiposo. Lipólise. Adipocinas. 


\begin{abstract}
Silvério R. Modulation of adipose triglyceride lipase (ATGL) and perilipin 1 contributes to increased lipolysis in cachectic patients. [Ph.D. thesis (Cell and Tissue Biology)] São Paulo: Instituto de Ciências Biomédicas, Universidade de São Paulo; 2011.

Cancer cachexia, a chronic inflammatory syndrome, presents as a major feature marked loss of fat mass. The adipose tissue is an important endocrine organ, secreting a myriad of factors, the adipokines. Therefore, the fat mass depletion in cachexia, whose the molecular bases are not yet established, could result in more drastic changes than simple reduction of energy reserves. It is postulated that an increase in lipolysis due to increased expression and activity of hormone-sensitive lipase (HSL) is the key factor behind the atrophy of adipose tissue in this syndrome. However, the contribution of novel proteins related to lipolysis [adipose triglyceride lipase (ATGL), comparative gene identification - 58 (CGI-58) and perilipin 1] is still controversial. Our purpose was to characterize the expression of lipolysisrelated proteins (HSL, ATGL, CGI-58 and perilipin 1) and adipokines (adiponectin, leptin and visfatin) along cachexia progression. Patients from University Hospital were divided into three groups: cachectic cancer patients (TBC), stable weight cancer patients (TB) and controls (CTR). Walker 256 carcinosarcoma, an experimental model of cachexia, was also studied. Animals were divided into: control (CTR), tumour-bearing studied on the seventh day (TB7) and tumour-bearing studied on the fourteenth day (TB14) after tumour inoculation. Subcutaneous adipose tissue of patients and epididymal adipose tissue of animals were investigated, regarding morphological (HE) and morphometric (area, perimeter and diameter of adipocytes) aspects. Molecular aspects were also examined by determining the protein content (Western blotting and ELISA) and gene expression (real-time PCR) of HSL, ATGL, CGI-58, perilipin 1, leptin, adiponectin, visfatin and tumor necrosis factor alpha (TNF-a). We found augmented lipolysis in cachectic patients associated with increased HSL expression, as well as upregulation of ATGL expression (almost 2.0 fold compared to CTR) and reduction in perilipin 1 content (by $51 \%$ ). In TB7 (intermediate stage of the syndrome, similar to the clinical study), there was an imbalance in the secretion of pro and antiinflammatory factors. The alterations at the end stage of cachexia were even more profound and there was a reduction in the expression of almost all proteins analysed in the animals. The marked decrease in adipokine and lipolysis-related protein expression, associated with changes in the extracellular matrix and adipocytes shape, suggests impairment of cellular function in terminal cachexia. We conclude that cachexia induces important morphological,
\end{abstract}


molecular and humoral alterations in white adipose tissue, which are specific to the stage of the syndrome.

Keywords: Cancer cachexia. Adipose tissue. Lipolysis. Adipokines. 


\section{LISTA DE ILUSTRAÇÕES}

Figura 1 - Fisiopatologia da caquexia .27

Figura 2 - Representação esquemática da função fisiológica das principais adipocinas secretadas pelo tecido adiposo branco.

Figura 3 - Componentes do tecido adiposo branco

Figura 4 - Modelo proposto para os mecanismos moleculares envolvidos na regulação da lipólise 38

Figura 5 - Rato portator do carcinossarcoma de Walker 256 no 140 dia após a inoculação tumoral .51

Figura 6 - Expressão gênica das adipocinas no tecido adiposo subcutâneo dos pacientes..59

Figura 7 - Expressão gênica das proteínas relacionadas à lipólise no tecido adiposo subcutâneo dos pacientes 60

Figura 8 - Expressão protéica das proteínas relacionadas à lipólise no tecido adiposo subcutâneo dos pacientes

Figura 9 - Ganho de peso corporal durante o período experimental

Figura 10 - Progressão do consumo de ração durante o período experimental .65

Figura 11 - Aspectos morfológicos do tecido adiposo epididimal dos animais .67

Figura 12 - Análise morfométrica dos adipócitos do tecido adiposo epididimal

Figura 13 - Expressão gênica das adipocinas no tecido adiposo epididimal dos animais ...69

Figura 14 - Expressão protéica das adipocinas no tecido adiposo epididimal dos animais..70 
Figura 15 - Correlação entre a concentração de TNF-a e adiponectina no tecido adiposo epididimal dos animais .71

Figura 16 - Expressão gênica das proteínas relacionadas à lipólise no tecido adiposo epididimal dos animais .72

Figura 17 - Expressão protéica das proteínas relacionadas à lipólise no tecido adiposo epididimal dos animais .73

Figura 18 - Capacidade lipolítica de adipócitos isolados do tecido adiposo epididimal dos animais. .74

Quadro 1 - Nomenclatura unificada para as proteínas envolvidas com as gotículas de estoque intracelular de lipídios 35

Quadro 2 - Sequência dos oligonucleotídeos para o modelo clínico .46

Quadro 3 - Sequência dos oligonucleotídeos para o modelo experimental 53 


\section{LISTA DE TABELAS}

Tabela 1 - Características gerais dos sujeitos.................................................43

Tabela 2 - Parâmetros plasmáticos dos pacientes ...............................................57

Tabela 3 - Peso relativo dos tecidos (percentual do peso corporal total) nos intervalos

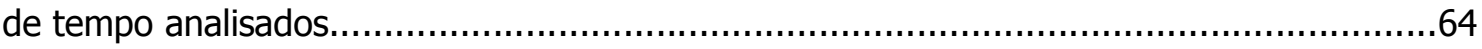

Tabela 4 - Consumo médio de ração por dia ao longo do período experimental...............64

Tabela 5 - Parâmetros plasmáticos dos animais..................................................66 


\section{LISTA DE ABREVIATURAS E SIGLAS}

ADRB1 Receptor adrenérgico do tipo $\beta 1$

ADRP Adipofilina

AIDS Síndrome da imunodeficiência adquirida

AMPc Adenosina monofosfato cíclico

ATGL Lipase de triacilglicerol do adipócito

CGI-58 Comparative gene identification 58

DPOC Doença pulmonar obstrutiva crônica

FABP-4 Proteína transportadora de ácidos graxos 4

GAPDH Gliceraldeído-3-fosfato desidrogenase

GLUT-4 Transportador de glicose do tipo 4

IFN- $\mathrm{Y}$ Interferon gama

IL Interleucina

IMC Índice de massa corporal

IRS-1 Substrato do receptor de insulina 1

LHS Lipase hormônio-sensível

LMF Fator mobilizador de lipídios

LPL Lipase de lipoproteína

MCP-1 Proteína quimioatraente de monócitos 1

NAMPT Nicotinamida fosforibosiltransferase

NPY Neuropeptídeo Y

OXPAT Oxidative tissues-enriched PAT protein

PBEF Pre- $\beta$ cell colony-enhancing factor

PCR Proteína C-reativa

PGE2 Prostaglandina E2

PIF Fator indutor de proteólise

PKA Proteína quinase $A$

TB Portador de tumor

TBC Portador de tumor com caquexia

TB7 Portador de tumor sacrificado no 70 dia após a inoculação tumoral

TB14 Portador de tumor sacrificado no $14^{\circ}$ dia após a inoculação tumoral

TGF- $\beta \quad$ Fator transformador de crescimento beta

TIP-47 Tail-interacting protein of 47 kilodaltons 
TNF-a Fator de necrose tumoral alfa

ZAG Zinco-alfa 2-glicoproteína 


\section{SUMÁRIO}

1 INTRODUÇÃO

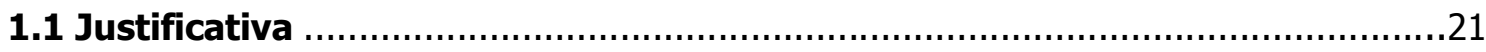

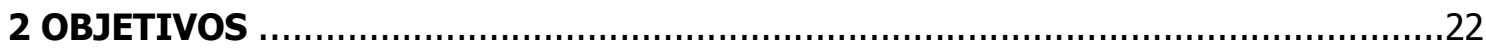

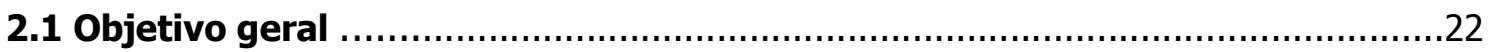

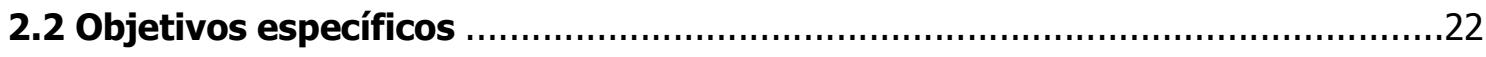

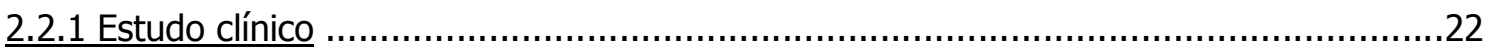

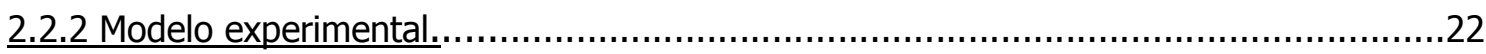

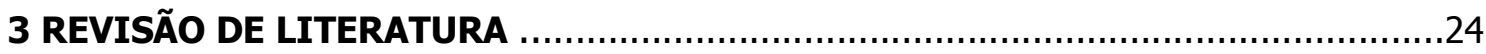

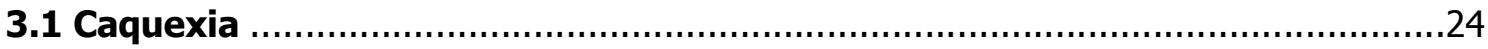

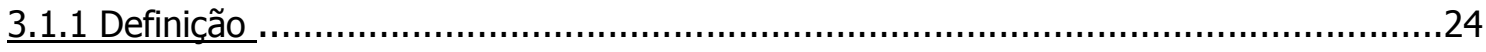

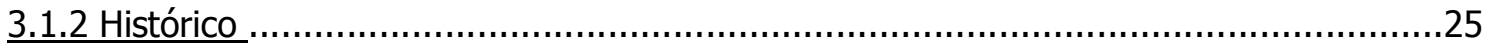

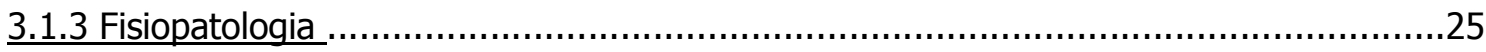

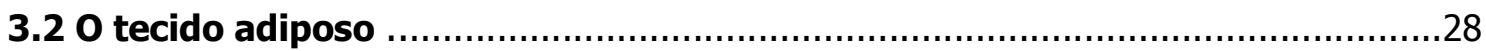

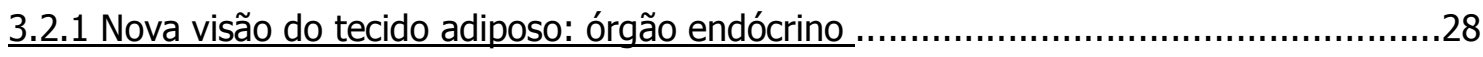

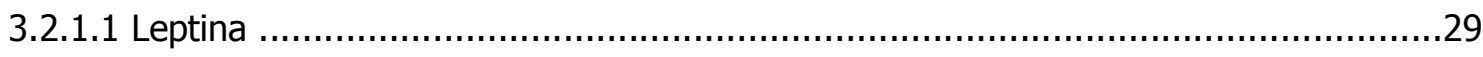

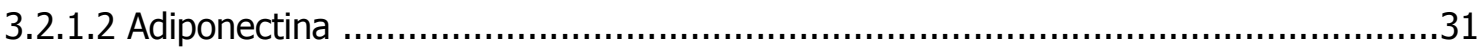

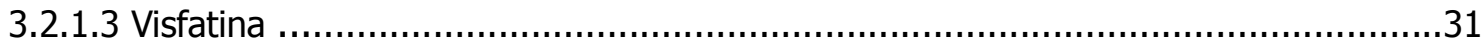

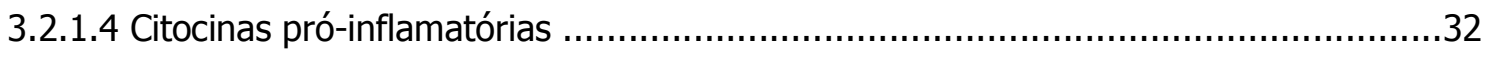

3.2.2 Metabolismo lipídico: requlação da lipólise no tecido adiposo ……..........................32

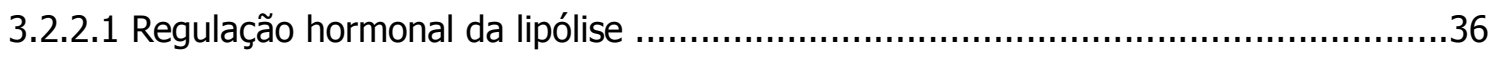

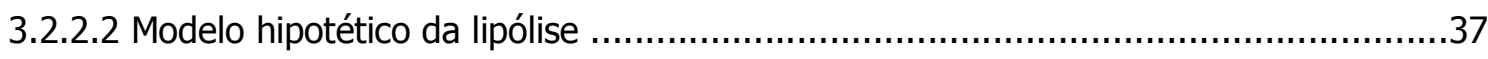

3.2.3 Alterações do tecido adiposo na caquexia ............................................................39

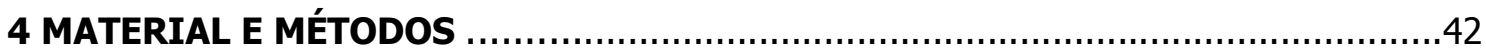

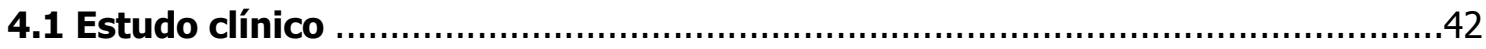

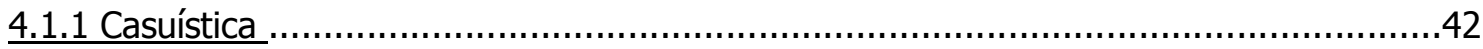

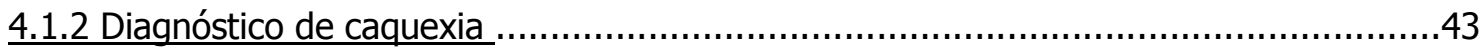

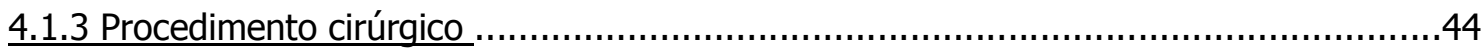

4.1.4 Coleta de plasma e tecido adiposo branco ……................................................4

4.1.5 Medida da expressão gênica por PCR tempo real ................................................45

4.1.6 Imunodeteç̧ão por Western blotting ..............................................................46

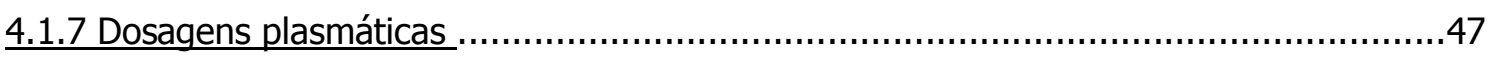

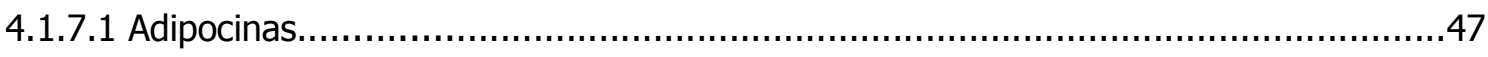




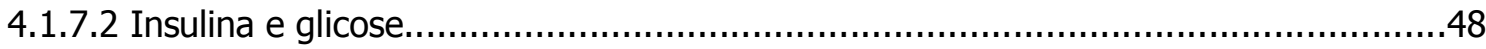

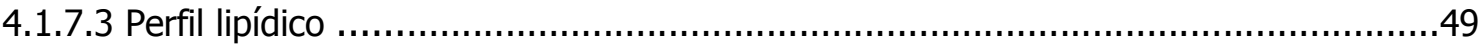

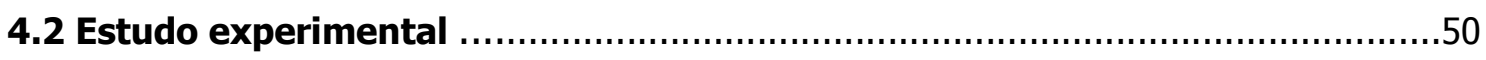

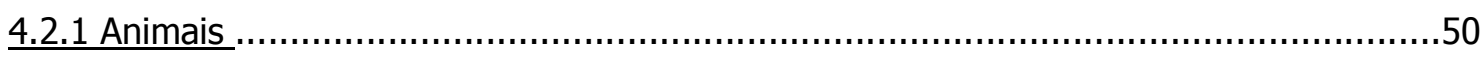

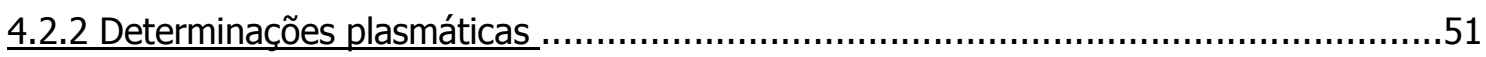

4.2.3 Medida da expressão gênica por PCR tempo real ............................................52

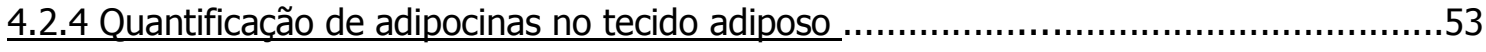

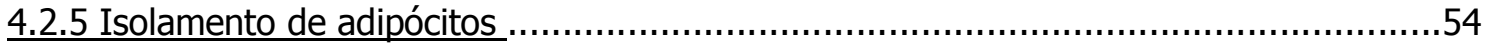

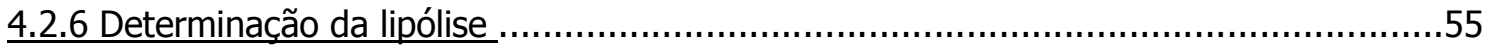

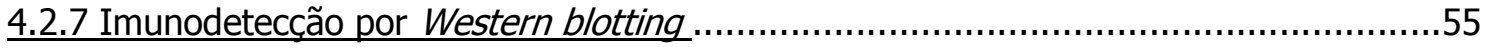

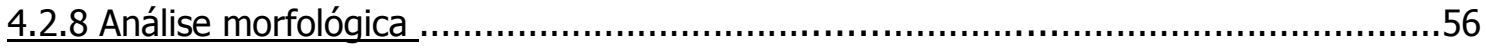

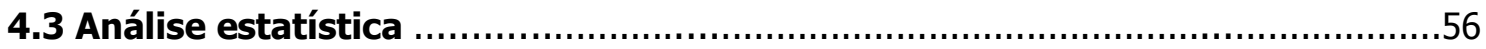

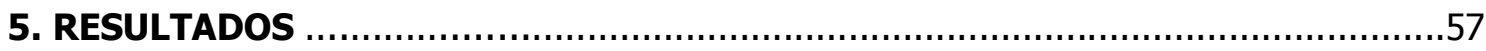

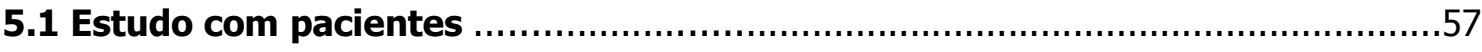

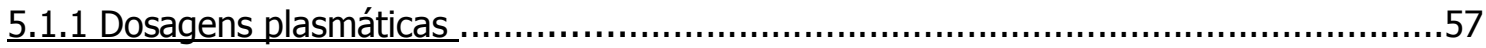

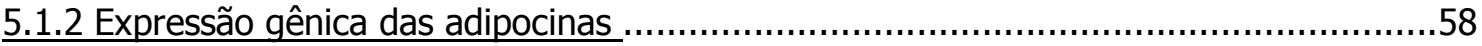

5.1.3 Expressão gênica e protéica das proteínas envolvidas no processo lipolítico ..............60

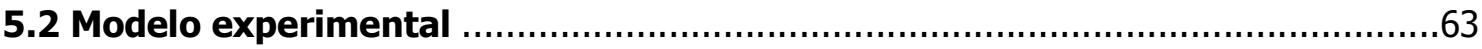

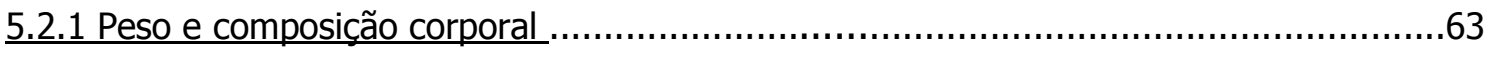

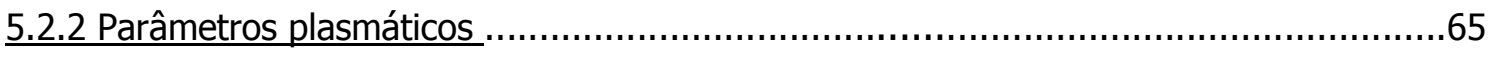

5.2.3 Aspectos morfológicos e análise morfométrica dos adipócitos ................................66

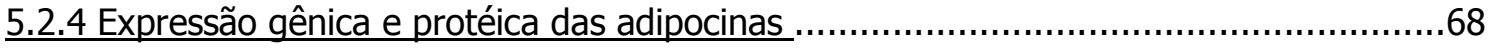

$\underline{5.2 .5}$ Expressão gênica e protéica das proteínas relacionadas à lipólise $\ldots \ldots \ldots \ldots \ldots \ldots \ldots \ldots \ldots . . .71$

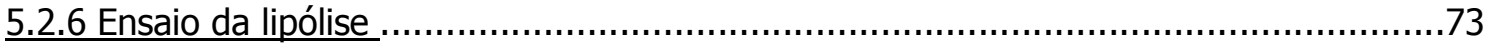

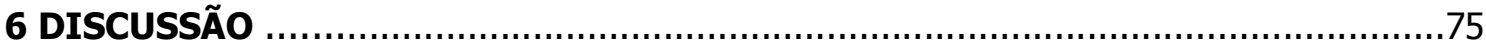

6.1 Efeitos sistêmicos da caquexia ..................................................... 75

6.2 Análise da expressão das proteínas relacionadas à lipólise ........................77

6.3 Expressão das adipocinas e seu papel na (des)regulação do metabolismo lipídico do tecido adiposo na caquexia .....................................85

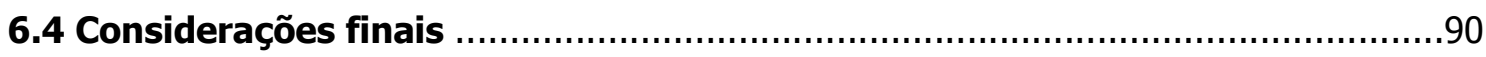

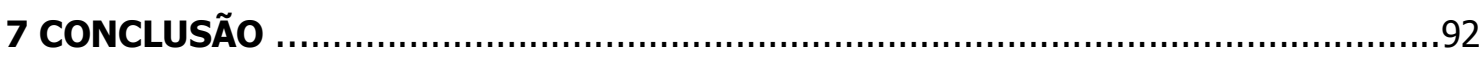

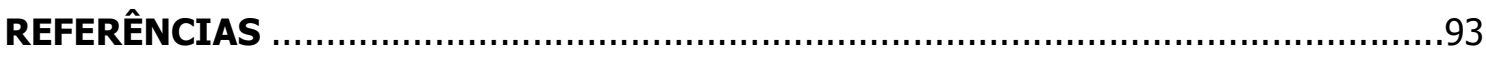

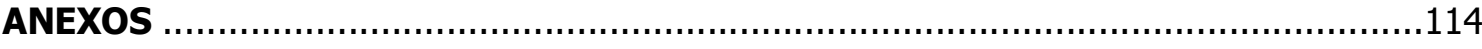

Anexo 1 - Termo de Consentimento Livre e Esclarecido ..............................115 


\section{INTRODUÇÃo}

A caquexia, cuja mais notável característica é a intensa e rápida perda de peso, é uma síndrome paraneoplásica que afeta cerca de dois terços dos pacientes com câncer avançado e é considerada a causa direta da morte em pelo menos $22 \%$ dos casos (Warren, 1932). Em cerca de 60 a $80 \%$ dos pacientes com câncer no trato digestório ou pulmão esta síndrome já está presente no momento do diagnóstico, reduzindo drasticamente a sobrevida e determinando prognóstico negativo (Bruera, 1997). A etiologia não completamente desvendada, associada à complexidade dos sintomas que a compõem, fazem com que a caquexia seja precariamente diagnosticada e, ainda com menor frequência, tratada (Springer et al., 2006; Evans et al., 2008).

Recentemente a caquexia foi concebida como uma síndrome multifatorial, com um quadro de inflamação sistêmica crônica, desencadeada tanto pelo tumor quanto pela reação do hospedeiro à sua presença (Fearon et al., 2011; Rydén et al., 2008). O papel do tumor da etiologia da síndrome inclui a secreção local de citocinas pró-inflamatórias que iniciam uma resposta inflamatória sistêmica e a produção de fatores pró-caquéticos que têm efeitos catabólicos diretos nos tecidos do hospedeiro (Skipworth et al., 2007). Os mecanismos do hospedeiro envolvem uma resposta exacerbada do organismo à presença do tumor, incluindo a ativação de uma resposta inflamatória sistêmica (Deans et al., 2006) e uma resposta de estresse neuro-endócrino (Barber et al., 2004; Costelli et al., 2006). Como resultado da interação tumor-hospedeiro há intensa depleção da musculatura esquelética e tecido adiposo, anorexia, alterações do gasto energético e do metabolismo de carboidratos, proteínas e lipídios (Argilés et al., 1997).

Se outrora imaginava-se que o tecido adiposo era um compartimento do qual o organismo podia prescindir, atualmente a sua importância fundamental como órgão endócrino está estabelecida.

Estudos prévios do nosso grupo mostraram que a caquexia afeta o tamanho, a morfologia e a composição de ácidos graxos em adipócitos (Bertevello e Seelaender, 2001). Posteriormente, demonstramos ainda a presença de macrófagos infiltrantes no tecido adiposo branco de animais caquéticos, concomitantemente à elevada produção de TNF-a e PGE2 por estas células, indicando a presença de inflamação local (Machado et al., 2004). É possível que este aumento na concentração de mediadores inflamatórios resulte em agravamento da inflamação sistêmica e, sendo assim, o tecido adiposo não seria apenas afetado por esta síndrome, como também possuiria papel fundamental no estabelecimento do quadro inflamatório característico da caquexia. 
Na última década a importância do tecido adiposo como órgão endócrino, capaz de sintetizar e secretar uma ampla gama de fatores, denominados adipocinas, foi reconhecida (Ahima, 2006). As adipocinas atuam localmente, de modo autócrino, parácrino e/ou como sinais endócrinos para regular uma série de processos fisiológicos como sensibilidade à insulina e inflamação (Ahima, 2006). O balanço entre a secreção de fatores pró e antiinflamatórios é dependente essencialmente do estímulo e do depósito do tecido adiposo (Coopack, 2001) e é adotado como marcador da severidade da caquexia associada ao câncer (Argilés et al., 1997). Neste contexto, Murphy et al. (2010) sugerem ainda que a perda de tecido adiposo na caquexia serve como um preditor de sobrevivência, podendo ser utilizada como ferramenta prognóstica.

Embora inúmeros estudos evidenciem o papel crucial do tecido adiposo na caquexia, as bases moleculares da sua depleção não são totalmente elucidadas. Estudos sugerem que um aumento na lipólise seja o fator-chave neste processo (Large et al., 1997; Skoog et al., 2001). Por muitos anos, a lipase hormônio sensível (LHS) foi considerada a enzima chave na regulação da lipólise (Langin, 2006a) e postula-se que a lipólise esteja aumentada na caquexia em decorrência do aumento na expressão e na atividade desta enzima (Agustsson et al, 2007). Todavia, é importante ressaltar que recentemente houve um considerável avanço em relação ao conhecimento da regulação do processo lipolítico e, atualmente, sabese que este é controlado por interações complexas entre proteínas que recobrem a gotícula lipídica e lipases, além de proteínas adicionais que atuam como cofatores enzimáticos.

Sendo assim, de acordo com o modelo lipolítico recentemente estabelecido, além da LHS outra lipase possui importante papel nesta via, a lipase de triacilglicerol do adipócito (ATGL). Esta enzima inicia a lipólise por remover especificamente o primeiro ácido graxo do triacilglicerol e o diacilclicerol resultante é então hidrolisado pela LHS (Jaworski et al., 2007). Outras proteínas estão também envolvidas na regulação do processo de lipólise, entre elas destacamos a perilipina 1, proteína mais abundante na superfície de gotículas lipídicas (Brasaemle, 2007), e a comparative gene identification-58 (CGI-58), proteína coativadora da ATGL.

Apesar do número crescente de pesquisas visando elucidar os mecanismos através dos quais essas novas proteínas regulam o processo lipolítico, ainda não existem na literatura dados referentes à expressão destas durante a progressão do estado caquético. 


\subsection{Justificativa}

Atualmente, o tecido adiposo é considerado um importante órgão endócrino tendo em vista o grande número de adipocinas que é capaz de secretar, estando estas envolvidas em uma ampla gama de respostas fisiológicas. Desta forma, a redução da massa do tecido adiposo, bem como as alterações morfofuncionais deste tecido observadas na caquexia, poderiam implicar em alterações que vão além da simples redução das reservas energéticas. Pela análise da literatura, verificamos que são poucos os estudos que avaliam as alterações fisiológicas no tecido adiposo durante a caquexia. Além disso, não encontramos, até o presente momento, estudos que verifiquem a expressão das recentemente descritas proteínas envolvidas no processo de lipólise (ATGL, perilipina e CGI-58) durante a progressão desta síndrome. Como buscamos a compreensão não apenas das alterações da via lipolítica per se, mas também a análise dessas modificações ao longo da progressão da caquexia, acreditamos que estes resultados poderão contribuir como base para 0 desenvolvimento futuro de possíveis intervenções terapêuticas. 


\section{OBJETIVOS}

\subsection{Objetivo geral}

Investigar as alterações na expressão de adipocinas e proteínas relacionadas à lipólise no tecido adiposo branco na vigência da caquexia, bem como as possíveis interações entre estes fatores, em pacientes e em modelo animal.

\subsection{Objetivos específicos}

\subsubsection{Estudo clínico}

a) Verificar os efeitos sistêmicos da caquexia associada ao câncer através da determinação da concentração plasmática dos seguintes parâmetros: glicose, insulina, perfil lipídico (triacilglicerol, ácidos graxos livres, colesterol total, HDL-colesterol e LDL-colesterol), leptina, adiponectina e TNF-a.

b) Analisar a expressão de adipocinas e proteínas relacionadas à lipólise no tecido adiposo branco, observando possíveis variações nas respostas entre pacientes portadores de tumor com caquexia, pacientes portadores de tumor com peso estável e pacientes controle. Para tal, foram examinados no tecido adiposo subcutâneo abdominal:

- O conteúdo protéico da LHS, ATGL e perilipina 1;

- A expressão gênica da LHS, ATGL, perilipina 1, CGI-58, adiponectina, leptina e visfatina.

\subsubsection{Modelo experimental}

a) Analisar a composição corporal e parâmetros plasmáticos de animais portadores de tumor para caracterização da caquexia e verificação dos seus efeitos sistêmicos, através da seguinte metodologia:

- Análise da progressão do peso corporal e ingestão alimentar dos animais ao longo do período experimental;

- Determinação do peso dos tecidos (fígado, músculo gastrocnêmio e tecidos adiposos brancos - mesentérico, epididimal e retroperitonial) e peso do tumor nos diferentes tempos estudados; 
- Determinação da concentração plasmática de glicose, insulina, triacilglicerol, ácidos graxos livres e adipocinas (leptina, adiponectina e visfatina) nos animais controles e caquéticos.

b) Analisar as alterações no tecido adiposo branco induzidas pela caquexia, com ênfase na expressão das adipocinas e das proteínas relacionadas à lipólise. Para tal, foram determinadas no tecido adiposo epididimal de animais controles e caquéticos:

- A expressão gênica da LHS, ATGL, perilipina 1, CGI-58, adiponectina, leptina e visfatina;

- A expressão protéica da LHS, ATGL, perilipina 1, CGI-58, leptina, adiponectina, visfatina e TNF-a;

- A capacidade lipolítica em adipócitos isolados;

- As características histológicas com posterior avaliação morfométrica dos adipócitos.

c) Realizar análise temporal dos fenômenos estudados com a progressão do estado caquético. 


\section{REVISÃO DE LITERATURA}

\subsection{Caquexia}

\subsubsection{Definição}

A caquexia, denominação derivada do grego "kakos" má e "hexis" condição, vem sendo reconhecida por muitos anos como um efeito adverso do câncer. Entretanto, o estado caquético é observado em outras condições patológicas além do câncer, como: doença pulmonar obstrutiva crônica (DPOC), sepse, síndrome da imunodeficiência adquirida (AIDS), queimaduras, falência renal e falência cardíaca (Associação Brasileira de Cuidados Paliativos, 2011). No câncer, está presente mais frequentemente em pacientes com tumores sólidos e é a mais comum manifestação do câncer avançado em pacientes com tumores gástricos, do pâncreas, de pulmão, de próstata e de cólon (Blum et al., 2010; Strasser e Bruera, 2002). O grau de manifestação da síndrome varia entre pacientes com o mesmo tipo histológico e estágio de progressão tumoral, não apresentando associação evidente com o tamanho da massa do tumor (Barton, 2001).

Há muitos anos discute-se na literatura a importância de uma definição padronizada de caquexia (Evans et al., 2008; Springer et al., 2006), tendo em vista que, na ausência de uma definição consensual, esta síndrome vem sendo muitas vezes não diagnosticada. De acordo com Fox et al. (2009), a utilização de diferentes definições, propostas por grupos independentes, leva à inclusão de cerca de $23 \%$ dos pacientes de câncer dentro do diagnóstico da síndrome, o que representa uma subestimação da prevalência da mesma.

Recentemente elaborou-se um consenso internacional o qual definiu caquexia como "uma síndrome multifatorial caracterizada por uma perda contínua de massa muscular (com ou sem perda de tecido adiposo) a qual não pode ser totalmente revertida através do suporte nutricional convencional, levando a um prejuízo funcional progressivo" (Fearon et al., 2011). Este consenso propõe ainda a classificação de caquexia, segundo a gravidade, em pré-caquexia, caquexia e caquexia refratária (Fearon et al., 2011). O primeiro estágio é definido como aquele no qual o paciente apresenta perda de peso involuntária (igual ou superior a $5 \%$ do peso corporal) e alterações metabólicas (por exemplo, anorexia e prejuízo na tolerância à glicose). Para a inclusão do paciente no segundo estágio, considera-se perda de peso igual ou superior a $5 \%$ num período de 6 meses, índice de massa corporal (IMC) < $20 \mathrm{~kg} / \mathrm{m}^{2}$ associado à perda de $2 \%$ do peso corporal ou ainda sarcopenia acompanhada de perda de peso corporal maior ou equivalente a 2 \%. Redução da ingestão alimentar e 
inflamação sistêmica são frequentemente observados neste estágio. Por fim, no último estágio (caquexia refratária) incluem-se os pacientes com elevado catabolismo e que não respondem à terapia anti-câncer, sendo a expectativa de vida inferior a três meses.

\subsubsection{Histórico}

Buscando a realização de uma minunciosa análise histórica da caquexia, Bem-Noum (2004) deparou-se com descrições bíblicas do rei Davi, de mais de 3.500 anos, que incluem as seguintes afirmações:

I forgot to eat my bread; My knees are weak through fasting; and my flesh failed of fatness; My strenght failed... and my bones are consumed; My bones wasted away through my anguished roaring all day long; My bones cleave my skin; and I am feeble and depressed.

De acordo com o autor, estas descrições sugerem a presença de anorexia, caquexia, fraqueza, dor óssea e depressão e que, possivelmente, o rei Davi sofria de câncer (BemNoum, 2004).

Em anos posteriores, físicos de renomada importância, como Hipócrates (460 - 377 a.C.) e Celsus (25 a.C - 50 d.C.), também descreveram uma condição fatal, a qual era associada à depleção intensa. Já no século XVI, a rainha da Inglaterra, Elizabeth I, ao descrever sua própria condição, refere depressão, imagem corporal alterada, alteração de paladar e anorexia (Bennani-Baiti e Walsh, 2009).

Nos anos subsequentes a caquexia foi vista como uma complicação séria e inevitável de doenças como tuberculose ou câncer ou ainda de disordens metabólicas não-controladas como diabetes (Doehner e Anker, 2002).

Embora descrições de indivíduos caquéticos remontem há mais de três mil anos, e que nas últimas décadas o estudo da síndrome tenha recebido atenção crescente, a sua etiologia continua desconhecida e não existe terapia conhecida que a reverta (Fearon et al., 2006; Muscaritoli et al., 2010).

\subsubsection{Fisiopatologia}

Os mecanismos fisiopatológicos envolvidos na severa depleção característica da caquexia são bastante complexos. As vias bioquímicas e aspectos celulares participantes do intenso quadro catabólico integram-se e superpõem-se entre si, formando uma rede ainda hoje não totalmente desvendada cuja compreensão é essencial para a adequada abordagem terapêutica (Associação Brasileira de Cuidados Paliativos, 2011). 
A caquexia é considerada o resultado de uma variedade de interações entre o hospedeiro e o tumor. Neste contexto, o papel do tumor inclui a produção local de citocinas pró-inflamatórias, as quais iniciam a resposta inflamatória sistêmica do hospedeiro, além da produção de fatores pró-caquéticos que têm efeitos catabólicos diretos nos tecidos do hospedeiro (exemplo: fator indutor de proteólise [PIF] e fator mobilizador de lipídios [LMF]) (Skipworth et al. 2007). Os mecanismos do portador envolvem uma resposta extravagante à presença do tumor e incluem a ativação tanto da resposta inflamatória sistêmica (Deans et al., 2006), quanto da resposta de estresse neuroendócrino (Barber et al., 2004; Costelli et al., 2006).

O resultado desta rede de interações entre o tumor e o hospedeiro leva à inflamação sistêmica, acarretando diversas alterações metabólicas que culminam nos sinais e sintomas característicos da caquexia (Figura 1). Segundo Blum et al. (2011), a perda de peso e de apetite são normalmente os primeiros sintomas percebidos pelo paciente. Esta perda involuntária de peso, uma das alterações metabólicas mais evidentes da caquexia, não pode ser relacionada apenas à anorexia observada nestes pacientes. Diferentemente do que se observa no jejum, a perda de massa magra nos pacientes caquéticos envolve a perda de proteínas não só a partir da musculatura esquelética, mas também da musculatura cardíaca, resultando em alterações da função do coração (Argilés et al., 2000). Estes pacientes apresentam ainda um maior gasto energético em repouso. Na musculatura esquelética, as taxas de síntese protéica tendem a estar diminuídas (ou inalteradas) enquanto as taxas de degradação de proteína estão aumentadas (ou inalteradas) (Bhogal et al., 2006; McMillan et al., 1994), resultando na perda de musculatura esquelética ou massa corporal magra (Fearon e Preston, 1990). A progressiva perda de proteína muscular resulta em fraqueza e redução de força e é mediada principalmente por citocinas e hormônios, como menor contribuição de compostos derivados do tumor (em casos de câncer) e neuropeptídios.

As citocinas, um grupo amplo e heterogêneo de pequenos polipeptídeos que regulam a comunicação intercelular e iniciam a resposta inflamatória (Pal'tsev, 1996; Trotta, 1991), são sintetizadas por diversos tipos celulares incluindo células do sistema imunitário, adipócitos e miócitos, em resposta a uma ampla variedade de estímulos. Além de influenciarem a síntese e degradação protéica, estes mediadores inflamatórios também interferem no metabolismo lipídico na caquexia (Figura 1). O TNF-a, por exemplo, induz redução na expressão e atividade da lipase de lipoproteína (LPL) no tecido adiposo (Inui, 2002), levando ao prejuízo na captação dos ácidos graxos das lipoproteínas e à aumentada lipólise no tecido adiposo. O fígado, importante órgão gerenciador do metabolismo, também é bastante afetado durante a caquexia. Estudos do nosso grupo mostram que apesar do 
fígado apresentar uma maior capacidade de incorporação de ácidos graxos nesta situação, há uma incapacidade na oxidação desse substrato, levando ao acúmulo de lipídios e um quadro de esteatose hepática (Kazantzis e Seelaender, 2005; Lira et al., 2008; Seelaender et al., 1996; Silverio et al., 2011).

Figura 1 - Fisiopatologia da caquexia

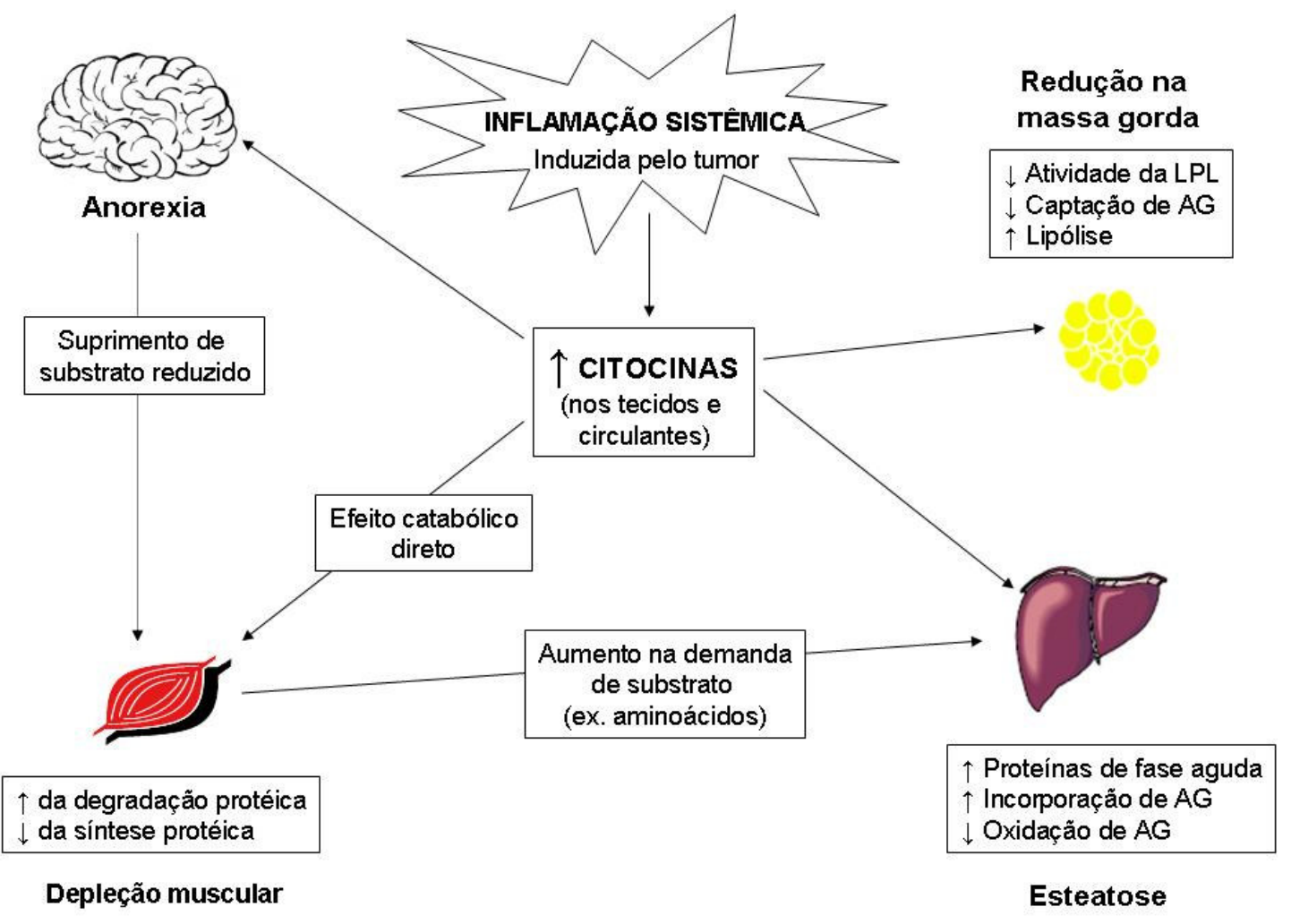

FONTE: Adaptado de Skipworth et al. (2007).

NOTA: Abreviaturas: AG, ácidos graxos; LPL, lipase de lipoproteína.

Levando-se em consideração a complexidade e diversidade das vias envolvidas na fisiopatologia da caquexia, a importância relativa de diferentes mecanismos realcionados ao tumor e ao hospedeiro na gênese desta síndrome, em pacientes individuais e diferentes tipos tumorais permanece ainda obscura. Além disso, a interação entre o tumor e o hospedeiro pode não ser o único fator conduzindo à caquexia (Skipworth et al., 2007). Dentro deste contexto, o tratamento clínico da caquexia é atualmente limitado e complexo (Associação Brasileira de Cuidados Paliativos, 2011). Vários mecanismos pró-caquéticos diferentes podem 
estar envolvidos e, portanto, deveriam ser analisados e classificados de acordo com a importância e reversibilidade, antes do estabelecimento de um plano de tratamento (Reid et al., 2010). Entretanto, a conduta clínica de rotina não atingiu tal nível de sofisticação (Hawkins et al., 2009).

Em decorrência dos fenômenos acima descritos, o tecido adiposo é profundamente afetado pela caquexia, sendo a sua atrofia considerada um importante marcador desta síndrome (Tisdale, 2009). Nosso grupo vem demonstrando há anos uma grande participação do tecido adiposo branco na etiologia da caquexia. Assim esse abundante compartimento do organismo detém importante papel neste quadro e a compreensão dos mecanismos que delineam a resposta deste tecido à presença do tumor é tida como crescentemente relevante.

\subsection{0 tecido adiposo}

\subsubsection{Nova visão do tecido adiposo: órgão endócrino}

Por muitos anos o tecido adiposo foi considerado um órgão passivo possuindo papel metabólico na homeostase energética total. Acreditava-se que sua única função era o armazenamento do excesso de energia como triacilglicerol e sua liberação, de acordo com a necessidade, na forma de ácidos graxos (Fischer-Posovszky et al., 2007). Entretanto, nos últimos anos houve uma mudança neste paradigma e tornou-se claro que o tecido adiposo possui um papel ativo na homeostase energética, além de vários outros processos (Ahima, 2006). O tecido adiposo é atualmente reconhecido como um importante órgão endócrino, frente à sua grande capacidade de secreção de hormônios, e outros fatores, conjuntamente denominados de adipocinas (Galic et al. 2010). Cabe esclarecer que o termo adipocinas é aplicado às substâncias ativas secretadas pelos adipócitos do tecido adiposo branco, todavia, estes fatores podem ser sintetizados em outros tecidos e terem ações não relacionadas às que apresentam no tecido adiposo (Fantuzzi, 2005). A Figura 2 sumariza os principais fatores secretados pelo tecido adiposo, de acordo com a sua função fisiológica.

As adipocinas permitem a comunicação entre o tecido adiposo e outros órgãos incluindo o cérebro, fígado e músculo esquelético e possuem papel importante em aspectos chave do metabolismo, como ingestão e gasto energético, resistência à insulina, oxidação de ácidos graxos, inflamação e imunidade (Huang et al., 2011). Nos últimos anos tornou-se evidente que a obesidade e vários componentes da síndrome metabólica, assim como resistência à insulina e hipertensão, estão intimamente interligados devido à alteração na 
função secretória do tecido adiposo. É importante ressaltar que o tecido adiposo é constituído não apenas por adipócitos, possuindo ainda a matriz de tecido conjuntivo, células do sistema imune, fibroblastos e pré-adipócitos, entre outros componentes (Figura 3). Neste contexto, a secreção de adipocinas interfere diretamente na função dos outros tipos celulares que constituem o tecido, e vice-versa. Sendo assim, as adipocinas podem possuir um importante papel na patogênese de diversas doenças. $O$ papel específico da cada uma das adipocinas investigadas neste estudo será discutido brevemente a seguir.

Figura 2 - Representação esquemática da função fisiológica das principais adipocinas secretadas pelo tecido adiposo branco

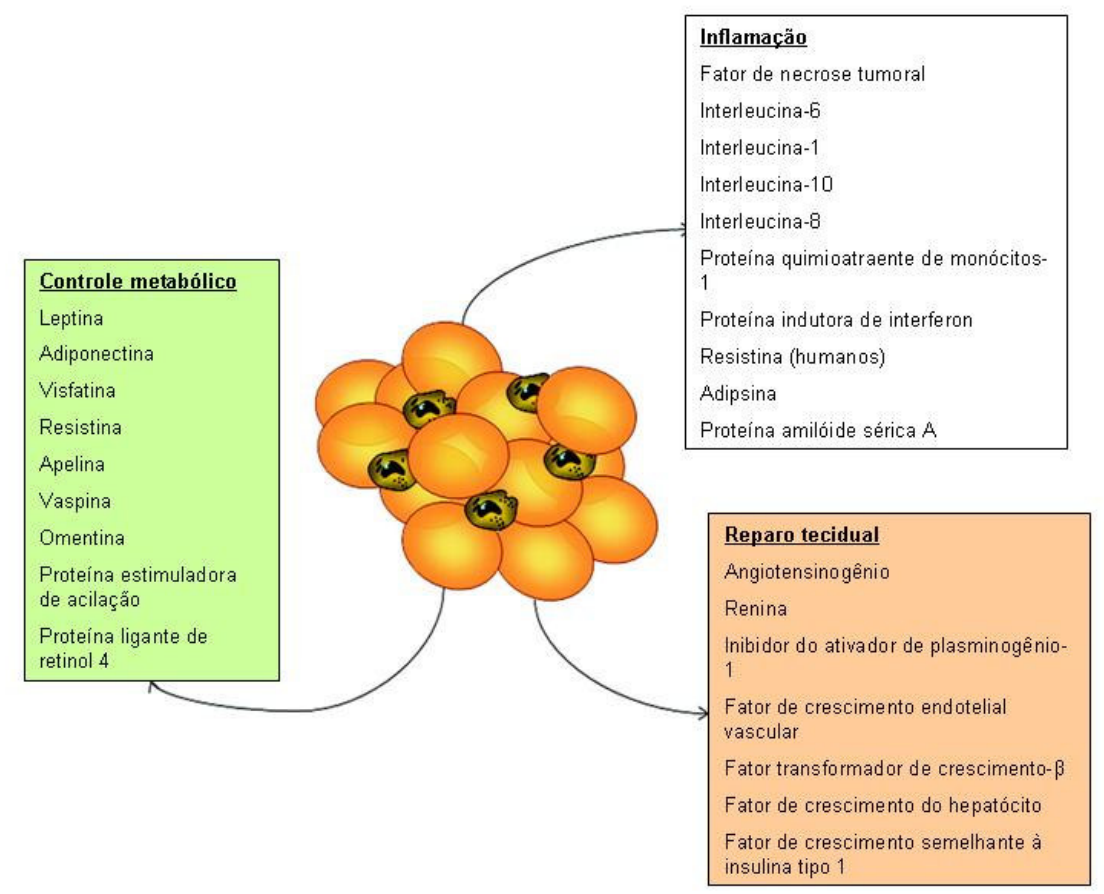

Fonte: Adaptado de Lago et al. (2009)

\subsubsection{Leptina}

Embora o papel do tecido adiposo como fonte central de energia seja reconhecido por séculos, apenas há pouco mais de 50 anos, hipotetizou-se a respeito da presença de uma molécula sinalizadora circulante, a qual teria um papel lipostático importante na regulação do peso corporal. De acordo com a teoria proposta por Kennedy (1953), quando a massa adiposa se expande, a concentração circulante da molécula sinalizadora poderia 
aumentar e esta substância poderia atuar nos circuitos neurais do cérebro, controlando o consumo alimentar e o balanço de energia. Alguns anos depois, através de um estudo com camundongos geneticamente obesos e diabéticos, Coleman (1973) confirmou a presença de tal fator circulante, o qual foi identificado por Zhang et al. (1994) e denominado leptina (do grego leptos, que significa magro). Logo após, diversos autores demonstraram que injeções diárias desta adipocina, em camundongos geneticamente obesos, rapidamente reduziam a ingestão alimentar e a massa corporal, bem como o percentual de gordura corporal (Campfield et al., 1995; Halaas et al., 1995; Pelleymounter et al., 1995). Em decorrência destes estudos, a leptina foi inicialmente considerada uma droga promissora no tratamento da obesidade. Entretanto, verificou-se posteriormente que a administração de leptina recombinante em indivíduos com sobrepeso ou obesidade não é eficiente em termos de perda de peso, uma vez que muitos destes indivíduos apresentam resistência central à leptina (Zelissen et al., 2005).

Figura 3 - Componentes do tecido adiposo branco

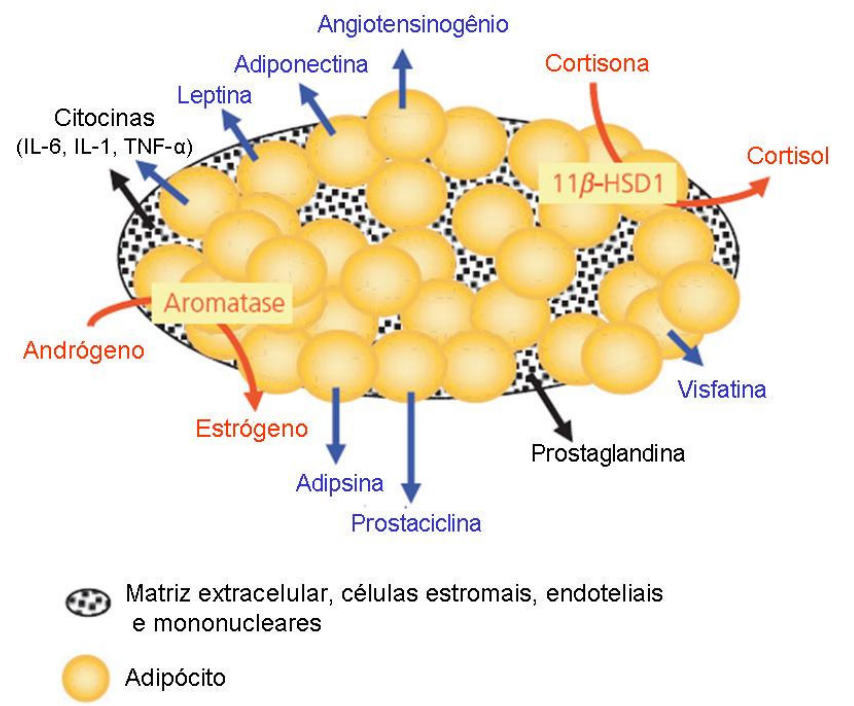

FONTE: Adaptado de Henry e Clarke (2008).

A leptina é produzida principalmente por adipócitos diferenciados, sendo também sintetizada em menor quantidade por outros órgãos e tecidos, como: estômago, músculo esquelético, fígado e placenta (Baratta, 2002). No sistema nervoso central, em particular no hipotálamo, a leptina suprime a ingestão alimentar e estimula o gasto energético (Webber, 
2003). Essas ações podem ser explicadas, pelo menos parcialmente, pelo efeito supressor da leptina na produção e secreção do neuropeptídio Y (NPY), um impotante neuropeptídio orexígeno, por neurônios do núcleo arqueado (Magni, 2003). As concentrações plasmáticas de leptina correlacionam-se diretamente com o conteúdo de gordura corporal (Considine et al., 1996) e sua produção pelos adipócitos declina rapidamente durante jejum. Além disso, a leptina também é produzida pelo tecido adiposo sob ação de citocinas pró-inflamatórias como, por exemplo, na reação da fase aguda da sepse (Alemán et al., 2002) e está envolvida na anorexia em casos de infecção (Arnalich et al., 1999; Carlson et al., 1999; Papathanassoglou et al., 2001).

\subsubsection{Adiponectina}

A adiponectina, adipocina anti-inflamatória sintetizada exclusivamente por adipócitos maduros, é a proteína mais abundantemente secretada pelo tecido adiposo (Lihn et al., 2004; Qi et al., 2006), chegando a representar aproximadamente 0,01 \% de todas as proteínas séricas (Berg et al., 2002).

Dentre as suas funções destacam-se a regulação do metabolismo de lipídios e glicose, estimulação da oxidação de ácidos graxos, sumpressão da gliconeogênese, aumento da sensibilidade à insulina, além de proteção contra inflamação crônica e regulação da ingestão alimentar e do peso corporal (Liu e Liu, 2009).

Em contraste com a maioria das proteínas derivadas do tecido adiposo, a concentração de adiponectina plasmática está reduzida em indivíduos obesos (Hu et al., 1996) e aumenta com a perda de peso corporal (Matsubara et al., 2002; Ouchi et al., 1999; Trujillo e Scherer, 2005), havendo uma correlação negativa entre obesidade, especialmente obesidade central, resistência à insulina, diabetes tipo 2 e concentração de adiponectina circulante (Chandran et al., 2003).

Devido ao seu importante papel no metabolismo, a redução na concentração plasmática de adiponectina tem sido associada com resistência à insulina, dislipidemia e aterosclerose em humanos e roedores (Kadowaki e Yamauchi, 2005).

\subsubsection{Visfatina}

A visfatina, também conhecida como PBEF (pre-B cell colony-enhancing factor) e Nampt (nicotinamida fosforibosiltransferase), é uma adipocina com papel pró-inflamatório e imuno-modulatório (Sommer et al., 2008). Recentes estudos indicam que a concentração 
sérica desta adipocina relaciona-se com a gravidade da doença em pacientes com hepatite $\mathrm{C}$ (Huang et al., 2011), podendo ainda predizer a presença de inflamação portal em pacientes com doença hepática (Aller et al., 2009). A visfatina é preferencialmente expressa pelo tecido adiposo visceral, em comparação ao subcutâneo, e também exerce efeitos que mimetizam a ação da insulina através da sua capacidade de ligar-se ao receptor de insulina em um sítio diferente ao deste hormônio (Fukuhara et al., 2005).

\subsubsection{Citocinas pró-inflamatórias}

O tecido adiposo produz uma série de fatores os quais podem originar-se tanto de adipócitos maduros quanto de outros tipos celulares. No início da década de 90, mostrou-se pela primeira vez um aumento na expressão de TNF-a no tecido adiposo de ratos obesos (Hotamisligil et al., 1993). A idéia de que um novo fator produzido pelo tecido adiposo estava envolvido no desenvolvimento da resistência à insulina foi revolucionário naquela época. Desde então, descobriu-se que o tecido adiposo é capaz de secretar diversos outros fatores, entre eles: fator transformador de crescimento- $\beta$ (TGF- $\beta$ ), interferon- $\gamma$ (IFN- $\gamma$ ), interleucinas (IL) como IL-1, IL-6, IL-10 e IL-8, proteína quimioatraente de monócitos - 1 (MCP-1) e fatores da cascata do sistema complemento (Boucher et al., 2005; Do et al., 2002; Fasshauer et al., 2003; Shoelson et al., 2006;).

A concentração circulante dos fatores pró-inflamatórios secretados pelo tecido adiposo está aumentada com o aumento da massa gorda, sendo que muitos destes fatores são produzidos por adipócitos e também por macrófagos ativados. Na obesidade, por exemplo, há aumento de citocinas, o qual está associado à infiltração de macrófagos no tecido adiposo (Fischer-Posovszky et al., 2007).

\subsubsection{Metabolismo lipídico: requlação da lipólise no tecido adiposo}

Nos adipócitos do tecido adiposo branco os triacilgliceróis estão estocados dentro de uma gotícula lipídica unilocular que é composta por um núcleo de triacilglicerol circundado por uma monocamada de fosfolipídios e proteínas associadas à gotícula lipídica, incluindo proteínas estruturais e coativadores enzimáticos (Goodman, 2009). Estes triacilgliceróis são continuamente metabolizados no processo de lipólise e reesterificação. Durante a lipólise, o triacilglicerol é sequencialmente hidrolisado em diacilglicerol, monoacilglicerol e glicerol, liberando uma molécula de ácido graxo livre em cada passo. No jejum ou períodos de 
demanda energética aumentada, os ácidos graxos livres são liberados na circulação e transportados para outros tecidos (Zechner et al., 2005).

A mobilização dos estoques de triacilglicerol é estreitamente regulada por hormônios e requer a ativação de enzimas lipolíticas. As catecolaminas são importantes estimuladoras da lipólise, enquanto a insulina é o hormônio antilipolítico mais importante (Holm, 2003). A regulação do processo lipolítico por esses e outros hormônios/fatores será discutida mais adiante.

Nos últimos 10 anos houve um expressivo progresso em relação ao conhecimento da regulação da lipólise. Atualmente sabe-se que várias lipases, cofatores e proteínas associadas aos lipídios participam da regulação do processo lipolítico.

Por muitos anos, a LHS foi considerada a enzima-chave na regulação da lipólise (Langin, 2006b). A LHS exibe uma ampla especificidade de substrato, sendo capaz de hidrolisar triacilglicerol, diacilglicerol, monoacilglicerol, ésteres de colesteril e outros substratos (Yeaman, 1990). Contudo, ao comparar-se a taxa máxima relativa de lipólise, verifica-se que dentre todos estes lipídios neutros, os triacilgliceróis são o pior substrato para a LHS, enquanto os diacilgliceróis são o melhor (Zechner et al., 2009).

Dois principais mecanismos determinam a atividade da LHS: a fosforilação da enzima por proteínas quinase e a interação com proteínas auxiliares. Inicialmente, acreditava-se que a fosforilação da LHS em dois resíduos de serina (563 e 565) era suficiente para mediar a ativação da LHS (Stralfors et al., 1984; Stralfors e Belfrage, 1983). A serina 565 era considerada o sítio de fosforilação basal e a serina 563 o sítio regulatório (Garton et al., 1988; Olsson e Belfrage, 1987). Entretanto, com o avanço dos estudos, verificou-se que a LHS pode ser fosforilada em cinco resíduos de serina diferentes e pesquisas recentes mostram um enorme aumento na complexidade dos mecanismos envolvidos com a modificação pós-traducional e a regulação da LHS (Zechner et al., 2009). Atualmente sabese que, apesar de indispensável, a fosforilação não é suficiente para ativar a LHS, sugerindo que alterações conformacionais e a sua translocação do citoplasma para a gotícula lipídica (através da formação de um complexo com a proteína ligante de ácido graxo 4 [FABP4]) estejam também envolvidas (Lampidonis et al., 2011).

Durante muitos anos, diversos estudos in vitro evidenciaram um papel dominante e exclusivo da LHS na lipólise de triacilglicerol no adipócito (Anthonsen et al., 1998; Fredrikson et al., 1981; Garton e Yeaman, 1990), contudo pesquisas com camundongos knockout para LHS esclareceram a importância de outras lipases na hidrólise de triacilglicerol nos adipócitos. Os camundongos knockout para LHS não eram obesos (Laurell et al., 1997), seu tecido adiposo possuía considerável atividade de hidrólise de triacilglicerol estimulada por 
hormônio (Shen et al., 1998) e apresentavam acúmulo de diacilglicerol no tecido adiposo branco e marrom, músculo e testículos (Garton e Yeaman, 1990). Além disso, verificou-se que estes animais apresentavam um bloqueio na liberação de glicerol do tecido adiposo estimulada por hormônio, levando à conclusão que a LHS seria uma enzima limitante para o catabolismo celular de diacilglicerol, mas que outra lipase era responsável pela hidrólise de triacilglicerol a diacilglicerol no tecido adiposo (Yeaman, 2004).

Comprovando esta hipótese, três grupos descreveram simultaneamente a identificação de uma nova lipase de triacilglicerol, denominada lipase de triacilglicerol do adipócito (ATGL), a qual possuia muitas das propriedades da lipase não indentificada até o momento (Jenkins et al., 2004; Villena et al., 2004; Zimmermann et al., 2004). A ATGL é expressa na maioria dos tecidos, sendo que os tecidos adiposos branco e marrom possuem elevada expressão e o músculo cardíaco e esquelético possuem menores níveis (Watt e Steinberg, 2008). A ATGL apresenta uma elevada especificidade de substrato para triacilglicerol, muito fraca afinidade para diacilglicerol e não possui atividade para ésteres de colesteril e retinil (Zimmermann et al., 2004).

Assim, de acordo com o modelo atualmente proposto, a cascata lipolítica envolve pelo menos três enzimas: a ATGL catalisa predominantemente a hidrólise do primeiro éster do triacilglicerol. Então, o diacilglicerol resultante é hidrolisado pela reação catalisada pela LHS, gerando monoacilglicerol. Finalmente, a hidrólise do monoacilglicerol é catalisada pela lipase de monoacilglicerol, a qual é indispensável para a lipólise completa, porém não é uma enzima limitante do processo tendo em vista a sua abundância (Bézaire e Langin, 2009; Jaworski et al., 2007).

Como descrito anteriormente, as células estocam os triacilgliceróis em gotículas lipídicas citoplasmáticas, que estão envoltas por uma monocamada de fosfolipídios e proteínas associadas. As lipases atuam na superfície das gotículas devido às propriedades hidrofóbicas da gotícula lipídica (Watt, 2009). A coordenação do metabolismo da gotícula lipídica é provavelmente controlada pelas proteínas que a recobrem, a família da perilipina. Incluem-se nesta família a perilipina, a adipofilina (também conhecida como ADRP ou ADFP), a tail-interacting protein of 47 kilodaltons (TIP 47), a S3-12 e a oxidative tissues-enriched PAT protein (OXPAT) (Ducharme e Bickel, 2008). Recentemente foi proposta uma alteração na nomenclatura das proteínas que compõe esta família, unificando os termos e facilitando os estudos (Kimmel et al., 2010). Esta nova nomenclatura, apresentada no Quadro 1, será por nós adotada. 
Quadro 1 - Nomenclatura unificada para as proteínas envolvidas com as gotículas de estoque intracelular de lipídios

\begin{tabular}{|l|l|l|}
\hline Símbolo Aprovado & Nome aprovado & Nomenclatura prévia \\
\hline PLIN1 & Perilipina 1 & Perilipina, perilipina A, PERI, PLIN \\
PLIN2 & Perilipina 2 & ADRP, ADFP, adipofilina \\
PLIN3 & Perilipina 3 & TIP47, PP17, M6PRBP1 \\
PLIN4 & Perilipina 4 & S3-12 \\
PLIN5 & Perilipina 5 & PAT1, LDSP5, OXPAT, MLDP \\
\hline
\end{tabular}

FONTE: Kimmel et al. (2010)

A perilpina 1, proteína mais abundante na superfície das gotículas lipídicas, possui um papel crítico na regulação da lipólise basal (na ausência de estímulo) e na lipólise estimulada pelos receptores $\beta$-adrenérgicos por coordenar o recrutamento de proteínas para a gotícula lipídica (Brasaemle, 2007). Na ausência de estímulo, a perilipina 1 pode atuar como uma barreira para lipases, mantendo desta forma uma baixa taxa basal de lipólise. Por outro lado, sob estímulo hormonal, a perilipina 1 sofre fosforilação, com consequente mudança conformacional, proporcionando assim um aumento na lipólise. Além disso, foi proposto que a fosforilação da perilipina 1 pode facilitar a translocação da LHS do citoplasma para a gotícula lipídica, favorecendo ainda mais o processo lipolítico (Jaworski et al., 2007).

Outra proteína envolvida na regulação da lipólise é a CGI-58, também localizada na superfície da gotícula lipídica (Subramanian et al., 2004). Em humanos, mutações desta proteína são indetificadas como a causa da síndrome Chanarin-Dorfman, uma doença rara autossômica recessiva, caracterizada pelo acúmulo intracelular anormal de gotículas lipídicas em diversos tecidos (Lefère et al., 2001). A CGI-58 não possui atividade de lipase, entretanto a ablação do seu gene leva ao acúmulo anormal de gotículas lipídicas em diversos tipos celulares e, além disso, faz com que estas células exibam redução da atividade lipolítica tanto no estado basal quanto estimulado (Yamaguchi et al., 2007). Este papel crucial da CGI-58 no processo lipolítico deve-se à sua capacidade de atuar como um cofator ou ativador da ATGL (Lass et al., 2006). A CGI-58 sozinha não possui atividade de lipase, entretanto, sob interação com a CGI-58, a atividade de lipase da ATGL aumenta expressivamente. Em células de cultura, a atividade lipolítica da ATGL aumenta no mínimo 30 a 70 \% até o máximo de 20 vezes sob interação da CGI-58, dependendo das condições experimentais (Watt e Steinberg, 2008).

Embora haja inúmeras evidências suportando o papel de coativador da CGI-58, o mecanismo preciso de como esta proteína estimula a atividade lipolítica da ATGL permanece 
indefinido. Lu et al. (2010) especulam que a CGI-58, localizada na superfície da gotícula lipídica, pode remodelar a monocamada de fosfolipídios e, dessa forma, permitir que a ATGL acesse o triacilglicerol no centro da gotícula. Na ausência de estímulo $\beta$-adrenérgico a maioria da ATGL reside no citossol e a CGI-58 pode auxiliar na manutenção da atividade basal (Lu et al., 2010). Para a ATGL que está localizada no citossol, este pode servir como um mecanismo essencial através do qual a ação hidrolítica é exercida. Entretanto, para a ATGL localizada na gotícula lipídica, a qual possui seu próprio domínio hidrofóbico penetrando a monocamada de fosfolipídios, o núcleo de triacilglicerol está em contato íntimo e como resultado, a ação da enzima pode ser menos dependente da coativação pela CGI-58.

\subsubsection{Regulação hormonal da lipólise}

Numerosos efetores lipolíticos e antilipolíticos controlam o catabolismo dos lipídios estocados em vários tecidos (Holm et al., 2000; Langin, 2006). Estes incluem hormônios, citocinas e adipocinas.

Durante o jejum as catecolaminas são os principais hormônios que estimulam a lipólise, principalmente em humanos (Carmen e Victor, 2006). Estes hormônios chegam ao tecido adiposo via circulação (principalmente epinefrina) ou via inervação simpática (norepinefrina). A ação lipolítica das catecolaminas é mediada por três diferentes subtipos de receptores $\beta$-adrenérgicos: $\beta_{1}, \beta_{2}$ e $\beta_{3}$. Enquanto os receptores do tipo $\beta_{1}$ e $\beta_{2}$ estão amplamente expressos em todos os tecidos, o subtipo $\beta_{3}$ é encontrado predominantemente nos adipócitos do tecido adiposo branco e marrom em roedores e é pobremente expresso em humanos (Zecher et al., 2009). Quando as catecolaminas ligam-se a estes receptores, proteínas G estimulatórias ativam a enzima adenilato ciclase, levando ao aumento na concentração de AMPc e elevando a atividade da PKA dependente de AMPc (Collins et al., 2004; Holm et al., 2000, 2003). A fosforilação de proteínas-alvo mediada pela PKA, incluindo enzimas lipolíticas e proteínas associadas à gotícula lipídica, induz o aumento da liberação de ácidos graxos livres do tecido adiposo em até 100 vezes. Os dois principais alvos da fosforilação da PKA são a LHS e a perilipina (Ducharme e Bickel, 2008), cuja fosforilação causa um dramático aumento na lipólise.

Alguns fatores antilipolíticos, como o NPY, prostaglandina e adenosina, ligam-se à receptores acoplados à proteínas $\mathrm{G}$ inibitórias, os quais inibem a adenilato ciclase, reduzindo assim a produção de AMPc (Langin e Arner, 2006). Interessantemente, as catecolaminas também podem exercer efeito antilipolítico através da sua ligação nos receptores $\alpha_{2}$, os quais encontram-se acoplados à proteínas G inibitórias. Os receptores adrenérgicos do tipo $\alpha_{2}$ são 
significativamente expressos nos adipócitos humanos, ao contrário dos roedores (Jaworski et al.,2007). Dessa forma, o balanço entre os receptores $\alpha$ e $\beta$ adrenérgicos pode ser importante na regulação da lipólise nos adipócitos (Carmen e Victor, 2006).

A insulina também regula a lipólise quando ligada ao seu receptor nos adipócitos, sendo considerada o hormônio antilipolítico mais potente. A capacidade da insulina de antagonizar a lipólise estimulada por hormônios é em grande parte devido à sua capacidade de diminuir a concentração de AMPc e, desta forma, a atividade da PKA (Zechner et al., 2005). A ligação da insulina ao substrato do receptor de insulina-1 (IRS-1) leva à ativação da fosfodiesterase 3B, a qual degrada AMPc e consequentemente reduz a ativação da PKA (Bézaire e Langin, 2009).

\subsubsection{Modelo hipotético da lipólise}

Recentemente, Bezaire et al. (2009), utilizando linhagem de adipócitos humanos, mostraram uma redução de 50 \% na lipólise basal após silenciamento simples ou duplo de ATGL ou CGI-58, enquanto o silenciamento da LHS não teve efeito algum. Além disso, os autores demonstraram a presença de uma importante quantidade de ATGL no citossol no estado basal, com translocação para pequenas gotículas lipídicas sob ativação da PKA. Portanto, acredita-se que um número aumentado de complexos ATGL-CGI-58 formados após a fosforilação da perilipina 1 e ancorados em pequenas gotículas lipídicas sejam importantes para a lipólise estimulada pela PKA. Na totalidade, há um efeito sequencial da hidrólise de triacilglicerol acentuada pela ATGL, LHS fosforilada e ação da lipase de monoacilglicerol que produz grandes aumentos na liberação de ácidos graxos livres em resposta à ativação da PKA.

A Figura 4 representa o modelo hipotético da lipólise nos adipócitos humanos, integrando as três principais lipases, cofatores e proteínas relacionadas. De acordo com o modelo proposto por Lampidonis et al. (2011), no estado basal a perilipina 1 recobre a superfície da gotícula lipídica e liga-se à CGI-58. Ainda em condições não estimuladas, a LHS está dispersa no citossol. Sob a ação de reguladores, como as catecolaminas, há um aumento na concentração de AMPc, que ativa a PKA, levando à fosforilação da perilipina 1 e da LHS. A fosforilação da perilipina 1 induz alterações físicas da superfície da gotícula lipídica, facilitando a ação da LHS. A fosforilação da perilipina 1 também promove a liberação da CGI-58, a qual liga-se à ATGL formando um complexo altamente ativo nas gotículas lipídicas pequenas, onde catalisam a degradação do triacilglicerol, resultando na produção de diacilglicerol. A LHS fosforilada associa-se com a FABP4 e transloca-se até a gotícula lipídica, 
onde hidrolisa o diacilglicerol produzido pela ATGL. A lipase de monoacilglicerol completa a lipólise por hidrolisar o monoacilglicerol à ácido graxo e glicerol.

Figura 4 - Modelo proposto para os mecanismos moleculares envolvidos na regulação da lipólise

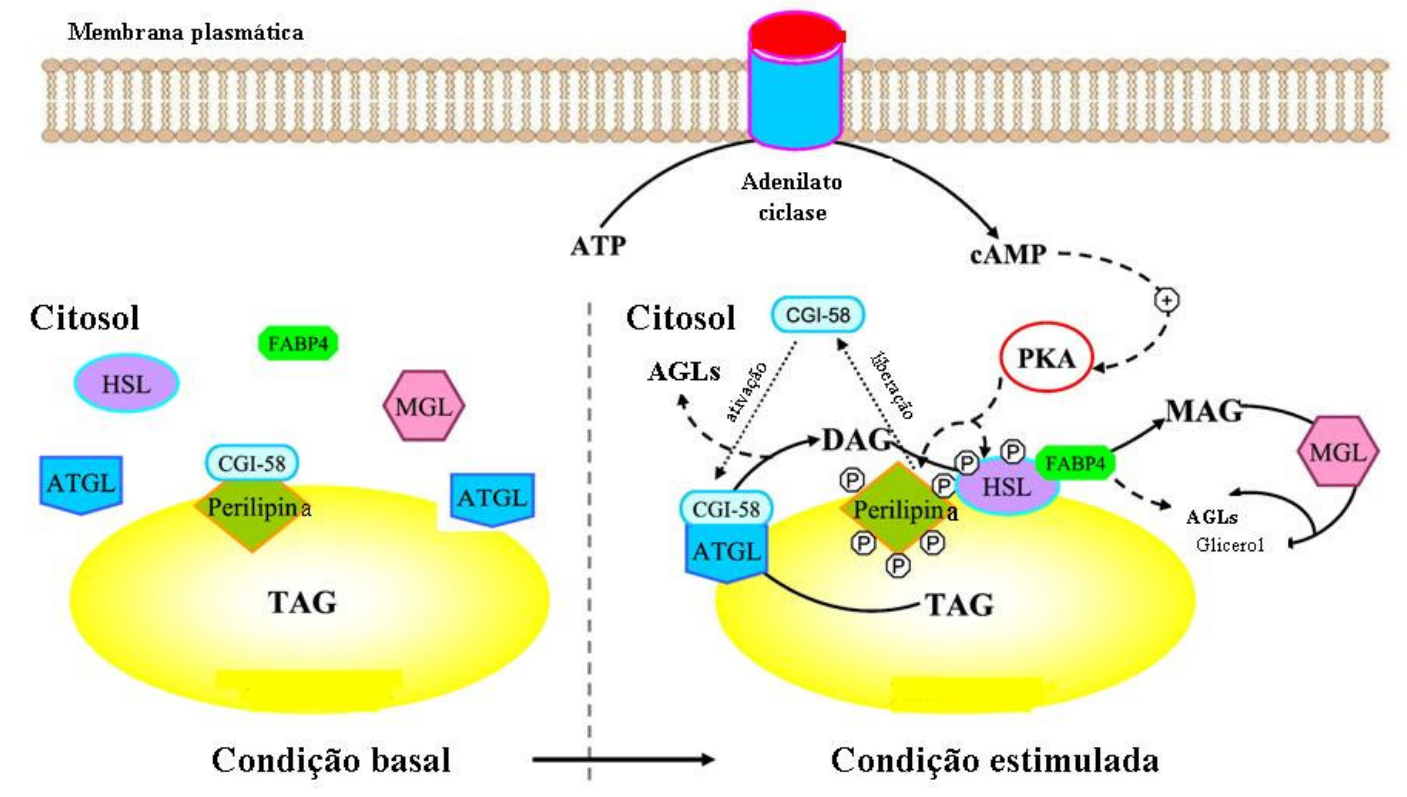

FONTE: Adaptado de Lampidonis et al. (2011).

ABREVIATURAS: ATGL, lipase de triacilglicerol do adipócito; HSL: lipase hormônio-sensível; MGL, lipase de monoacilglicerol; CGI-58: comparative gene identification 58; FABP4, proteína transportadora de ácidos graxos 4; AGL, ácidos graxos livres; DAG, diacilglicerol; MAG, monoacilglicerol.

É importante ressaltar o fato que a lipólise estimulada é drasticamente reduzida em animais que não expressam perilipina 1, indicando que esta proteína coordena o recrutamento e/ou a ativação das lipases sob condições lipolíticas (Wat e Steinberg, 2008). É notável que durante a lipólise estimulada a perilipina 1 é absolutamente essencial para o recrutamento da LHS para as gotículas lipídicas e sua completa ativação enzimática (Sztalryd et al., 2003). Contudo, a fosforilação da perilipina não é necessária para a translocação da LHS, uma vez que em mutantes da perilipina fosforilada ainda há o recrutamento da LHS para a superfície da gotícula lipídica (Miyoshi et al., 2006). Watt e Steinberg (2008), sugerem que a fosforilação da perilipina 1 aumenta a atividade da LHS por fatores independentes da translocação sozinha, talvez por melhorar o remodelamento das gotículas lipídicas e permitir 
um melhor acesso para a LHS, ou indiretamente por aumentar a co-localização com a ATGL, melhorando o fornecimento de substrato (diacilglicerol) para a LHS.

O turnover do pool de triacilglicerol nos adipócitos é rápido. Sendo assim, variações relativamente pequenas na lipólise (ou na síntese de triacilglicerol) podem, em um tempo relativamente curto, ter efeitos profundos na massa de gordura e no destino metabólico dos ácidos graxos livres (Langin e Arner, 2006). Vale ressaltar que os ácidos graxos livres não servem apenas como fonte energética, mas também são moléculas sinalizadoras e quando presentes em abundância podem interferir no metabolismo normal (Bezaire e Langin, 2009). Recentes estudos demonstram que os ácidos graxos livres são capazes de promover a expressão de citocinas pró-inflamatórias no pâncreas (Böni-Schnetzler et al., 2009), prejudicar a sensibilidade à insulina no músculo de indivíduos obesos e diabéticos (Reyna, Ghosh, Tantiwong et al., 2008) e exacerbar a inflamação induzida por elevada concentração de glicose em monócitos humanos (Dasu e Jialal, 2011).

\subsubsection{Alterações do tecido adiposo na caquexia}

Embora a extensiva perda de gordura corporal seja um dos marcadores da caquexia, durante muitos anos o estudo do tecido adiposo nesta condição foi de certa forma, negligenciado. Ao longo das últimas décadas, inúmeros grupos de estudo vêm pesquisando as alterações na musculatura esquelética induzidas pela síndrome, e diversas vias envolvidas na depleção muscular já estão bem estabelecidas (Argilés et al., 2006; Kilgour et al., 2010). Por outro lado, o conhecimento a cerca das alterações do tecido adiposo induzidas pela caquexia ainda é limitado.

É digno de nota que a perda de tecido adiposo que ocorre na caquexia não pode ser explicada somente pela perda de apetite, uma vez que ela muitas vezes precede o início da anorexia (Ishiko et al., 1999) e é muito mais severa em modelos animais de caquexia do que em restrição alimentar (Sobin e Wittekind, 2002).

Estudos prévios do nosso grupo mostraram que animais caquéticos apresentam modificações na composição dos ácidos graxos e um aumento na dimensão dos adipócitos em dois diferentes depósitos do tecido adiposo branco: mesentérico e retroperitonial (Bertevello e Seelaender, 2001). Uma vez que a caquexia promove um aumento no conteúdo de água corporal, especulou-se que o aumento destes adipócitos era decorrente, ao menos parcialmente, por retenção hídrica e não por aumento no conteúdo lipídico. Posteriormente foi descrita a infiltração de macrófagos no tecido adiposo branco de animais caquéticos (Machado et al., 2004), indicando a presença de inflamação local. Verificou-se 
ainda que esses macrófagos eram capazes de produzir mediadores inflamatórios, como TNFa e prostaglandina E2 $\left(\mathrm{PGE}_{2}\right)$. O aumento na concentração destes mediadores inflamatórios resulta em agravamento da inflamação local e sistêmica (Lira et al., 2009). Dessa forma, pode-se imaginar que o tecido adiposo não apenas é afetado pela caquexia, mas tem ainda papel fundamental no estabelecimento e progressão do quadro inflamatório observado nesta síndrome.

A função endócrina do tecido adiposo também está bastante alterada na caquexia. A associação entre a caquexia induzida pelo câncer e alteração na concentração de adipocinas vem sendo descrita nos últimos anos (Nakajima et al., 2009; Smiechowska et al., 2010). Alguns autores sugerem que um prejuízo na resposta das adipocinas à perda de peso possua um papel na patogênese da caquexia (Nakajima et al., 2009), entretanto, a associação entre a expressão de adipocinas e a caquexia induzida pelo câncer não está completamente elucidada.

Já está bem estabelecido que as concentrações plasmáticas de leptina estão diretamente correlacionadas com a massa do tecido adiposo em indivíduos saudáveis (Trayhurn e Beattie, 2001), mas os dados a respeito da concentração plasmática de leptina na caquexia são controversos. Assim, em relação à concentração plasmática de leptina e caquexia, os estudos mostram redução (Machado et al., 2004; Smiechowska et al., 2010; Takashi et al., 2009; Werynska et al., 2009), aumento (Moses et al., 2001) ou até mesmo ausência de alteração (Wallace et al., 1998), variando de acordo com o tipo de tumor e a espécie estudada.

Resultados semelhantes são observados em relação à outra adipocina, a adiponectina. A concentração plasmática de adiponectina demonstra relação inversa com o peso corporal; sendo assim, em situações onde há perda voluntária de peso corporal há aumento na concentração desta adipocina (Silva et al., 2011). Jamieson et al. (2004) e Nakajima et al. (2009) descrevem uma redução na concentração de adiponectina no plasma de pacientes com caquexia na vigência de câncer. Entretanto, resultados opostos foram encontrados em outros estudos, nos quais foi descrita uma elevada concentração de adiponectina no plasma destes pacientes (Kerem et al., 2008; Smiechowska et al., 2010).

Embora a base molecular da atrofia do tecido adiposo seja pouco compreendida, algumas evidências sugerem que a perda de gordura seja consequência de aumento na resposta catabólica associado ao prejuízo nos processos anabólicos. De acordo com Large et al. (1997) e Skoog et al. (2001), um aumento da lipólise parece ser o fator-chave neste processo. Em pacientes com caquexia na vigência de câncer, há aumento no turnover de glicerol e ácidos graxos, em comparação com pacientes com câncer sem caquexia (Shaw e 
Wolfe, 1987). Também foi mostrado que a lipólise corporal, medida através da taxa de aparecimento de glicerol, está aumentada em pacientes com câncer que estavam perdendo peso quando comparados com indivíduos saudáveis (Zuijdgeest-van et al., 2000). Ainda nesse contexto, estudos mostraram que o RNAm e o conteúdo protéico de LHS estão aumentados no tecido adiposo de pacientes com caquexia na vigência do câncer (Agustsson et al., 2007; Thompson et al., 1993).

Vários fatores derivados do tumor ou dos tecidos do portador estão implicados na depleção de gordura durante a progressão da caquexia (Tisdale, 2009). Dentre estes estão as citocinas pró-inflamatórias, como TNF-a, e os fatores lipolíticos, como a zinco-a2glicoproteína (ZAG). O TNF-a, por exemplo, exerce efeitos pró-lipolíticos independentemente do conteúdo de lipases. Primeiramente, o TNF-a inibe a ativação do IRS-1 (Engelman et al., 2000; Fujishiro et al., 2003), anulando a ação anti-lipolítica da insulina. Além disso, o tratamento com TNF-a reduz o conteúdo total de perilipina 1 nos adipócitos (Souza et al., 1998) e sua fosforilação pela PKA (Souza et al., 2003). Segundo Bézaire e Langin (2009), este efeito promove a lipólise por aumentar a exposição dos lipídios à ATGL e à LHS.

A ZAG é uma glicoproteína solúvel, expressa em diversos tecidos (Tada et al., 1991), incluindo diferentes tipos de tumores malignos (Albertus et al., 2008; Diez-Itza et al., 1993; Hale et al., 2001). A propriedade mais estudada da ZAG é o seu envolvimento no metabolismo lipídico (Bing e trayhurn, 2009). O tratamento com ZAG induz a redução de gordura corporal em animais obesos (Bing et al., 2002; Hirai et al., 1998; Russell e Tisdale, 2011), tanto por indução direta da lipólise, quanto por sensibilizar o tecido adiposo à outros estímulos lipolíticos (Russell e Tisdale, 2011). Em recente estudo com pacientes com câncer gastrointestinal, Mracek e col. demonstraram que não há diferenças na concentração plasmática de ZAG entre pacientes caquéticos e com peso estável (Mracek et al., 2011). Contudo, houve uma superexpresão desta proteína no tecido adiposo subcutâneo dos pacientes caquéticos, sugerindo uma ação local deste fator.

Enquanto certos fatores estimulam a via lipolítica, produtos da lipólise medeiam a inflamação no tecido adiposo (Suganami et al., 2005). Usando experimento de co-cultura de adipócitos e macrófagos, Suganami et al. (2007) mostraram que ácidos graxos livres, os quais são liberados pela lipólise, podem ativar macrófagos e ativar vias inflamatórias. Assim, a comunicação entre adipócitos e macrófagos provavelmente agrava a inflamação do tecido adiposo.

Dessa forma, pensamos que a resposta do tecido adiposo à caquexia possa induzir alterações na composição tecidual que, por sua vez, poderiam modular a biologia dos adipócitos, gerando um ciclo vicioso. 


\section{MATERIAL E MÉTODOS}

\subsection{Estudo clínico}

\subsubsection{Casuística}

Os sujeitos da pesquisa foram recrutados por médicos especialistas da Clínica Médica Cirúrgica do Hospital Universitário (HU) da Universidade de São Paulo (USP), após consulta médica ambulatorial. Para a inclusão do sujeito na pesquisa, foram utilizados os seguintes critérios:

a) Ambos os sexos;

b) Idade entre 18 e 100 anos;

c) Diagnóstico de câncer no sitema gastrointestinal com indicação cirúrgica ou pacientes com indicação cirúrgica para hérnia inguinal, epigástrica, umbilical ou incisional.

Foram adotados como critérios de exclusão: falência hepática ou renal, AIDS, doenças inflamatórias do intestino e doenças autoimunes.

O estudo foi realizado de acordo com os princípios da declaração de Helsinki e foi previamente aprovado pelo Comitê de Ética em Pesquisa com Seres Humanos do Instituto de Ciências Biomédicas - USP, sob o número 788. Todos os pacientes incluídos no estudo assinaram um termo de consentimento livre e esclarecido, o qual se encontra em anexo (Anexo A).

O diagnóstico dos pacientes foi realizado através de exames clínicos, laboratoriais, endoscópicos ou de imagem, solicitados de acordo com a necessidade pelo médico responsável pelo paciente. No caso dos pacientes com tumor, o procedimento cirúrgico antecedeu ao tratamento quimioterápico ou radioterápico, ou qualquer outro tipo de tratamento.

A partir destes critérios, foram coletadas amostras de 47 pacientes, de ambos os gêneros, com idade entre 35 e 81 anos, que realizaram a cirurgia no HU - USP durante o período de novembro de 2008 a março de 2010. Os pacientes foram divididos em 3 grupos experimentais: controle (CTR), portador de tumor com peso estável (TB), portador de tumor com caquexia (TBC). As características gerais dos sujeitos estão descritas na Tabela 2. 
Tabela 1 - Características gerais dos sujeitos

\begin{tabular}{lccc}
\hline & CTR & TBC & TB \\
\hline $\mathrm{n}$ & 20 & 17 & 10 \\
Homens/Mulheres & $11 / 9$ & $10 / 7$ & $4 / 6$ \\
Idade (anos) & $51,1 \pm 3,6$ & $58,4 \pm 4,0$ & $66,9 \pm 4,3$ \\
IMC (Kg/m²) & $23,3 \pm 0,9$ & $20,6 \pm 0,8$ & $22,9 \pm 0,7$ \\
Perda de peso (\%) & $1,94 \pm 1,00$ & $19,9 \pm 1,9^{\mathrm{a}}$ & $4,0 \pm 0,5$ \\
Plasma & & & \\
PCR (mg/dL) & $50,8 \pm 40,9$ & $92,3 \pm 15,4$ & $90,4 \pm 31,2$ \\
Hemoglobina (mg/dL) & $12,4 \pm 0,5$ & $11,4 \pm 0,4$ & $11,3 \pm 0,6$ \\
Uréia (mg/dL) & $36,9 \pm 2,7$ & $35,3 \pm 6,5$ & $36,9 \pm 3,5$ \\
\hline
\end{tabular}

FONTE: Seelaender e Batista Jr (2010).

NOTA: Resultados são média \pm EPM. a $p<0,001$ em relação aos demais grupos. Abreviaturas: CTR, controle; TB, portador de tumor com peso estável; TBC, portador de tumor com caquexia; IMC, índice de massa corporal; PCR, proteína C-reativa.

O grupo controle foi constituído por pacientes que sofreram cirurgia eletiva para hérnia. No caso do grupo portador de tumor com caquexia, as amostras foram obtidas de pacientes com câncer gástrico (35\%), câncer de cólon (42\%) ou outros tipos tumorais (23\%). O grupo tumor sem caquexia foi composto por pacientes com câncer gástrico (30\%), câncer de cólon (20\%), câncer retal (10\%) ou outros tipos de tumor (40\%).

Não foram realizadas mudanças na conduta do procedimento cirúrgico, da anestesia ou do tratamento e nenhuma conduta causou dor ou sofrimento dos pacientes. As amostras foram coletadas somente após a assinatura do termo de consentimento livre e esclarecido e todo o material coletado foi usado exclusivamente para o propósito da pesquisa. 0 projeto foi previamente aprovado pelo Comitê de Ética do Instituto de Ciências Biomédicas (788) e Hospital Universitário/USP (752/07).

\subsubsection{Diagnóstico de caquexia}

Para o diagnóstico de caquexia foram utilizados os seguintes parâmetros (Morley et al., 2006):

a) Variação no peso corporal: diminuição involuntária de massa corporal nos últimos 6 meses (maior ou igual a $5 \%$ da massa corporal inicial); 
b) Índice de massa corporal (IMC): menor que $20 \mathrm{~kg} \cdot \mathrm{m}^{-2}$ para pacientes com menos de 65 anos e menor que $22 \mathrm{~kg} \cdot \mathrm{m}^{-2}$ para pacientes com idade maior ou igual a 65 anos. 0 IMC foi determinado a partir da fórmula seguinte fórmula: massa corporal $(\mathrm{kg}) / \operatorname{altura}^{2}(\mathrm{~m})$;

c) Concentração plasmática de albumina inferior a $35 \mathrm{~g} / \mathrm{L}$;

d) Evidência de inflamação: concentração plasmática de proteína C-reativa superior a $10 \mathrm{mg} / \mathrm{L}$.

Os pacientes que possuíam a variação no peso corporal descrita no item "a", associada a um ou mais destes critérios foram considerados caquéticos.

\subsubsection{Procedimento cirúrgico}

Para o procedimento cirúrgico o sujeito se manteve deitado em uma maca, com monitoração cardíaca e arterial. Os pacientes realizaram banho com sabão antisséptico e receberam limpeza na área do procedimento cirúrgico, a qual foi tricotomizada com o uso de lâminas descartáveis. Aplicou-se anestesia geral ou peridural, sempre de acordo com o médico anestesista responsável e individualizada para cada caso. A incisão na pele foi realizada com lâmina de bisturi esterilizada, individual e descartável e, a retirada do tecido adiposo foi realizada com o auxílio de pinça e lâmina cirúrgicas, pelo médico responsável pelo procedimento cirúrgico.

Dentre os procedimentos cirúrgicos foram realizados: videolaparoscopia ou laparotomia convencional no caso de hérnias, ressecção segmentar no caso dos tumores de cólon e gastrectomias parciais ou totais para os casos de tumores gástricos.

\subsubsection{Coleta de plasma e tecido adiposo branco}

Foram coletados aproximadamente $10 \mathrm{~mL}$ de sangue durante 0 procedimento cirúrgico através do acesso venoso da anestesia. Após coletado, o sangue foi centrifugado a $3.000 \mathrm{rpm}$ por 15 minutos a $4{ }^{\circ} \mathrm{C}$. Logo após, o plasma foi acondicionado em tubos plásticos e estocados a $-80{ }^{\circ} \mathrm{C}$ para posterior análise. $\mathrm{O}$ modo de coleta do sangue não afetou $\mathrm{O}$ procedimento cirúrgico.

Durante a cirurgia também foi coletado aproximadamente $1 \mathrm{~g}$ de tecido adiposo branco subcutâneo, sempre em região superior ao umbigo e nunca adjacente ao tumor, sendo o tempo total de coleta inferior a 5 minutos.

Este procedimento teve um grau mínimo de risco, não interferindo no procedimento cirúrgico padrão. Os tecidos foram imediatamente colocados em nitrogênio líquido ou 
reagente Trizol ${ }^{\circ}$ (Invitrogen, Camarillo, CA, Estados Unidos) e armazenados a $-80{ }^{\circ} \mathrm{C}$ para análises posteriores.

\subsubsection{Medida da expressão gênica por PCR tempo real}

O RNA total do tecido foi extraído a partir de alíquotas de $300 \mathrm{mg}$ de tecido através da extração com reagente Trizol $^{\circledR}$ (Invitrogen). As amostras foram homogeneizadas em aparelho Polytron (PT 3100) e incubadas por 10 minutos a temperatura ambiente. As amostras foram precipitadas com $200 \mu \mathrm{L}$ de clorofórmio e centrifugadas por 15 minutos a $12.000 \times \mathrm{g}\left(4^{\circ} \mathrm{C}\right)$ para a obtenção do RNA total (fase superior) que foi precipitada com 500 $\mu \mathrm{L}$ de álcool isopropílico e incubada por 10 minutos a temperatura ambiente. Os pellets foram lavados com etanol $75 \%$ e as amostras foram centrifugadas por 5 minutos a $7.500 \mathrm{x}$ g, a $4{ }^{\circ} \mathrm{C}$. $\mathrm{O}$ álcool foi removido e os pellets, secos a temperatura ambiente por 15 minutos. As amostras foram então solubilizadas com água-DEPC autoclavada. A concentração de RNA foi determinada por espectofotômetro (UVmini 1240, Shimadzu). A síntese de DNA complementar foi realizada a partir de $3 \mu \mathrm{g}$ de RNA total, $10 \mathrm{U}$ de inibidor de RNAse, $2 \mu \mathrm{L}$ de random primers, $2 \mu \mathrm{L}$ de dNTP $(10 \mathrm{nmol}), 2 \mu \mathrm{L}$ de DTT, $10 \mathrm{U}$ de transcriptase reversa $\mathrm{M}$ MLV e $4 \mu \mathrm{L}$ de tampão (TRIS- $\mathrm{HCl} 100 \mathrm{mM}, \mathrm{KCl} 500 \mathrm{mM} ; \mathrm{MgCl}_{2} 150 \mathrm{mM}$ em água livre de nuclease) (Invitrogen). Em um volume final de $25 \mu \mathrm{L}, 5 \mu \mathrm{L}$ de DNA complementar foram misturados com 2x SYBR Green PCR master mix (Applied Biosystems, Foster City, CA, Estados Unidos) e sequências específicas de oligonucleotídios (Invitrogen). A análise de PCR tempo real foi usada para determinação da expressão gênica de adiponectina, leptina, visfatina, LHS, ATGL, perilipina 1 e CGI-58 no tecido adiposo subcutâneo de pacientes dos grupos controle, portador de tumor com peso estável e portador de tumor com caquexia. No Quadro 2 estão descritas as sequências de oligonucleotídeos utilizadas. A concentração de RNAm foi determinada através do método de comparação de $C_{t}$. Para cada amostra, um valor de $\Delta \mathrm{C}_{t}$ foi obtido pela subtração dos valores do gene-referência (RNA ribossômico $18 \mathrm{~S}$ ) daqueles do gene de interesse. $\mathrm{O}$ valor do $\Delta \mathrm{C}_{t}$ do grupo controle foi então subtraído de cada

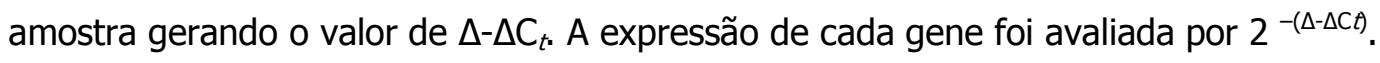


Quadro 2 - Sequência dos oligonucleotídeos para o modelo clínico

\begin{tabular}{|c|c|c|}
\hline Gene (NCBI Genbank) & Sequência de oligonucleotídeos (5'-3') & $\begin{array}{c}\text { Produto } \\
\text { (pb) }\end{array}$ \\
\hline LHS (NM_005357) & $\begin{array}{l}\text { Sense: AACTGCCAGCTGCCTTAAAA } \\
\text { Antisense: TTCCCTCACGGGAGATATTG }\end{array}$ & 163 \\
\hline ATGL (NM_020376) & $\begin{array}{l}\text { Sense: TCCTCGGCGTCTACTACGTC } \\
\text { Antisense: CTCAATGAACTTGGCACCAG }\end{array}$ & 164 \\
\hline CGI-58 (NM_016006) & $\begin{array}{l}\text { Sense: GTGCCCTAGGATTGGACAAA } \\
\text { Antisense: GGCTCTGATCCAAACTGGAA }\end{array}$ & 182 \\
\hline Perilipina 1 (NM_002666) & $\begin{array}{l}\text { Sense: CCCAGGAGTGACAGGAATTG } \\
\text { Antisense: CTCGCTCCTCAAGCTTCAAC }\end{array}$ & 167 \\
\hline Leptina (NM_013076) & $\begin{array}{l}\text { Sense: 5'ACAGAAAGTCACCGGTTTGG3 } \\
\text { Antisense: 5'GTGAAGAAGATCCCGGAGGT3 }\end{array}$ & 163 \\
\hline Adiponectina (NM_144744) & $\begin{array}{l}\text { Sense: 5'ATG ACCAGGAAACCACGACT3' } \\
\text { Antisense: 5'CACC GATGTCTCCCTTAGGA3' }\end{array}$ & 155 \\
\hline Visfatina (NM_177928) & $\begin{array}{l}\text { Sense: 5'AAAATCCAGGAAGCCAAAGA3' } \\
\text { Antisense: 5'TCCTCTGGGAATGACAAAGC3 }\end{array}$ & 165 \\
\hline 18S (HQ387008) & $\begin{array}{l}\text { Sense: CCTGCGGCTTAATTTGACTC } \\
\text { Antisense: ATGCCAGAGTCTCGTTCGTT }\end{array}$ & 168 \\
\hline
\end{tabular}

FONTE: Silvério (2011)

NOTA: Abreviaturas: LHS, lipase hormônio-sensível; ATGL, lipase de triacilglicerol do adipócito; CGI58, comparative gene identification-58.

\subsubsection{Imunodetecção por Western blotting}

Inicialmente, $100 \mathrm{mg}$ de tecido adiposo epididimal foram homogeneizados em homogeneizador Polytron (PT 3100) em $1 \mathrm{~mL}$ de tampão de extração (Trizma base $100 \mathrm{mM}$ pH 7,5, EDTA 10 mM, SDS $10 \%$, fluoreto de sódio $100 \mathrm{mM}$, pirofosfato de sódio $10 \mathrm{mM}$, ortovanadato de sódio $10 \mathrm{mM}$ ). O tampão foi preparado no dia do experimento e aquecido em banho-maria fervente. O homogenato resultante foi transferido para tubos eppendorfs e centrifugado (40 minutos, $12.000 \mathrm{rpm}$, a $4{ }^{\circ} \mathrm{C}$ ). Em seguida, a fração líquida foi cuidadosamente coletada evitando-se a contaminação com a fração lipídica na fase superior do tubo. $O$ teor de proteínas totais foi determinado através do kit BCA ${ }^{\mathrm{TM}}$ (Thermo Scientific, Rockford, IL, Estados Unidos). 
As amostras foram adicionadas, na proporção de 4:1, de tampão de Laemmli (azul de bromofenol 0,01\%, fosfato de sódio $50 \mathrm{mM}$, glicerol 25\%, SDS 1\%) contendo $200 \mathrm{mM}$ de DTT. O volume de $90 \mu \mathrm{g}$ de proteína foi submetido à eletroforese em gel de poliacrilamida desnaturante a $10 \%$. Após separação eletroforética, as amostras foram transferidas para membrana de nitrocelulose por 2 horas à temperatura ambiente (ou overnight a $4^{\circ} \mathrm{C}$ ) e a membrana foi então bloqueada por 2 horas em $15 \mathrm{ml}$ de solução bloqueadora, composta de solução basal (Trizma base 10 mM, NaCl 150 mM, Tween-20 $50 \mu \mathrm{l} / \mathrm{ml}$ ) contendo $5 \%$ de leite desnaturado. Em seguida, foi feita a incubação com o anticorpo primário específico, overnight em temperatura ambiente, com o anticorpo dissolvido em solução basal e BSA $1 \%$. A seguir, a membrana foi incubada por uma hora com anticorpo secundário associado à peroxidase. $\mathrm{O}$ anticorpo secundário constituiu-se sempre de uma anti-imunoglobulina dirigida contra o animal produtor de anticorpo primário. Após algumas lavagens com solução basal, a membrana foi revelada por quimioluminescência após adição do reagente de revelação ECL (Amersham Biosciences, Piscataway, NJ, Estados Unidos) e então a membrana foi exposta a filme de raio $X$. As bandas de interesse foram identificadas pelo seu padrão de migração eletroforética, por comparação com padrões de peso molecular conhecido e quantificadas por densitometria, utilizando-se o programa Scion Image.

Para a detecção da expressão protéica da LHS, ATGL e perilipina 1, foram utilizados anticorpos primários produzidos em coelho e adquiridos da empresa Santa Cruz Biotechnology (Santa Cruz, CA, Estados Unidos), na diluição 1:1.000. O anticorpo secundário (Sigma, St. Louis, MO, Estados Unidos) foi utilizado na diluição 1:5.000.

\subsubsection{Dosagens plasmáticas}

\subsubsection{Adipocinas}

Para a dosagem de adiponectina foi utilizado o método ELISA (Invitrogen). Inicialmente o plasma foi diluído (1:2.000) em solução diluente fornecida pelo próprio kit. Adicionou-se $100 \mu \mathrm{L}$ das amostras e padrões de adiponectina recombinante em uma placa de 96 poços previamente sensibilizada com anticorpo policlonal anti-adiponectina, a qual foi incubada por 1 hora a $37{ }^{\circ} \mathrm{C}$. Após este período, os poços foram lavados 3 vezes com tampão para lavagem e então foram adicionados 100 uL de anticorpo secundário em cada poço e a placa foi novamente incubada por 1 hora a $37{ }^{\circ} \mathrm{C}$. Findo este tempo, os poços foram lavados novamente como descrito anteriormente. Posteriormente, a placa foi incubada por 1 hora $\left(37^{\circ} \mathrm{C}\right)$ com a solução de deteção (anticorpo IgG conjugado com HRP) $(100 \mu \mathrm{L}$ 
por poço). A placa foi novamente lavada (5 vezes) e uma nova incubação com a solução substrato (a qual possui agentes cromogênicos) foi feita por 20 minutos em temperatura ambiente, evitando-se o contato da placa com a luz. A reação foi interrompida através da adição de $100 \mu \mathrm{L}$ de $\mathrm{H}_{3} \mathrm{PO}_{4} 1 \mathrm{M}$ por poço. A leitura foi realizada em leitor de ELISA (Spectra Max Plus, Molecular Devices), utilizando-se filtro de $450 \mathrm{~nm}$.

A determinação da concentração plasmática de leptina foi realizada através do método de radioimunoensaio (Linco Research Inc., St. Charles, MO, Estados Unidos). Inicialmente, $100 \mu \mathrm{L}$ das amostras e padrões de leptina recombinante humana foram pipetados em tubos de poliestireno. Logo após, pipetou-se $100 \mu \mathrm{L}$ de anticorpo anti-leptina multi-espécies, os tubos foram agitados em vórtex, cobertos com filme plástico de PVC e incubados overnight a $4{ }^{\circ} \mathrm{C}$. No segundo dia de experimento, $100 \mu \mathrm{L}$ de ${ }^{125} \mathrm{I}$-leptina foram adicionados em cada um dos tubos, os quais foram posteiormente agitados em vórtex, cobertos e novamente incubados overnight à $4{ }^{\circ} \mathrm{C}$. No dia seguinte, $1,0 \mathrm{~mL}$ do reagente precipitante frio $\left(4^{\circ} \mathrm{C}\right)$ foi adicionado às amostras. Os tubos foram incubados por 20 minutos a $4{ }^{\circ} \mathrm{C}$ e posteriormente centrifugados por 40 minutos a $2.000 \mathrm{~g}$. Imediatamente após, os tubos foram invertidos por cerca de 30 segundos, para a retirada de todo o sobrenadante. 0 excesso de líquido remanecente na borda dos tubos foi retirado com papel toalha. A radioatividade presente nos pellets foi contada em contador gama (Cobra II, Perkin Elmer).

A dosagem das adipocinas no plasma dos pacientes foi realizada em colaboração com o Professor Miguel Batista Jr. (Universidade de Mogi das Cruzes).

\subsubsection{Insulina e glicose}

A concentração de insulina no plasma também foi determinada através de RIA (Millipore, St. Charles, MO, Estados Unidos). No primeiro dia de experimento, $100 \mu \mathrm{L}$ das amostras e dos padrões de insulina recombinante foram adicionados à tubos de poliestireno. Em seguida, foram pipetados em cada tubo $100 \mu \mathrm{L}$ de ${ }^{125} \mathrm{I}$-insulina e $100 \mu \mathrm{L}$ de anticorpo anti-insulina. Os tubos foram agitados em vórtex, cobertos com filme plástico de PVC e incubados overnight à $4{ }^{\circ} \mathrm{C}$. Após este período, foi adicionado $1,0 \mathrm{~mL}$ de reagente precipitante aos tubos, os quais foram posteriormente agitados em vórtex em incubados durante 20 minutos à $4{ }^{\circ} \mathrm{C}$. Logo após, os tubos foram centrifugados (40 minutos, 2.000g, 4 ${ }^{\circ} \mathrm{C}$ ) para a obtenção de um pellet firme. Imediatamente após a centrifugação, 0 sobrenadante foi decantado através da inversão cuidadosa dos tubos, os quais permaneceram nesta posição por cerca de 30 segundos. A radioatividade presente nos pellets foi então determinada em contador gama (Cobra II, Perkin Elmer). 
Para a dosagem da glicemia foi utilizado kit colorimétrico (Labtest ${ }^{\circledR}$ ). Para este ensaio a mistura da amostra com o reagente de trabalho foi incubada por 15 minutos à $37^{\circ} \mathrm{C}$ e a intensidade da cor determinada através da leitura a $505 \mathrm{~nm}$. O método baseia-se no princípio de que a enzima glicose oxidase catalisa a oxidação da glicose da seguinte forma:

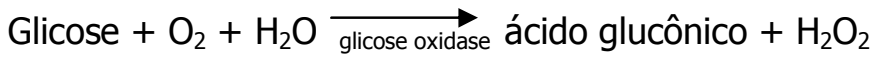

O peróxido de hidrogênio formado reage com 4-aminoantipirina e fenol, sob a ação catalisadora da peroxidase, através de uma reação oxidativa formando uma antipirilquinonimia vermelha cuja intensidade é proporcional à concentração de glicose na amostra.

\subsubsection{Perfil lipídico}

A determinação de triacilglicerol, colesterol total e HDL-colesterol foi realizada através de kits colorimétricos (Labtest $^{\circledR}$, Lagoa Santa, M.G., Brasil).

Para a determinação do triacilglicerol, as amostras, misturadas ao reagente de trabalho, foram incubadas em banho-maria a $37{ }^{\circ} \mathrm{C}$ durante 10 minutos. As absorbâncias foram determinadas em espectofotômetro Spectra Max Plus (Molecular Devices) em 505 nm. Neste ensaio, a lipase de lipoproteína promove a hidrólise dos triacilgliceróis liberando glicerol, que é convertido, pela ação da glicerolquinase, em glicerol-3-fosfato. Este é oxidado a dihidroxiacetona e peróxido de hidrogênio na presença de glicerolfosfato oxidase. Em seguida ocorre uma reação de acoplamento entre peróxido de hidrogênio, 4-aminoantipirina e 4-clorofenol, catalisada pela peroxidase, e a intensidade da cor vermelha formada é diretamente proporcional à concentração de triacilglicerol nas amostras.

Para a dosagem do colesterol total as amostras foram incubadas com reagente de trabalho em banho-maria a $37{ }^{\circ} \mathrm{C}$ durante 10 minutos. As absorbâncias foram então determinadas em $500 \mathrm{~nm}$. A determinação de colesterol por este kit baseia-se nas seguintes reações: os ésteres de colesterol são hidrolisados pela colesterol esterase a colesterol livre e ácidos graxos. O colesterol livre é oxidado pela colesterol oxidase gerando peróxido de hidrogênio, o qual reage com fenol e 4-aminoantipirina formando uma antipirilquinonimina vermelha. A intensidade da cor vermelha formada na reação final é diretamente proporcional à concentração do colesterol na amostra.

A concentração de HDL-colesterol foi determinada através da mistura das amostras com o reagente de trabalho 1 , seguida de incubação a $37{ }^{\circ} \mathrm{C}$ durante 5 minutos. Fez-se então uma primeira leitura das absorbâncias a $600 \mathrm{~nm}$. Posteriormente, o reagente de trabalho 2 foi adicionado às amostras, as quais foram novamente submetidas à incubação a 
$37{ }^{\circ} \mathrm{C}$ durante 5 minutos. Uma nova leitura das absorbâncias foi feita em espectofotômetro a $600 \mathrm{~nm}$. A seletividade deste método está baseada nas tecnologias de aceleração da reação de colesterol oxidase com o colesterol livre das lipoproteínas não HDL e solubilização seletiva das partículas HDL por ação de um detergente específico. Após a solubilização específica do colesterol HDL, com a ação das enzimas colesterol esterase e colesterol oxidase e acoplamento com 4-aminoantipirina e um cromogênio, em reação catalisada pela peroxidase, ocorre o desenvolvimento de uma coloração proporcional à concentração de HDL-colesterol nas amostras.

O LDL-colesterol (LDL-C) foi calculado através das equações propostas por Friedewald (1972):

$$
\begin{gathered}
\text { VLDL-colesterol }=\text { triacilglicerol } / 5 \\
\text { LDL-colesterol }=\text { colesterol total }-(\mathrm{HDL} \text {-colesterol }+ \text { VLDL-colesterol })
\end{gathered}
$$

A dosagem da concentração de ácidos graxos livres (AGL) foi realizada através de kit colorimétrico (Randox, Crumlin, Antrim, Reino Unido). O kit baseia-se nas seguintes reações:

$$
\begin{aligned}
& \mathrm{AGL}+\mathrm{ATP}+\text { coenzima A } \stackrel{\text { acetil-CoA sintetase }}{\longrightarrow} \text { acil-Coa }+\mathrm{AMP}+\text { pirofosfato } \\
& \text { Acil-CoA + O2 } \stackrel{\text { acil-CoA oxidase }}{\longrightarrow} \text { trans-enoil-CoA }+\mathrm{H}_{2} \mathrm{O}_{2}
\end{aligned}
$$

Sendo que o peróxido de hidrogênio $\left(\mathrm{H}_{2} \mathrm{O}_{2}\right)$ formado, através da ação da peroxidase, reage com outros substratos formando um complexo de cor púrpura, o qual é proporcional à concentração de ácidos graxos livres nas amostras.

\subsection{Estudo experimental}

\subsubsection{Animais}

Ratos Wistar machos (150 a $200 \mathrm{~g}$ ) provenientes do Biotério Central do Instituto de Ciências Biomédicas, da Universidade de São Paulo foram mantidos no Biotério do Departamento de Biologia Celular e Tecidual, recebendo água e ração ad libitum. O peso corporal e o consumo de ração foram aferidos a cada 2 dias.

Os animais foram divididos em três grupos experimentais: controle (CTR), portador de tumor sacrificado no 70 (TB7) e no $14^{\circ}$ dia após a inoculação das células tumorais. Nos animais portadores de tumor, as células do carcinossarcoma de Walker 256 foram injetadas subcutaneamente no flanco direito, na proporção de $2 \times 10^{7}$ células, em $1 \mathrm{~mL}$ de solução salina $(\mathrm{NaCl}$ 0,9\%), por rato. Após o sacrifício dos animais, em jejum de 12 horas, realizado por 
decaptação, o sangue, tecido adiposo epididimal, tecido adiposo retroperitonial, tecido adiposo mesentérico, fígado, músculo e tumor foram retirados, pesados e armazenados em freezer $-80{ }^{\circ} \mathrm{C}$. Uma fração do tecido adiposo epididimal foi utilizada imediatamente após o sacrifício, para o isolamento dos adipócitos e outra alíquota foi ainda colocada em paraformaldeído 4\% para processamentos dos cortes histológicos.

O carcinossarcoma de Walker 256, modelo de caquexia em ratos, é adotado por nosso grupo de pesquisa há mais de 15 anos. Trata-se do modelo experimental de caquexia mais amplamente estudado na literatura (Peluso et al., 2000), induzindo nos animais a grande maioria dos sintomas relacionados à síndrome (Kurth et al., 2001; Piffar et al., 2003), e que estão também presentes nos pacientes da doença (Heymsfield e McManus, 1985).

O protocolo $n^{0}$ 050/2011 para uso de animais em experimentação foi realizado segundo os princípios éticos adotados pelo Colégio Brasileiro de Experimentação Animal (COBEA) e pela Comissão de Ética em Experimentação Animal (CEEA), do Instituto de Ciências Biomedicas da Universidade de São Paulo.

Figura 5 - Rato portator do carcinossarcoma de Walker 256 no $14^{\circ}$ dia após a inoculação tumoral

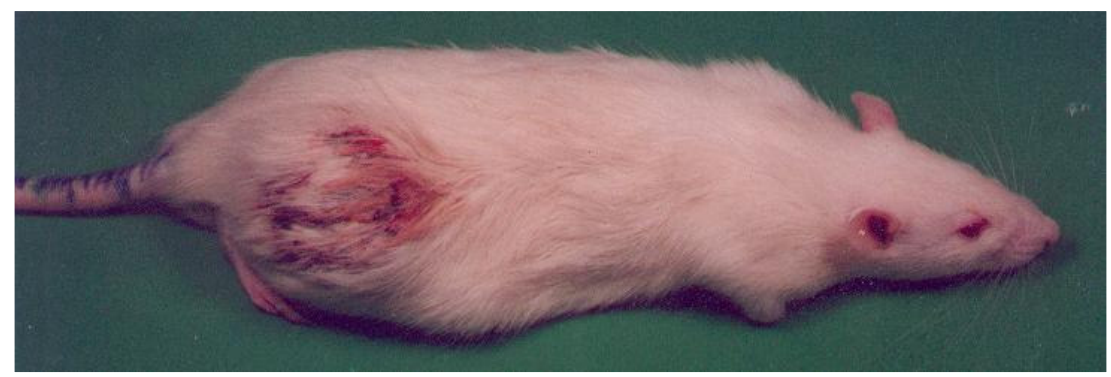

FONTE: Silvério (2011).

\subsubsection{Determinações plasmáticas}

O sangue foi coletado em tubos contendo solução de EDTA (Labtest ${ }^{\circledR}$ ) e as amostras de plasma foram obtidas após centrifugação (3.000 rpm, durante 15 minutos, a $4{ }^{\circ} \mathrm{C}$ ) sendo posteriormente armazenadas em freezer $-80^{\circ} \mathrm{C}$.

A determinação da concentração plasmática de adiponectina, leptina, insulina, glicose, triacilglicerol e ácidos graxos livres foram realizadas através dos mesmos métodos descritos para o modelo clínico (seção 4.1.7).

Para a quatificação da concentração plasmática de visfatina, realizada através de kit de ELISA (Life Science Inc., Wuhan, China), as amostras de plasma foram inicialmente 
diluídas (1:20) em tampão PBS 0,2 M. Após, foram pipetados $100 \mu \mathrm{L}$ das amostras em uma placa de 96 poços previamente sensibilizada com anticorpo monoclonal anti-visfatina. A placa foi coberta com um adesivo plástico e incubada por 2 horas em temperatura ambiente. O conteúdo de cada poço foi então removido pela inversão da placa e $100 \mu \mathrm{L}$ do reagente de detecção A foram adicionados a cada poço. Após 1 hora a $37{ }^{\circ} \mathrm{C}$, a placa foi lavada 3 vezes com tampão para lavagem e foi realizada uma nova incubação de 30 minutos a $37{ }^{\circ} \mathrm{C}$ com $100 \mu \mathrm{L}$ do reagente de detecção B. A placa foi novamente lavada (3 vezes) e $90 \mu \mathrm{L}$ de solução de substrato foi adicionada em cada poço. A placa foi coberta e protegida da luz por 15 minutos a $37{ }^{\circ} \mathrm{C}$. Por fim, $50 \mu \mathrm{L}$ de $\mathrm{H}_{3} \mathrm{PO}_{4} 1 \mathrm{M}$ foram adicionados aos poços, interrompendo a reação. A absorbância das amostras foi lida imediatamente em um comprimento de onda de $450 \mathrm{~nm}$ em espectofotômetro Spectra Max Plus (Molecular Devices).

\subsubsection{Medida da expressão gênica por PCR tempo real}

O RNA total do tecido foi extraído a partir de alíquotas de $300 \mathrm{mg}$ de tecido através da extração com reagente Trizol $^{\circledR}$ (Invitrogen). A extração do RNA total, bem como a síntese de DNA complementar e o ensaio de PCR tempo real foram realizados de acordo com a metodologia descrita na seção 4.1.6. A análise de PCR tempo real foi usada para determinação da expressão gênica de adiponectina, leptina, visfatina, LHS, ATGL, perilipina 1 e CGI-58 no tecido adiposo epididimal de animais controle e portadores de tumor (TB7 e TB14) usando sequência específica de oligonucleotídeos (Quadro 3). As reações de PCR tempo real foram realizadas como descrito por Wang e Edens (2007) em equipamento ABI 7300 (Applied Biosystems). A concentração de RNAm foi determinada através do método de comparação de $\mathrm{C}_{t}$. Para cada amostra, um valor de $\Delta \mathrm{C}_{t}$ foi obtido pela subtração dos valores do gene-referência (gliceraldeído-3-fosfato desidrogenase [GAPDH]) daqueles do gene de interesse. $\mathrm{O}$ valor do $\Delta \mathrm{C}_{t}$ do grupo controle foi então subtraído de cada amostra gerando o valor de $\Delta-\Delta C_{t . .}$ A expressão de cada gene foi avaliada por $2^{-(\Delta-\Delta C t)}$. 
Quadro 3 - Sequência dos oligonucleotídeos para o modelo experimental

\begin{tabular}{|c|c|c|}
\hline Gene (NCBI Genbank) & Sequência de oligonucleotídeos $\left(5^{\prime}-3^{\prime}\right)$ & $\begin{array}{l}\text { Produto } \\
(\mathrm{pb})\end{array}$ \\
\hline LHS (NM_012859) & $\begin{array}{l}\text { Sense: CCTCAAAGTCAAACCCTCCA } \\
\text { Antisense: GTGCGTAAATCCATGCTGTG }\end{array}$ & 196 \\
\hline ATGL (NM_001108509) & $\begin{array}{l}\text { Sense: CAACGCCACTCACATCTACG } \\
\text { Antisense: AGCAGGCAGGGTCTTCAGTA }\end{array}$ & 199 \\
\hline CGI-58 (NM_212524) & $\begin{array}{l}\text { Sense: TGTGTCCCCTGCACTTACAA } \\
\text { Antisense: AAAATTCAGGGCCCAAAGTC }\end{array}$ & 153 \\
\hline Perilipina 1 (NM_013094) & $\begin{array}{l}\text { Sense: ATCTCCTGCCACCAGACAAG } \\
\text { Antisense: GATCCACATGGCCAGAGAGT }\end{array}$ & 175 \\
\hline Leptina (NM_013076) & $\begin{array}{l}\text { Sense: CCTGGTGACAATGGTCTTGA } \\
\text { Antisense: AGCTGCAAGGTCCAAGAAGA }\end{array}$ & 163 \\
\hline Adiponectina (NM_144744) & $\begin{array}{l}\text { Sense: CATCTCCTGGGTCACCCTTA } \\
\text { Antisense: ACCCAAGGAAACTTGTGCAG }\end{array}$ & 155 \\
\hline Visfatina (NM_177928) & $\begin{array}{l}\text { Sense:TTTCCTCGTATTTCACСTTCC } \\
\text { Antisense: AAGCCGAGTTCAACATCCTG }\end{array}$ & 165 \\
\hline GAPDH (NM_017008) & $\begin{array}{l}\text { Sense: AGACAGCCGCATCTTCTTGT } \\
\text { Antisense: CTTGCCGTGGGTAGAGTCAT }\end{array}$ & 175 \\
\hline
\end{tabular}

FONTE: Silvério (2011).

NOTA: Abreviaturas: LHS, lipase hormônio-sensível; ATGL, lipase de triacilglicerol do adipócito; CGI58, comparative gene identification-58; GAPDH, gliceraldeído-3-fosfato desidrogenase.

\subsubsection{Quantificação de adipocinas no tecido adiposo}

Inicialmente, $100 \mathrm{mg}$ de tecido adiposo epididimal foram homogeneizados em $1 \mathrm{~mL}$ de tampão de extração de proteínas (Trizma base 100 mM pH 7,5, EDTA 10 mM, SDS 10 \%, fluoreto de sódio $100 \mathrm{mM}$, pirofosfato de sódio $10 \mathrm{mM}$, ortovanadato de sódio $10 \mathrm{mM}$ ). $\mathrm{O}$ homogeneizado resultante foi centrifugado (40 minutos, $12.000 \mathrm{rpm}$, a $4{ }^{\circ} \mathrm{C}$ ) e, então, a fase aquosa foi cuidadosamente coletada, evitando-se a contaminação com a fase lipídica superior.

A dosagem de adiponectina e de visfatina no tecido foi realizada através de kits de ELISA (Invitrogen e Life Science Inc., respectivamente), seguindo os mesmos passos utilizados para a sua determinação destas adipocinas no plasma (seção 4.2.2.1). Para a 
determinação da leptina foi utilizado método de radioimunoensaio (Linco Research Inc.), como previamente descrito para a determinação plasmática desta adipocina (seção 4.2.2.1).

Para a quantificação da concentração do TNF-a tecidual utilizou-se o método de ELISA (Invitrogen). Uma placa com 96 poços foi sensibilizada com $100 \mu \mathrm{L}$ de anticorpo antiTNF-a de rato e incubada overnight a $4^{\circ} \mathrm{C}$. Após este período, os poços foram lavados por 3 vezes com tampão para lavagem (0,05\% Tween ${ }^{\circledR} 20$ em PBS, pH 7,2 - 7,4). Posteriormente, a placa foi bloqueada para evitar ligações inespecíficas com $300 \mu \mathrm{L}$ de solução de bloqueio (1\% BSA em PBS, pH 7,4, 0,2 $\mu \mathrm{m}$ filtrado) e incubada por 1 hora em temperatura ambiente. Após, os poços foram novamente lavados como descrito acima. Então, foram adicionados $100 \mu \mathrm{L}$ por poço das amostras e dos padrões diluídos previamente em reagente de diluição. Imediatamente após, $50 \mu \mathrm{L}$ do anticorpo de detecção foram pipetados em cada poço. A placa foi coberta com plástico adesivo e incubada por 2 horas em temperatura ambiente. Após este período, a placa foi lavada 5 vezes, $100 \mu \mathrm{L}$ de solução estreptavidina-HRP foi adicionado em cada poço e a placa foi coberta e incubada novamente em temperatura ambiente, por 30 minutos. Findo este prazo, os poços foram novamente lavados 5 vezes e a solução de substrato (mistura dos reagentes $\mathrm{H}_{2} \mathrm{O}_{2}$ e Tetrametilbenzidina) foi adicionada na diluição de 1:1 por poço, seguido de incubação por 30 minutos à temperatura ambiente, evitando-se contato direto da placa com a luz. A reação foi interrompida com $100 \mu \mathrm{L}$ de $\mathrm{H}_{2} \mathrm{SO}_{4}$ 1,8 $\mathrm{N}$ por poço. A leitura foi feita em espectofotômetro Spectra Max Plus (Molecular Devices), utilizando-se filtro de $450 \mathrm{~nm}$.

A quantificação das proteínas totais no tecido avaliado foi realizada através do kit Pierce ${ }^{\circledR}$ BCA (Thermo Scientific).

\section{$\underline{4.2 .5 \text { Isolamento de adipócitos }}$}

Logo após o sacrifício, o tecido adiposo epididimal foi removido e pesado para a obtenção dos adipócitos (Lima et al., 1991). Uma alíquota de $1 \mathrm{mg}$ foi colocada imediatamente em um recipiente plástico contendo $1 \mathrm{~mL}$ de meio de digestão (DMEM $1 \%$, HEPES 0,6 \%, albumina sérica bovina 4\%, $\mathrm{NaHCO}_{3} 4,2 \mathrm{mM}$, colagenase tipo II 0,1\%, pH 7,4). O tecido adiposo foi então fragmentado com uma tesoura afiada e de ponta fina, até adquirir uma consistência homogênea. Após, o tecido picado foi transferido para um frasco coletor, adicionou-se $4 \mathrm{~mL}$ de meio de digestão e o material foi incubado por aproximadamente 1 hora em banho-maria a $37{ }^{\circ} \mathrm{C}$, sob leve agitação orbital. Após a digestão, as células foram filtradas através de uma peneira com malha fina de plástico ou nylon e transferidas para um tubo cônico. Adicionou-se meio de cultura (DMEM 0,83 \%, 
HEPES 0,48 \%, soro fetal bovino $5 \%, \mathrm{NaHCO}_{3} 4,2 \mathrm{mM}$, albumina sérica bovina $1 \%$, pH 7,4) para um volume total de $25 \mathrm{~mL}$ e a suspensão foi centrifugada por 30 segundos a $400 \mathrm{x} \mathrm{g}$. Após a centrifugação, o sedimento no fundo do tubo e o infranadante foram aspirados. Esta etapa foi realizada mais 2 vezes, a fim de assegurar uma lavagem adequada dos adipócitos e a retirada efetiva da colagenase do meio. A determinação do número de adipócitos isolados foi feita conforme o método descrito por Di Girolamo et al. (1971).

\subsubsection{Determinação da lipólise}

De acordo com Borges-Silva et al. (2005), após o isolamento dos adipócitos, uma alíquota de $40 \mu \mathrm{L}$ de suspensão de adipócitos (10 \%) em Krebs/Ringer/Tampão fosfato com $1 \%$ de BSA foi transferida para tubos contendo $20 \mu \mathrm{L}$ de adenosina deaminase $(0,2 \mathrm{U} / \mathrm{mL})$ e incubada a $37^{\circ} \mathrm{C}$ por 5 minutos. Após, as células foram incubadas por 1 hora a $37^{\circ} \mathrm{C}$ na presença ou ausência de isoproterenol $\left(10^{-3} \mathrm{M}\right)$ em um volume final de $200 \mu \mathrm{L}$. Após este período, a reação foi então bloqueada ao colocar-se a mistura em banho frio, seguido por centrifugação a $3.500 \times \mathrm{g}$, durante 5 minutos a $4^{\circ} \mathrm{C}$. $\mathrm{O}$ infranadante foi cuidadosamente transferido para tubos eppendorf. O conteúdo de glicerol do meio de incubação foi utilizado como índice de lipólise e expresso como nanomoles de glicerol liberados por $10^{6}$ células por hora.

A concentração de glicerol foi determinada através de técnica enzimáticacolorimétrica, na qual a amostra foi misturada com o reagente de glicerol livre (Sigma) e incubada por 5 minutos a $37^{\circ} \mathrm{C}$. A absorbância foi lida em espectofotômetro (Spectra Max Plus, Molecular Devices), utilizando-se filtro de $540 \mathrm{~nm}$. Este mesmo protocolo foi realizado utilizando-se um padrão de glicerol (Sigma), para posterior cálculo da concentração de glicerol livre presente nas amostras.

\subsubsection{Imunodetecção por Western blotting}

Para esta técnica, $100 \mathrm{mg}$ de tecido adiposo subcutâneo foram homogeneizados em homogeneizador Polytron (PT 3100) em $1 \mathrm{~mL}$ de tampão de extração e seguiu-se a mesma metodologia descrita previamente na seção 4.1.7.

Os anticorpos primários para ATGL, LHS, CGI-58 e perilipina 1 foram produzidos em coelho (Santa Cruz Biotechnology). Utilizou-se a diluição 1:1.000 dos anticorpos primários e 1:5.000 do anticorpo secundário (Sigma). 


\subsubsection{Análise morfológica}

Após a sua excisão, o tecido adiposo epididimal foi lavado com $\mathrm{NaCl} 0,9 \%$ a $37^{\circ} \mathrm{C}$, fragmentado com o auxílio de navalha e fixado por 4 horas em paraformaldeído $4 \%$ em tampão fosfato $0,1 \mathrm{M}, \mathrm{pH} 7,4$, a $4^{\circ} \mathrm{C}$. Após, o tecido foi lavado 30 minutos em água corrente e as amostras foram desidratadas com concentração crescente de etanol ( 2 x 70 \%, 1 × 95 \%, 2 x $100 \%$ ), incubadas com xilol e infiltradas em Paraplast. Depois de embebidas, foram obtidas seções de $5 \mu \mathrm{m}$ (micrótomo R. Jung, Heideiberg) as quais foram colocadas em lâminas previamente cobertas com polilisina (Sigma). Os cortes receberam sucessivos banhos de xilol ( $3 \times 1$ hora, $3 \times 30$ minutos, $3 \times 20$ minutos), foram desidratados com concentração decrescente de soluções de etanol e lavados com água destilada. Finalmente, os cortes foram corados com hematoxilina e eosina ( $\mathrm{HE})$, e então analisados por microscopia de luz. Para a quantificação do tamanho dos adipócitos, os cortes foram analizados utilizando um microscópio (Alphaphot-2 YS2, Nikon) equipado com uma câmera digital. O perímetro e a área seccional foram medidos em 100 adipócitos por corte (3 cortes para cada ratos e 5 animais por grupo), e a análise dos dados realizada através do programa Image Pro ${ }^{\circledR}$ Plus (Media Cybernetics) para processamento de imagem digital.

\subsection{Análise estatística}

Os resultados foram analisados por ANOVA one-way, com pós-teste de Tukey. 0 nível de significância adotado foi de, pelo menos, 0,05. Os valores estão representados como média \pm erro padrão da média (EPM). 


\section{RESULTADOS}

\subsection{Estudo com pacientes}

\subsubsection{Dosagens plasmáticas}

Na Tabela 2 estão descritos os valores da concentração plasmática dos seguintes parâmetros: adiponectina, leptina, TNF-a, ácidos graxos livres, glicose, insulina, índice HOMA, colesterol total, HDL-colesterol, VLDL-colesterol, LDL-colesterol e triacilglicerol.

Verificamos um aumento de 6,5 vezes na concentração plasmática de TNF-a no grupo TBC ( $p<0,05$ versus CTR). A concentração de ácidos graxos livres neste grupo também apresentou um aumento $(2,6$ vezes) em relação ao grupo CTR $(P<0,05)$.

Tabela 2 - Parâmetros plasmáticos dos pacientes

\begin{tabular}{lccc}
\hline & CTR & TB & TBC \\
& $\mathbf{n = 1 0}$ & $\mathbf{n = 1 1}$ & $\mathbf{n = 1 0}$ \\
\hline Adiponectina (ug/mL) & $7,8 \pm 2,7$ & $11,1 \pm 8,5$ & $19,1 \pm 7,3$ \\
Leptina $(\mathrm{pM})$ & $645,7 \pm 158,1$ & $309,4 \pm 270,9$ & $220,8 \pm 191,5$ \\
TNF-a (pg/mL) & $11,1 \pm 4,5$ & $13,8 \pm 4,3$ & $72,5 \pm 29,1^{\mathrm{a}}$ \\
Ácidos graxos livres $(\mu \mathrm{M})$ & $680,94 \pm 30,07$ & $917,30 \pm 43,30$ & $1.786,98 \pm 551,0^{\mathrm{a}}$ \\
Glicose $(\mathrm{mM})$ & $5,51 \pm 0,25$ & $6,01 \pm 0,42$ & $5,37 \pm 0,22$ \\
Insulina (ng/mL) & $0,56 \pm 0,13$ & $0,67 \pm 0,17$ & $0,32 \pm 0,07$ \\
Colesterol total (mg/dL) & $183,91 \pm 13,69$ & $300,00 \pm 54,10^{\mathrm{a}}$ & $287,34 \pm 65,21^{\mathrm{a}}$ \\
HDL-C (mg/dL) & $52,85 \pm 3,37$ & $64,12 \pm 9,90$ & $42,85 \pm 7,00$ \\
VLDL-C (mg/dL) & $29,57 \pm 1,56$ & $36,43 \pm 3,04^{\mathrm{b}}$ & $28,52 \pm 0,65$ \\
LDL-C (mg/dL) & $104,08 \pm 11,69$ & $200,30 \pm 42,46^{\mathrm{a}}$ & $239,81 \pm 54,16^{\mathrm{a}}$ \\
TAG (mg/dL) & $147,89 \pm 9,25$ & $182,15 \pm 17,99$ & $142,60 \pm 3,89$ \\
\hline
\end{tabular}

FONTE: Silvério (2011).

NOTA: Resultados expressos como média \pm EPM. a $\mathrm{P}<0,05$ em relação ao $\mathrm{CTR}$; $\mathrm{b} \mathrm{P}<0,05$ em relação ao TBC. Abreviaturas: CTR, controle; TB, portador de tumor com peso estável; TBC, portador de tumor com caquexia.

Ao analisar o perfil lipídico do plasma, notamos que os pacientes portadores de tumor apresentaram um quadro de dislipidemia (Tabela 2). O colesterol total foi 1,5 vezes maior no grupo TBC ( $P<0,05$ em relação ao CTR) e 1,6 vezes maior no grupo TB. Da mesma forma, observamos um aumento na concentração plasmática de LDL-colesterol de 2,3 vezes no 
grupo TBC $(P<0,05)$ e de 1,9 vezes no grupo TB. Verificamos ainda o aumento na concentração de VLDL-colesterol no plasma dos pacientes do grupo TB em comparação com o grupo TBC $(P<0,05)$. Em relação às concentrações plasmáticas de triacilgicerol e HDLcolesterol não encontramos diferenças entre os diferentes grupos estudados.

Ainda na Tabela 2 pode-se verificar que não houve alterações nas concentrações plasmáticas de adiponectina, leptina, glicose e insulina $(P>0,05)$.

\subsubsection{Expressão gênica das adipocinas}

Os resultados das análises da expressão gênica da leptina, adiponectina e visfatina no tecido adiposo subcutâneo estão demonstrados na Figura 6. Verificamos que a expressão gênica de leptina esteve drasticamente reduzida (83 \%) no grupo TBC quando comparados ao $C T R$, entretanto está redução não foi considerada estatisticamente significante $(P=0,06)$ (Figura 6-A). Nota-se ainda que houve aumento na expressão gênica desta adipocina no grupo TB, quando comparado ao TBC $(P<0,01)$.

Em relação à adiponectina (Figura 6-B), observou-se um aumento de quase 5 vezes na sua expressão gênica no grupo TBC em relação ao CTR $(P<0,01)$.

Vemos ainda na Figura 6-C que houve um grande aumento no RNAm para visfatina do grupo TBC (18 vezes em relação ao CTR e 5 vezes em relação ao TB; $P<0,01$ em relação aos demais grupos). 
Figura 6 - Expressão gênica das adipocinas no tecido adiposo subcutâneo dos pacientes

A

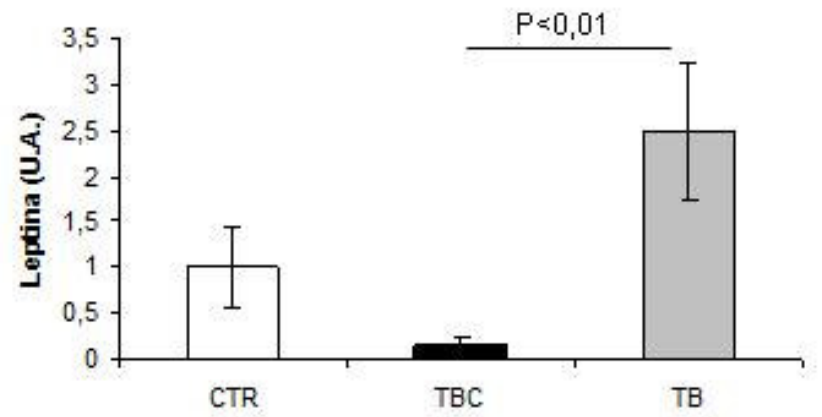

B

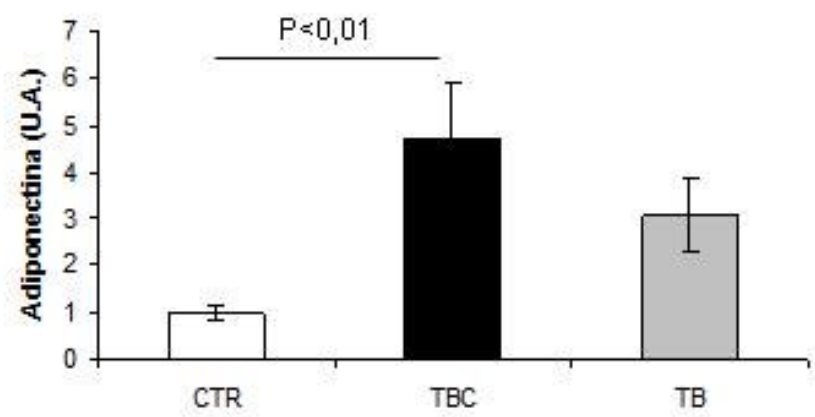

C

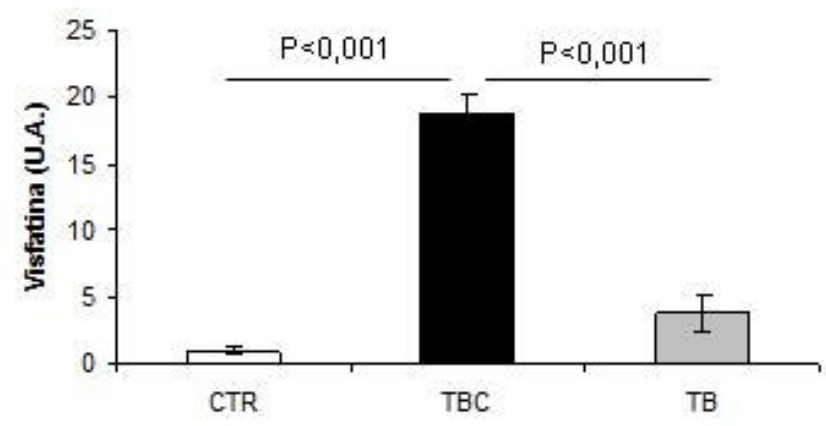

FONTE: Silvério (2011).

NOTA: Valores expressos como média \pm EPM. Normalizado com a expressão gênica do 18S. (A) Leptina, (B) Adiponectina e (C) Visfatina. CTR $(n=12)$, TBC $(n=9)$, TB $(n=7)$. Abreviaturas: CTR, controle; TBC, portadores de tumor com caquexia; TB, portadores de tumor com peso estável. 


\subsubsection{Expressão gênica e protéica das proteínas envolvidas no processo lipolítico}

Na Figura 7 encontram-se os resultados da expressão gênica das proteínas envolvidas no processo lipolítico: LHS, ATGL, CGI-58 e perilipina 1. Como esperado, a expressão gênica da LHS esteve bastante aumentada no grupo TBC (18,8 vezes em relação ao CTR; $P<0,001$ ) (Figura 7-A). Em relação à $A T G L$, não observamos alteração na sua expressão gênica (Figura 7-B). Já em relação ao seu coativador, a CGI-58, houve um aumento de 4 vezes no seu RNAm no grupo TBC ( $P<0,05$ em relação ao controle), como demonstrado na Figura 7-C. Encontramos ainda um aumento na expressão gênica de perilipina 1 no grupo TB ( $P<0,01$ em relação aos demais grupos) (Figura 7-D).

Figura 7 - Expressão gênica das proteínas relacionadas à lipólise no tecido adiposo subcutâneo dos pacientes.

A

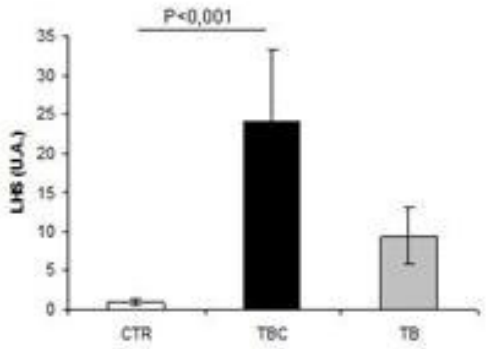

C

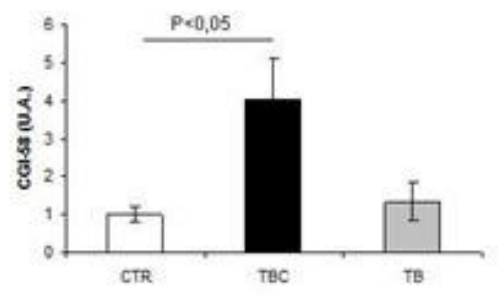

B

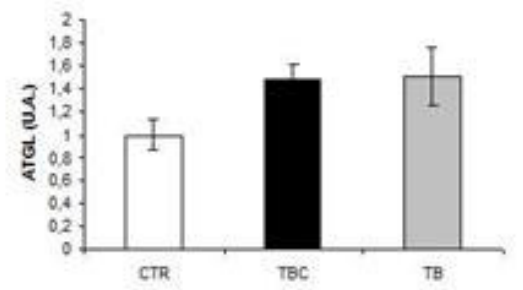

D

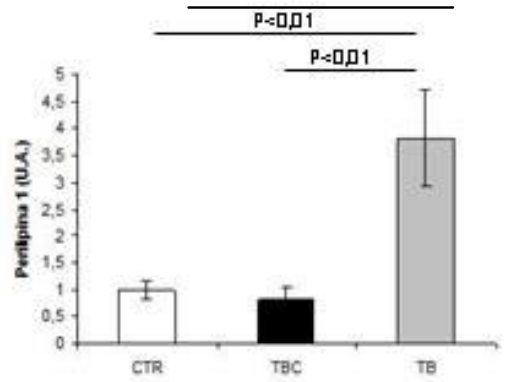

FONTE: Silvério (2011).

NOTA: Valores expressos como média \pm EPM. (A) LHS, (B) ATGL, (C) CGI-58, (D) Perilipina 1. CTR $(n=12)$, TBC $(n=9)$, TB $(n=7)$. Abreviaturas: CTR, controles; TBC, portadores de tumor com caquexia; TB, portadores de tumor com peso estável; LHS, lipase hormônio-sensível; ATGL, lipase de triacilglicerol do adipócito; CGI-58, comparative gene identification-58. 
A expressão protéica da LHS, ATG e perilipina 1 estão demonstradas na Figura 8. Do mesmo modo que a expressão gênica, observamos um aumento no conteúdo protéico de LHS no grupo TBC (51 \% maior em comparação ao CTR, $P<0,01)(P>0,05)$ (Figura 8-A). Verificamos também um aumento de quase 2 vezes na expressão protéica da ATGL no grupo TBC em comparação ao CTR $(P<0,05)$ (Figura 8-B). Finalmente, podemos observar na Figura 8-C uma redução de 51 \% no conteúdo de perilipina 1 no grupo TBC em relação ao CTR $(P<0,05)$. 
Figura 8 - Expressão protéica das proteínas relacionadas à lipólise no tecido adiposo subcutâneo dos pacientes

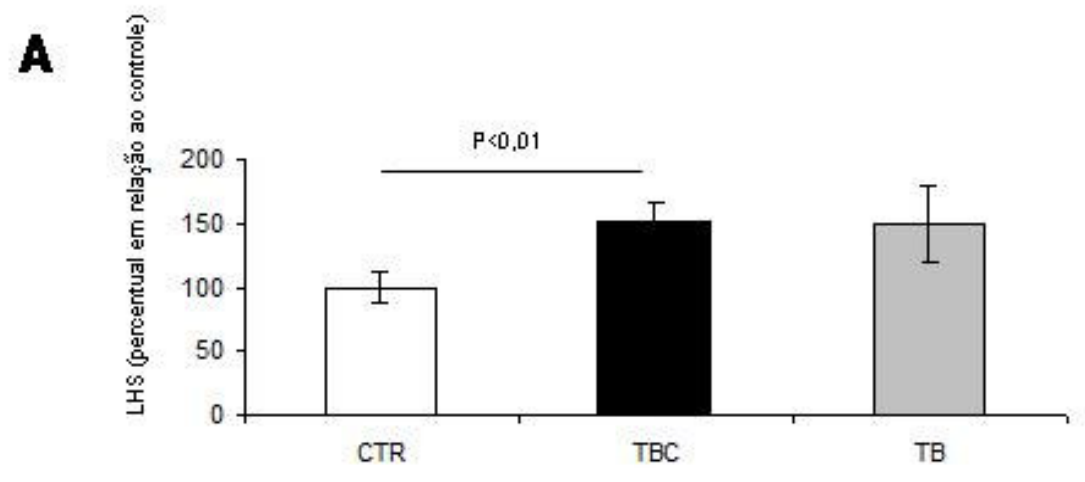

$\mathbf{B}$
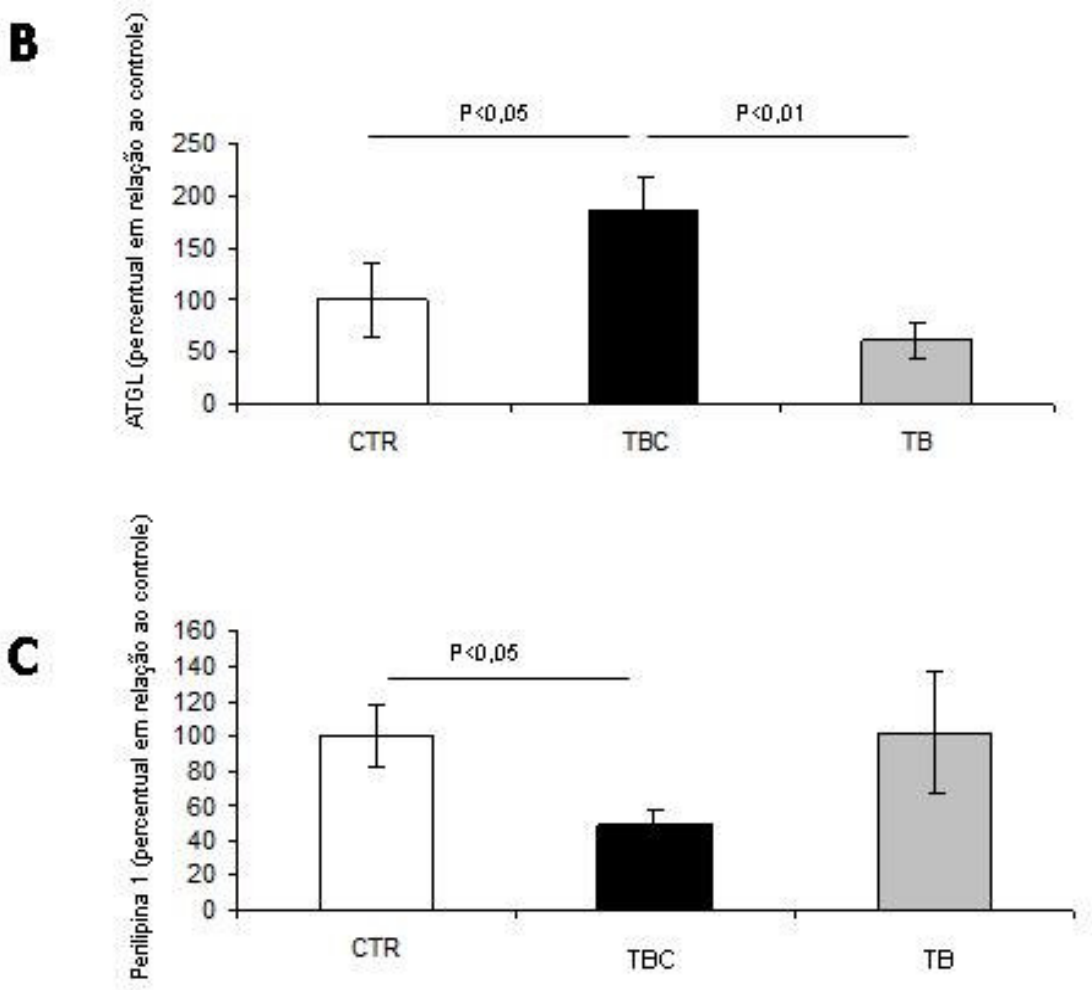

FONTE: Silvério (2011).

NOTA: Valores expressos como média \pm EPM. $n=8$. (A) LHS, (B) ATGL, (C) Perilipina 1. Abreviaturas: CTR, controle; TBC, portador de tumor com caquexia; TB, portador de tumor com peso estável; LHS, lipase hormônio-sensível; ATGL, lipase de triacilglicerol do adipócito; CGI-58, comparative gene identification-58. 


\subsection{Modelo experimental}

\section{$\underline{5.2 .1}$ Peso e composição corporal}

Os animais portadores de tumor apresentaram um menor ganho de peso corporal (TB7) ou mesmo perda de peso ao longo do período experimental (TB14) (Figura 9). Os animais controle tiveram um aumento de 77,20 $\pm 6,16 \mathrm{~g}$, os animais do grupo TB 7 ganharam apenas 20,00 $\pm 6,12 \mathrm{~g}$ ( $\mathrm{p}<0,01$ em relação aos demais grupos), enquanto os animais do grupo TB14 perderam 28,66 $\pm 12,07 \mathrm{~g}$ ( $\mathrm{p}<0,01 \mathrm{em}$ relação aos demais grupos).

Figura 9 - Ganho de peso corporal durante o período experimental

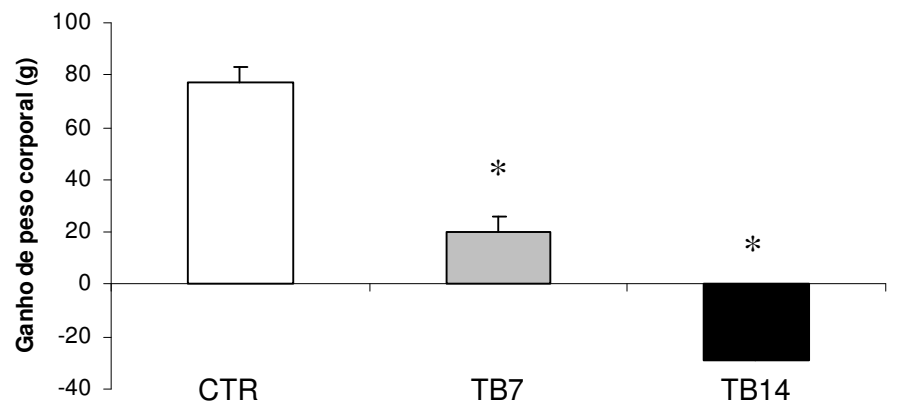

FONTE: Silvério (2011).

NOTA: Dados expressos como média \pm EPM. * $\mathrm{P}<0,01$ em relação aos demais grupos. Abreviaturas: CTR, controle; TB, portador de tumor sacrificado no 70 dia após a inoculação tumoral; TB14, portador de tumor sacrificado no $14^{\circ}$ dia após a inoculação tumoral.

Os dados referentes ao peso relativo dos tecidos (\% do peso corporal total) encontram-se na Tabela 8. Houve redução significativa do TARP e do TAE nos grupos de animais portadores de tumor ( $P<0,001$ e $P<0,05$ em relação ao controle, respectivamente). Não houve diferença significativa em relação ao TAME, fígado e músculo. O peso relativo do tumor foi 3,7 vezes maior no grupo TB14 (3,21 \pm 1,23 \%) em comparação ao TB7 $(12,08 \pm$ $1,91 \%)(P<0,01)$.

A presença de anorexia ficou evidente nos animais portadores de tumor (Tabela 9). Ao analisarmos o consumo diário médio de ração ao longo do período experimental verificamos que os animais do grupo TB7 tiveram um consumo $38 \%$ inferior ao controle $(P<0,01)$. Os animais do grupo TB14 apresentaram uma redução ainda mais significativa (54 $\%$ menor do que o grupo controle, $\mathrm{P}<0,001)$. A redução no consumo de ração pelos animais 
portadores de tumor foi perceptível a partir do $5^{\circ}$ dia após a inoculação tumoral e permaneceu constante até o final do período experimental (Figura 10).

Tabela 3 - Peso relativo dos tecidos (percentual do peso corporal total) nos intervalos de tempo analisados

\begin{tabular}{lccc}
\hline & $\begin{array}{c}\text { Controle } \\
(\mathbf{n = 6})\end{array}$ & $\begin{array}{c}\text { TB7 } \\
\mathbf{( n = 7 )}\end{array}$ & $\begin{array}{c}\text { TB14 } \\
\mathbf{( n = 9 )}\end{array}$ \\
\hline TARP (\%) & $0,87 \pm 0,13$ & $0,30 \pm 0,07 *$ & $0,38 \pm 0,03 *$ \\
TAE (\%) & $0,90 \pm 0,12$ & $0,53 \pm 0,05 * *$ & $0,54 \pm 0,09 * *$ \\
TAME (\%) & $0,39 \pm 0,02$ & $0,40 \pm 0,02$ & $0,32 \pm 0,06$ \\
Fígado (\%) & $3,45 \pm 0,08$ & $3,51 \pm 0,10$ & $3,59 \pm 0,26$ \\
Músculo (\%) & $1,24 \pm 0,02$ & $1,20 \pm 0,06$ & $1,14 \pm 0,05$ \\
Tumor (\%) & ------- & $3,21 \pm 1,23$ & $12,08 \pm 1,91 \#$ \\
\hline
\end{tabular}

FONTE: Silvério (2011).

NOTA: Dados expressos como média \pm EPM. * $\mathrm{P}<0,001$ em relação ao $C T R, * * P<0,05$ em relação ao CTR, \#P<0,01. Abreviaturas: CTR, controle; TB7, portador de tumor sacrificado no 70 dia após a inoculação tumoral; TB14, portador de tumor sacrificado no $14^{\circ}$ dia após a inoculação tumoral; TARP, tecido adiposo retroperitonial; TAE, tecido adiposo epididimal; TAME, tecido adiposo mesentérico.

Tabela 4 - Consumo médio de ração por dia ao longo do período experimental

\begin{tabular}{lc}
\hline & Ração consumida (g) \\
\hline CTR $(n=6)$ & $33,85 \pm 4,30$ \\
TB7 $(n=7)$ & $20,85 \pm 1,63^{*}$ \\
TB14 $(n=9)$ & $15,30 \pm 1,90^{* *}$ \\
\hline
\end{tabular}

FONTE: Silvério (2011).

NOTA: Dados expressos como média \pm EPM. * $\mathrm{P}<0,01$ em relação ao $C T R ; * * \mathrm{P}<0,001$ em relação ao CTR. Abreviaturas: CTR, controle; TB7, portador de tumor sacrificado no 70 dia após a inoculação tumoral; TB14, portador de tumor sacrificado no $14^{\circ}$ dia após a inoculação tumoral. 
Figura 10 - Progressão do consumo de ração durante o período exerimental

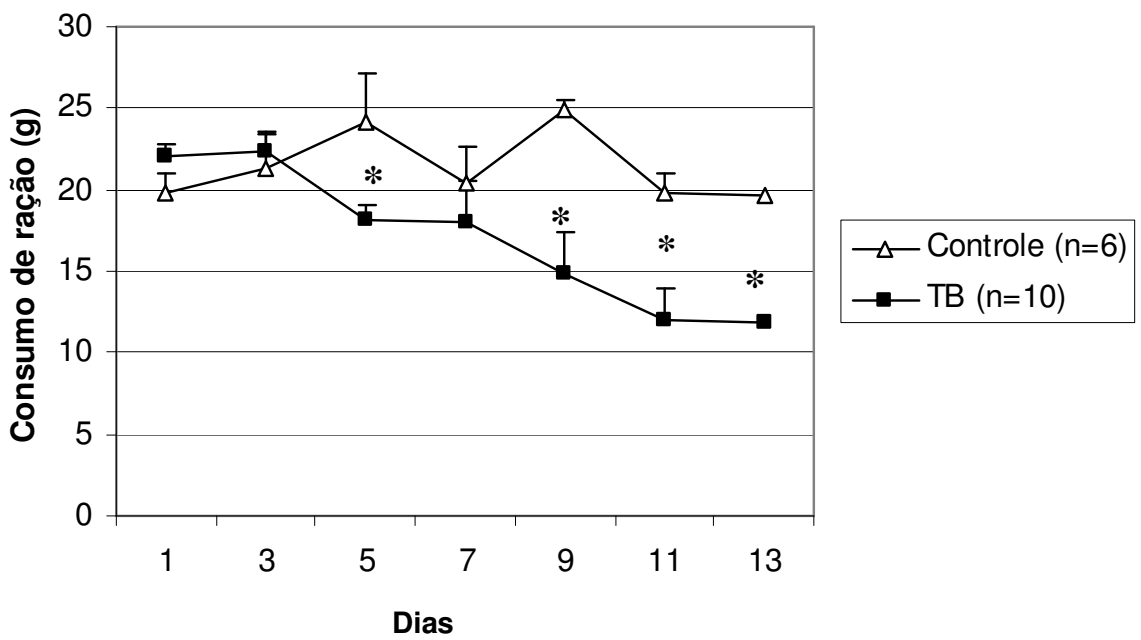

FONTE: Silvério (2011).

NOTA: Dados expressos como média \pm EPM. * P $<0,05$. Abreviatura: TB, portador de tumor.

\subsubsection{Parâmetros plasmáticos}

Os parâmetros plasmáticos estão apresentados na Tabela 10.

A concentração de adiponectina plasmática permaneceu inalterada no grupo TB7 em relação ao controle, entretanto houve redução significativa no grupo TB14 $(P<0,05$ em relação ao controle e em relação ao TB7). A concentração de leptina no plasma esteve reduzida nos animais dos grupos TB7 e TB14 ( $P<0,05$ em relação ao controle). Ao analisar a concentração de visfatina plasmática, podemos observar uma redução de mais de $50 \%$ apenas no $14^{\circ}$ dia após a inoculação das células tumorais $(P<0,05$ em relação ao controle e TB7).

A Tabela 10 ilustra um aumento de mais de $100 \%$ na concentração plasmática de ácidos graxos livres nos animais TB14 ( $P<0,05$ em relação ao controle e TB7). Notamos também que os animais portadores de tumor apresentarm hipertriacilglicerolemia já no 70 dia após o implante tumoral ( $\mathrm{P}<0,05$ em relação ao controle), que foi mais acentuada no estágio final de caquexia ( 3,6 vezes superior ao controle) $(\mathrm{P}<0,05$ em relação ao controle e TB7).

Não houve diferença significativa na concentração plasmática de insulina e glicose. 
Tabela 5 - Parâmetros plasmáticos dos animais

\begin{tabular}{lccc}
\hline & $\begin{array}{c}\text { Controle } \\
(\mathbf{n}=\mathbf{6})\end{array}$ & $\begin{array}{c}\text { TB7 } \\
(\mathbf{n}=\mathbf{7})\end{array}$ & $\begin{array}{c}\text { TB14 } \\
(\mathbf{n}=\mathbf{9})\end{array}$ \\
\hline Adiponectina $(\mathrm{ng} / \mathrm{mL})$ & $20,65 \pm 1,42$ & $19,46 \pm 2,94$ & $7,77 \pm 0,92^{\mathbf{a}, \mathbf{b}}$ \\
Leptina $(\mathrm{ng} / \mathrm{mL})$ & $2,53 \pm 0,12$ & $1,11 \pm 0,20^{\mathbf{a}}$ & $0,70 \pm 0,36^{\mathbf{a}}$ \\
Visfatina $(\mathrm{ng} / \mathrm{mL})$ & $68,12 \pm 5,89$ & $80,27 \pm 7,85$ & $33,01 \pm 6,644^{\mathbf{a} \mathbf{b}}$ \\
Insulina $(\mathrm{ng} / \mathrm{mL})$ & $1,09 \pm 0,08$ & $0,60 \pm 0,25$ & $0,53 \pm 0,20$ \\
Glicose $(\mathrm{mg} / \mathrm{dL})$ & $100,19 \pm 4,25$ & $96,74 \pm 5,32$ & $105,09 \pm 6,31$ \\
Ácidos graxos livres $(\mu \mathrm{M})$ & $629,66 \pm 94,52$ & $758,94 \pm 37,05$ & $1.423,84 \pm 66,56^{\mathbf{a}, \mathbf{b}}$ \\
Triacilglicerol $(\mathrm{mg} / \mathrm{dL})$ & $64,93 \pm 8,47$ & $124,10 \pm 26,45$ & $236,46 \pm 36,55^{\mathbf{a}, \mathbf{b}}$ \\
\hline
\end{tabular}

FONTE: Silvério (2011).

NOTA: Dados expressos como média \pm EPM. a $\mathrm{P}<0,05$ em relação ao $\mathrm{CTR}, \mathrm{b} \mathrm{P}<0,05$ em relação ao TB7. Abreviaturas: TB7, portador de tumor sacrificado no 70 dia após a inoculação tumoral; TB14, portador de tumor sacrificado no 140 dia após a inoculação tumoral.

\section{$\underline{\text { 5.2.3 Aspectos morfológicos e análise morfométrica dos adipócitos }}$}

A Figura 11 mostra o aspecto do tecido adiposo epididimal dos animais portadores de tumor e controle sob microscopia eletrônica. A análise morfológica revelou importantes alterações deste depósito entre os ratos caquéticos e os controles (Figura 11-A). A partir do 70 dia da inoculação tumoral já foi possível notar adipócitos disformes e de vários tamanhos (Figura 11-B e C). Análises morfométricas realizadas posteriormente revelaram que o tamanho do adipócito, determinado como perímetro, área seccional e diâmetro, estava drasticamente reduzido no TB7 e TB14 em comparação com o controle $(P<0,001)$ (Figura 11). 
Figura 11 - Aspectos morfológicos do tecido adiposo epididimal dos animais
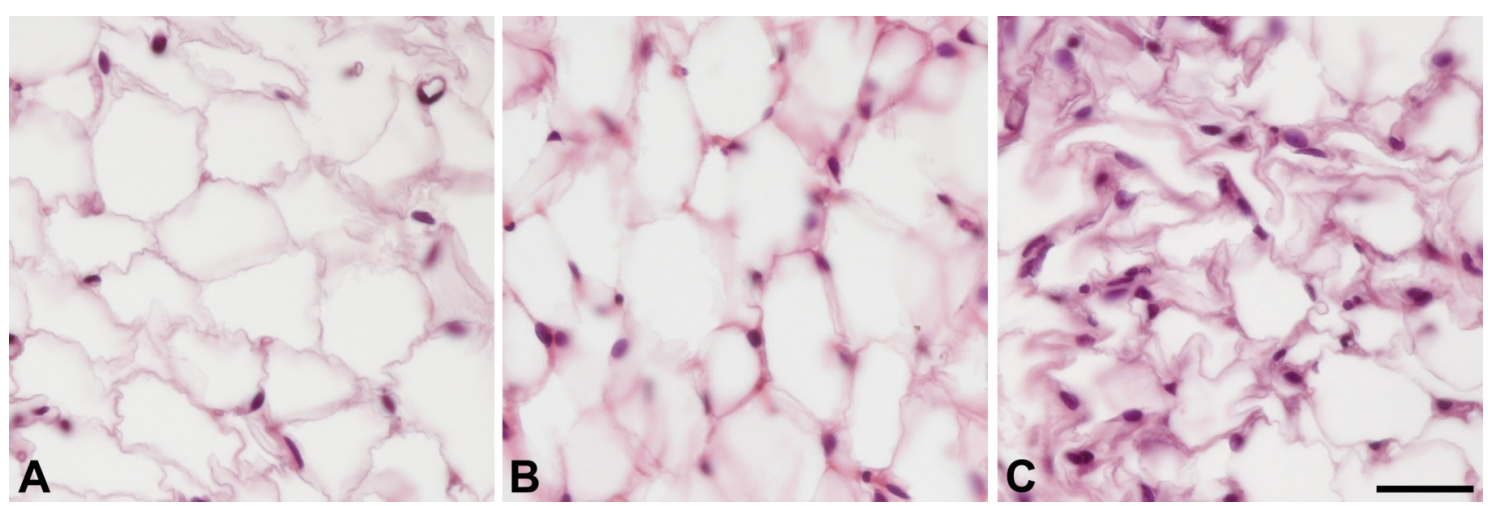

FONTE: Silvério (2011).

NOTA: (A) Controle, (B) TB7, portador de tumor sacrificado no 70 dia após a inoculação tumoral, (C) TB14, portador de tumor sacrificado no $14^{\circ}$ dia após a inoculação tumoral. Notar adipócitos de vários tamanhos no grupo TB7 (B) e adipócitos poligonais e retraídos no grupo TB14 (C). Barra $=50 \mu \mathrm{m}$.

Figura 12 - Análise morfométrica dos adipócitos do tecido adiposo epididimal.

A

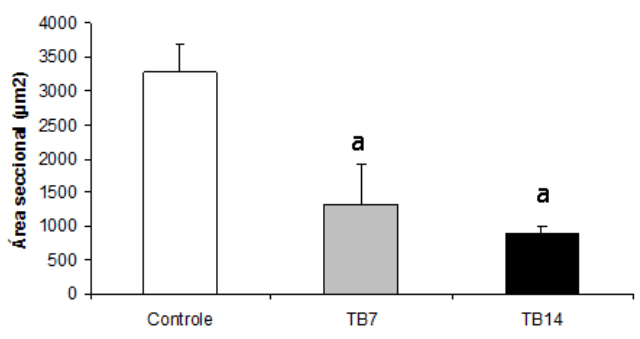

B

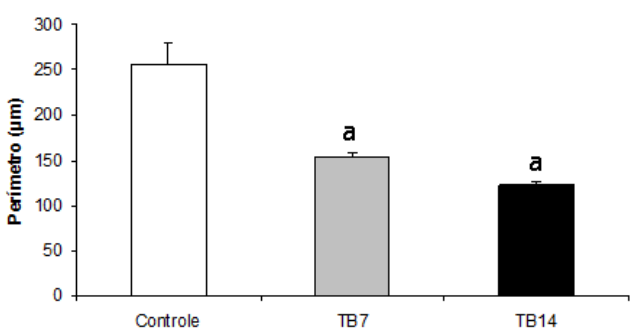

C

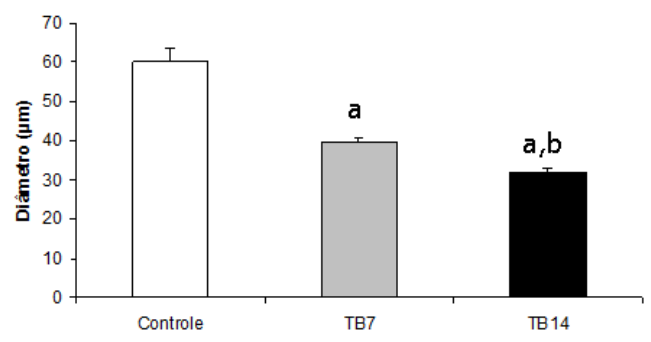

FONTE: Silvério (2011).

NOTA: Dados expressos como média \pm EPM. (A) Área seccional, (B) Perímetro, (C) Diâmetro. a $\mathrm{P}<0,05$ em relação ao controle, $\mathrm{b} P<0,05$ em relação ao TB7. Abreviaturas: TB7, portador de tumor sacrificado no $7^{\circ}$ dia após a inoculação tumoral; TB14, portador de tumor sacrificado no $14^{\circ}$ dia após a inoculação tumoral. 


\subsubsection{Expressão gênica e protéica das adipocinas}

A fim de determinar se a concentração plasmática das adipocinas estava diretamente relacionada com a sua expressão no tecido adiposo, determinou-se sua expressão gênica e protéica no tecido adiposo epididimal.

Como mostrado na Figura 13, no grupo TB7 houve redução na expressão gênica de leptina ( $P<0,01$ em relação ao controle) e aumento na expressão gênica de adiponectina e visfatina ( $P<0,01$ em relação ao controle). Entretanto, no estágio final de caquexia (TB14) os animais apresentaram grande redução da expressão gênica da adiponectina $(P<0,01$ comparado ao controle e TB7) e a concentração de visfatina retornou aos valores controle $(P<0,01$ em relação ao TB7), enquanto a leptina apresentou uma redução ainda mais pronunciada neste grupo ( $P<0,01$, em relação ao controle e TB7).

Ao analisarmos a expressão protéica (Figura 14), observamos redução no conteúdo de leptina no TB7 ( $\mathrm{P}<0,05$ comparado ao controle), o qual permaneceu reduzido no TB14 ( $P<0,05$ em relação ao controle). Verificamos ainda, que ao contrário do observado para 0 RNAm, a expressão protéica de adiponectina apresentou-se reduzida no TB7 $(P<0,001$ em relação aos demais grupos) e esta redução foi ainda mais evidente no TB14 ( $P<0,001$ em relação ao controle e TB7). Também de forma distinta ao observado em relação à expressão gênica, o conteúdo protéico de visfatina permaneceu inalterado no grupo TB7, havendo redução deste parâmetro nos animais do grupo TB14 $(\mathrm{P}<0,05$ em relação aos demais grupos).

A determinação da expressão protéica de TNF-a também foi realizada (Figura 14-C). Observamos um aumento desta citocina no grupo TB7 ( $P<0,05$ em relação ao controle e TB14), o qual se apresentou ainda maior nos animais TB14 ( $P<0,05$ comparado com os demais grupos). Como podemos observar na Figura 15, ao analisarmos uma correlação linear, notamos que existe uma correlação negativa moderada $(P=0,003)(r=-0,64)$ entre a concentração tecidual de adiponectina e TNF-a. Desta forma, quanto maior a concentração de TNF-a no tecido adiposo epididimal, menor é a quantidade de adiponectina. 
Figura 13 - Expressão gênica das adipocinas no tecido adiposo epididimal dos animais
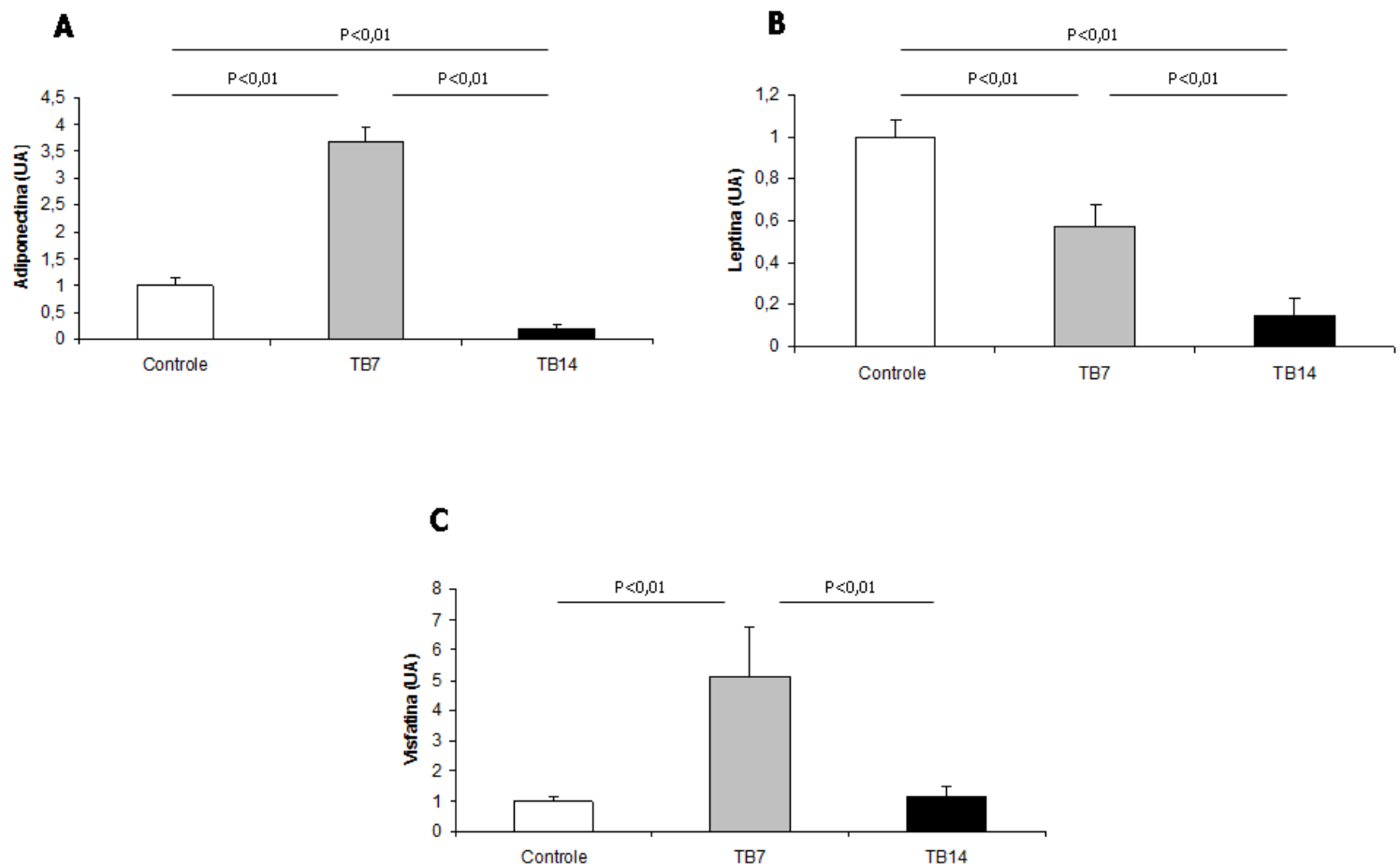

FONTE: Silvério (2011).

NOTA: Dados expressos como média \pm EPM. (A) Adiponectina, (B) Leptina, (C) Visfatina. Controle (n $=12)$, TB7 $(n=8)$, TB14 $(n=10)$. Abreviaturas: UA, unidades arbitrárias; TB7, portador de tumor sacrificado no 70 dia após a inoculação tumoral; TB14, portador de tumor sacrificado no $14^{\circ}$ dia após a inoculação tumoral. 
Figura 14 - Expressão protéica das adipocinas no tecido adiposo epididimal dos animais

A
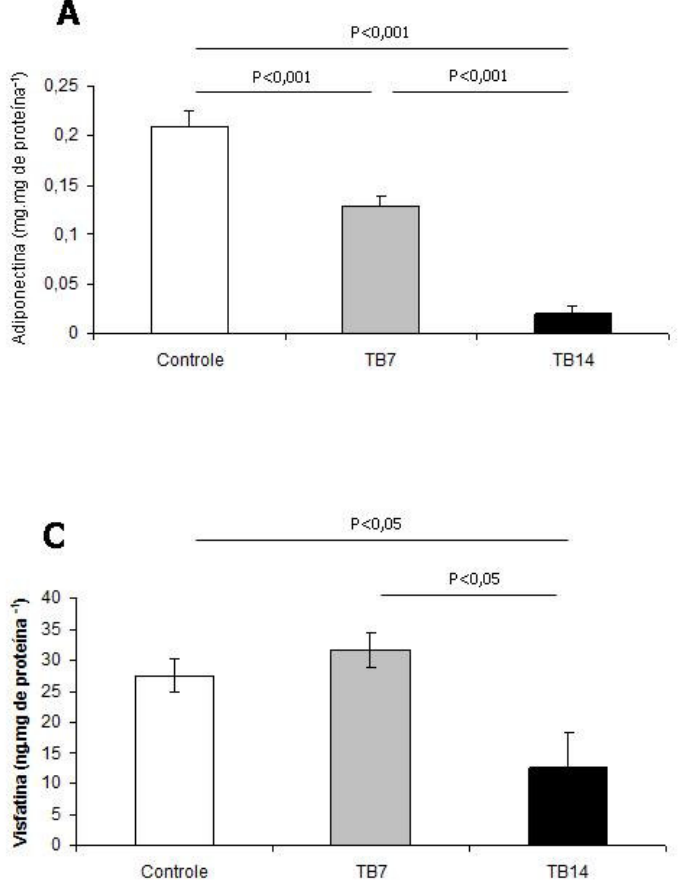
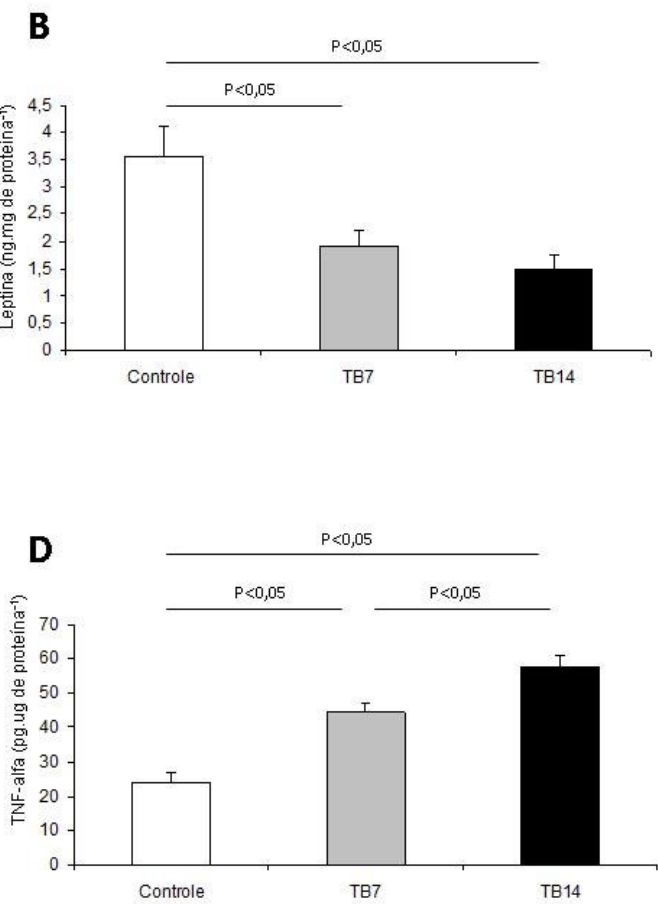

FONTE: Silvério (2011).

NOTA: Dados expressos como média \pm EPM. (A) Adiponectina, (B) Leptina, (C) Visfatina, (D) TNF-a. Controle $(n=12)$, TB7 $(n=8)$, TB14 $(n=10)$. Abreviaturas: TNF-a, fator de necrose tumoral alfa; TB7, portador de tumor sacrificado no 70 dia após a inoculação tumoral; TB14, portador de tumor sacrificado no $14^{\circ}$ dia após a inoculação tumoral. 
Figura 15 - Correlação entre a concentração de TNF-a e adiponectina no tecido adiposo epididimal dos animais

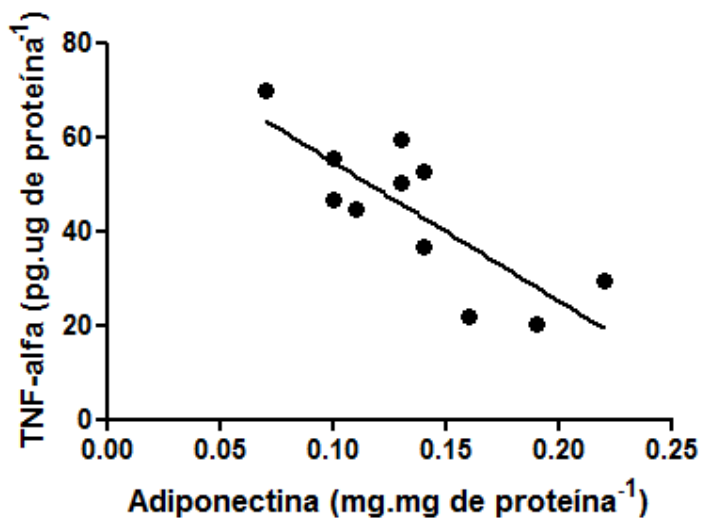

FONTE: Silvério (2011).

NOTA: $n=11 ; P=0,003 ; r=-0,64$. Abreviatura: TNF-a, fator de necrose tumoral alfa.

\subsubsection{Expressão gênica e protéica das proteínas relacionadas à lipólise.}

Os resultados obtidos através do PCR-tempo real e do Western blotting para as proteínas relacionadas à lipólise no tecido adiposo epididimal estão apresentados nas Figuras 16 e 17, respectivamente. As proteínas estudadas foram: LHS, ATGL, CGI-58 e perilipina 1.

Em relação à expressão gênica, notamos um aumento da LSH no grupo TB7 $(P<0,05$ em relação aos demais grupos), a qual retorna aos valores iniciais nos animais TB14 (Figura 16-A). Já o conteúdo de RNAm da ATGL permaneceu inalterado no TB7, sendo drasticamente reduzido no estágio final da progressão da caquexia (TB14) $(P<0,05$ em relação ao controle e TB7) (Figura 16-B). Resultados semelhantes foram obtidos para as outras proteínas estudadas. Como demonstrado na Figura $16-C$, encontramos uma tendência de aumento na expressão da CGI-58 no grupo TB7 ( $\mathrm{P}=0,06$ em relação ao controle) e redução no grupo TB14 ( $P<0,05$ em relação aos demais grupos). 0 conteúdo de RNAm de perilipina 1 também esteve reduzido no grupo TB14 ( $P<0,001$ em relação ao TB7). 
Figura 16 - Expressão gênica das proteínas relacionadas à lipólise no tecido adiposo epididimal dos animais

A

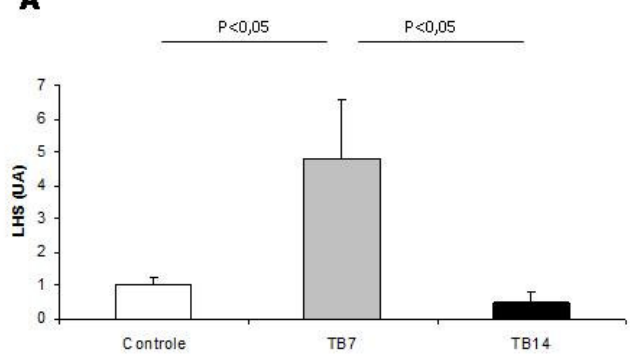

C

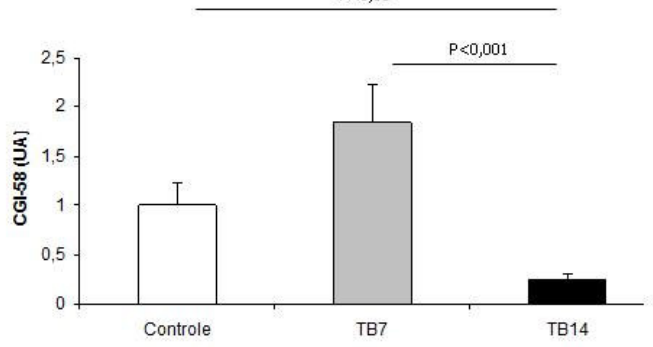

B

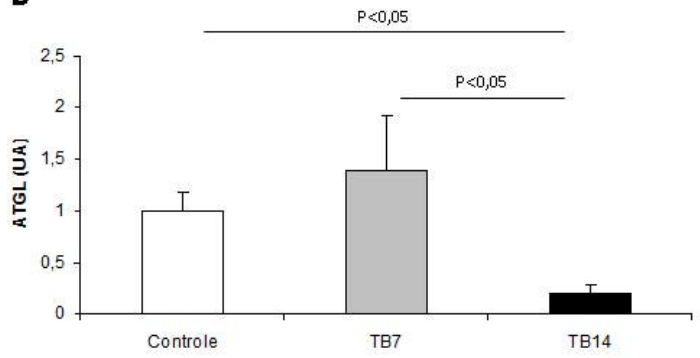

D

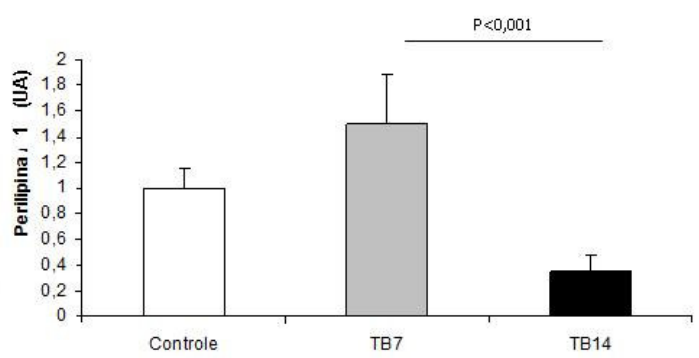

FONTE: Silvério (2011).

NOTA: Valores expressos como média \pm EPM. (A) LHS, (B) ATGL, (C) CGI-58, (D) Perilipina 1. Controle $(n=12)$, TB7 $(n=6)$, TB14 $(n=10)$. Abreviaturas: LHS, lipase hormônio-sensível; ATGL, lipase de triacilglicerol do adipócito, CGI-58, comparative gene identification 58; UA, unidades arbitrárias; TB7, portador de tumor sacrificado no 70 dia após a inoculação tumoral; TB14, portador de tumor sacrificado no $14^{\circ}$ dia após a inoculação tumoral.

A Figura 17 ilustra os resultados da expressão protéica das proteínas relacionadas à lipólise. Em relação ao conteúdo protéico da LHS (Figura 17-A) não foram observadas mudanças ao longo da progressão do estágio tumoral. De forma semelhante ao observado para a expressão gênica, a ATGL e a CGI-58 (Figura 17-B e C) tiveram a sua expressão protéica reduzida no grupo TB14 ( $\mathrm{P}<0,05$ em relação ao controle). Por fim, notamos uma redução de 44 \% no conteúdo de perilipina 1 no grupo TB14 (Figura 17-D), entretanto esta alteração reflete apenas uma tendência $(P=0,06)$, não sendo estatisticamente significante. 
Figura 17 - Expressão protéica das proteínas relacionadas à lipólise no tecido adiposo epididimal dos animais
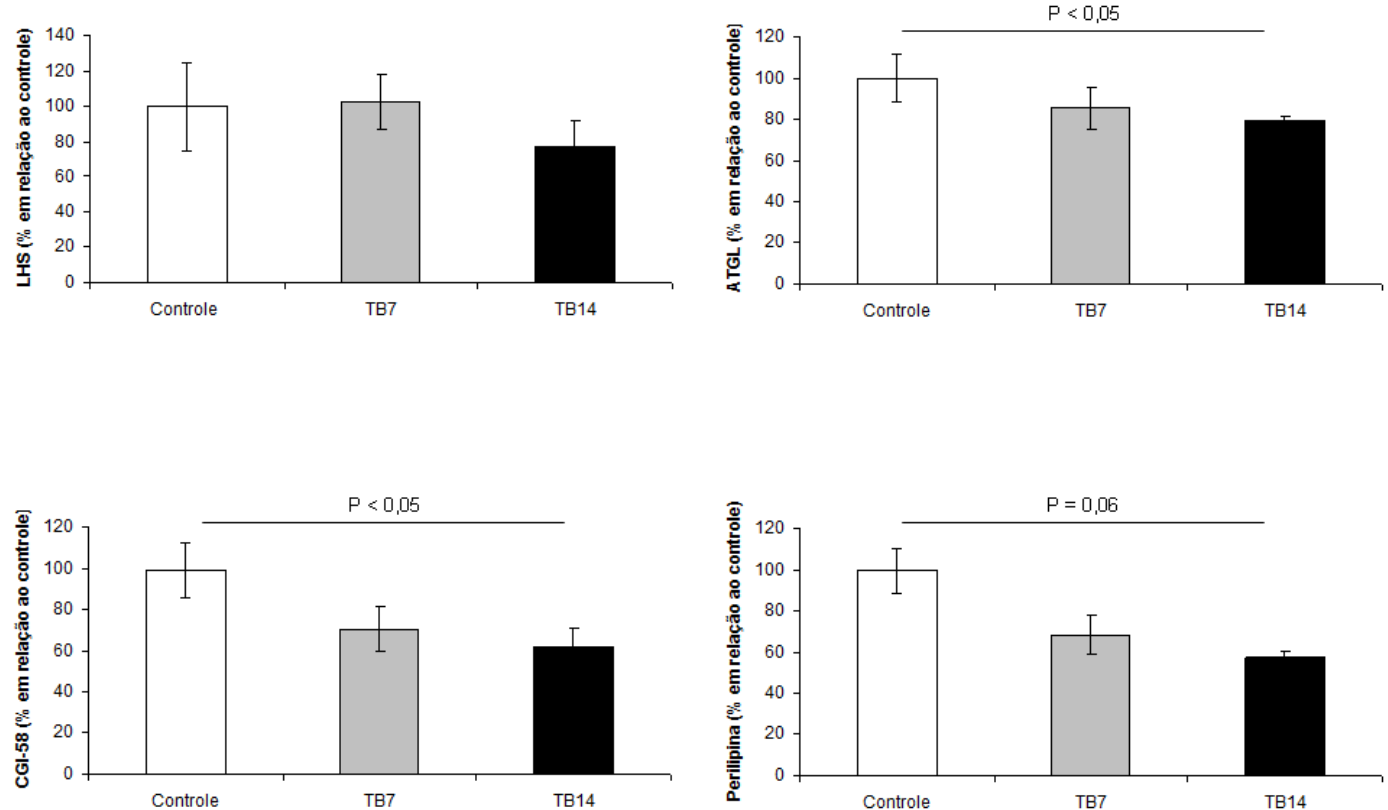

FONTE: Silvério (2011).

NOTA: Valores expressos como média \pm EPM. (A) LHS, (B) ATGL, (C) CGI-58, (D) Perilipina 1. Controle $(n=9)$, TB7 $(n=7)$, TB14 $(n=6)$. Abreviaturas: LHS, lipase hormônio-sensível; ATGL, lipase de triacilglicerol do adipócito, CGI-58, comparative gene identification 58; TB7, portador de tumor sacrificado no 70 dia após a inoculação tumoral; TB14, portador de tumor sacrificado no $14^{\circ}$ dia após a inoculação tumoral.

\subsubsection{Ensaio da lipólise}

A Figura 18 mostra o resultado do ensaio da lipólise. A lipólise basal, representada pela quantidade de glicerol liberada pelos adipócitos na ausência de estímulo, está representada pelas barras pretas. As barras brancas ilustram a condição de lipólise estimulada com isoproterenol. Através deste ensaio, notamos uma redução de $55 \%$ na capacidade lipolítica na presença de estímulo no grupo TB14 $(P<0,01$ em relação aos demais grupos). Não verificamos diferenças em relação à lipólise basal. 
Figura 18 - Capacidade lipolítica de adipócitos isolados do tecido adiposo epididimal dos animais

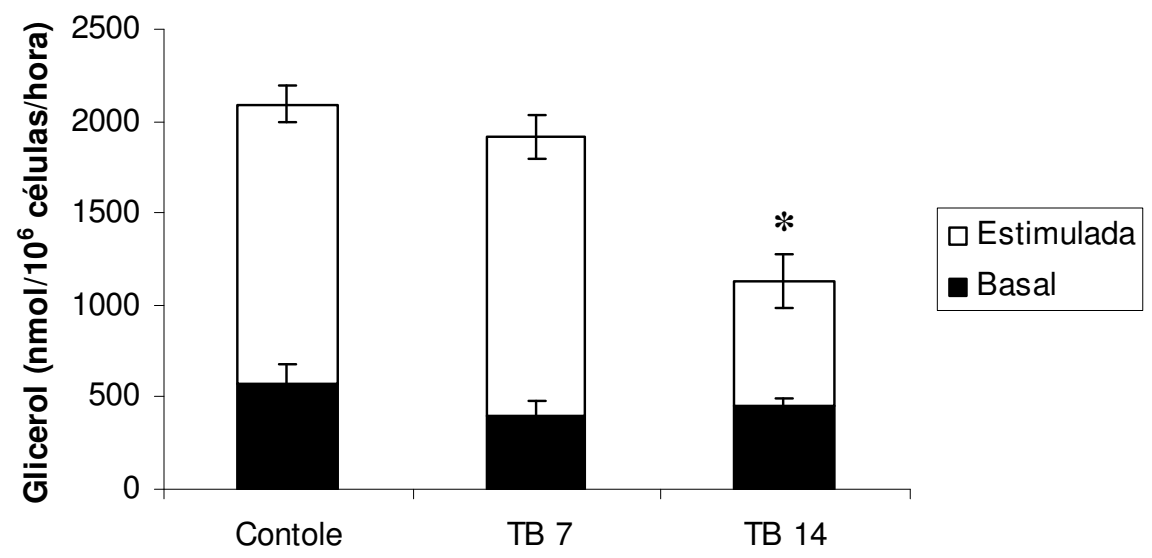

FONTE: Silvério (2011).

NOTA: As barras pretas correspondem à lipólise basal e as barras brancas correspondem à lipólise estimulada com isoproterenol. Valores expressos como média \pm EPM. $n=5$ por grupo. ${ }^{*} P<0,01$ em relação aos demais grupos. Abreviaturas: TB7, portador de tumor sacrificado no 70 dia após a inoculação tumoral; TB14, portador de tumor sacrificado no $14^{\circ}$ dia após a inoculação tumoral. 


\section{DISCUSSÃO}

\subsection{Efeitos sistêmicos da caquexia}

Segundo recente consenso, a caquexia pode ser definida como uma síndrome multifatorial caracterizada por perda contínua de massa muscular (com ou sem perda de tecido adiposo) a qual não pode ser totalmente revertida através do suporte nutricional convencional, levando a um prejuízo funcional progressivo (Fearon et al., 2011). A caquexia afeta a maioria dos pacientes com câncer em estágio terminal e estima-se que esta síndrome seja responsável por 20 a 30 \% das mortes por câncer (Loberg et al., 2007).

Conforme esta recente definição de caquexia, a perda de massa adiposa não é uma condição essencial para o estabelecimento do quadro, entretanto está amplamente descrito na literatura que a perda de tecido adiposo é uma importante característica desta síndrome (Bing, 2011, Mracek et al., 2011; Tisdale, 2010). Utilizando modelos experimentais de caquexia, diversos autores demonstraram que a perda de gordura ocorre antes da perda de massa magra e da redução de ingestão alimentar (Byerley et al., 2010; Ishiko et al., 1999). Além disso, os efeitos da caquexia sobre o metabolismo lipídico no tecido adiposo levam a alterações precoces do perfil lipídico plasmático de forma tão acentuada e característica que têm sido preconizadas como marcadores na triagem de pacientes para o diagnóstico inicial de câncer (Argilés et al., 1997).

Neste contexto, observamos em nosso modelo experimental a redução de dois depósitos adiposos, retroperitonial e epididimal, já no 70 dia após a inoculação tumoral (Tabela 3), sem que houvesse redução no peso corporal dos animais (Figura 9) ou alteração no peso do músculo gastrocnêmio (Tabela 3). Verificamos ainda a característica alteração do perfil lipídico plasmático tanto no nosso modelo experimental (Tabela 5), quanto na caquexia humana (Tabela 2).

Estudos longitudinais com humanos também sugerem que a perda de gordura é um evento inicial na patogênese da caquexia. Fouladiun et al. (2005) acompanharam as alterações na composição corporal de pacientes diagnosticados com câncer gastrointestinal, observando que a perda de gordura ocorreu antes da perda de massa magra. Somando-se a estes resultados, Murphy et al. (2010), em estudo de coorte envolvendo 108 pacientes, recentemente mostraram que durante o curso de progressão da caquexia uma acelerada perda de gordura (visceral, subcutânea e intra-muscular) inicia-se 7 meses antes da morte, chegando à uma redução de $29 \%$ do tecido adiposo dois meses antes da morte dos pacientes. Com base nestes estudos, percebe-se que a perda de massa adiposa não é 
apenas um evento precoce no estabelecimento da caquexia, mas também serve como um preditor de sobrevivência, podendo ser utilizado como ferramenta prognóstica (Murphy et al., 2010).

A relação direta entre a perda de massa gorda e a sobrevida dos pacientes caquéticos evidencia a enorme importância deste tecido para o metabolismo corporal. Tal importância é ressaltada na classificação do tecido adiposo em dois principais compartimentos, a gordura de armazenamento e a gordura essencial (Katch et al., 1980). A gordura essencial representa cerca de 2 a $4 \%$ do peso corporal em homens e aproximadamente $14 \%$ do peso corporal em mulheres e localiza-se na medula óssea, no sistema nervoso central, intramuscular e, no sexo feminino, compreende ainda a gordura específica do gênero (Katch et al., 1980).

O tecido adiposo é constituído principalmente pelos adipócitos, mas contém outros componentes como a matriz de tecido conjuntivo, estroma vascular, fibras nervosas, células do sistema imunitário (leucócitos e macrófagos), nódulos linfáticos, fibroblastos e préadipócitos (Ahima, 2006). Através da análise morfológica observamos um marcante remodelamento do tecido adiposo epididimal dos animais caquéticos. Verificarmos a presença de adipócitos poliédricos e de várias dimensões nos animais caquéticos (Figura 11) e a análise morfométrica posterior revelou uma redução significante no tamanho destas células já a partir do 70 dia após a inoculação tumoral (Figura 12). Nos animais TB7 notou-se que a matriz extracelular foi afetada, apresentando um leve aumento nos espaços entre os adipócitos, enquanto nos animais do grupo TB14 houve uma maior expansão do espaço estromal com a presença de células infiltrantes (Figura 11). Características morfológicas similares as descritas no grupo TB14 foram encontradas no tecido adiposo omental e subcutâneo de pacientes com caquexia na vigência do câncer (Seelaender e Batista Jr., 2010).

A presença de macrófagos infiltrantes no tecido adiposo branco de animais caquéticos já havia sido descrita previamente por nosso grupo (Machado et al., 2004). Neste mesmo estudo, relatou-se ainda uma elevada produção de TNF-a e PGE2 pelos macrófagos infiltrantes, indicando a presença de inflamação local. Interessantemente, o aumento na quantidade de macrófagos no tecido adiposo visceral tem sido descrito na obesidade, situação oposta à caquexia (Kawanishi et al., 2010; Samaan, 2011; Titos et al., 2011). Em ambas as situações, os macrófagos são uma importante fonte de citocinas pró-inflamatórias, como por exemplo, o TNF-a, que induz a expressão de uma variedade de citocinas inflamatórias e fatores quimioatraentes de macrófagos pelos adipócitos (Lumeng et al., 
2007). Desta forma, a comunicação parácrina entre os adipócitos e os macrófagos constitui um ciclo vicioso, acelerando a progressão da inflamação do tecido adiposo.

Ainda em relação ao remodelamento do tecido adiposo na caquexia, recentemente descrevemos um aumento na expressão gênica de colágeno VI e fibronectina, além de maior imunopositividade para colágeno VI, III e fibronectina no tecido adiposo subcutâneo de pacientes caquéticos (Alves, 2011). Estes resultados mostram que a caquexia associada ao câncer afeta o tecido adiposo tão profundamente que induz fibrose tecidual. É importante ressaltar que a integridade da matriz extracelular é essencial para o funcionamento adequado do tecido (Divoux e Clément, 2011) e alterações na sua composição podem ter implicações diretas no metabolismo, funcionalidade e integridade dos tipos celulares que o constituem.

\subsection{Análise da expressão das proteínas relacionadas à lipólise}

A perda de tecido adiposo na caquexia associada ao câncer é resultante de um desequilíbrio entre a hidrólise e a síntese de lipídios (Bing, 2011). Embora a redução na lipogênese possa estar implicada, vários estudos demonstram que a lipólise aumentada é o fator determinante (Agustsson et al., 2007; Hyltander et al., 2000; Klein e Wolfe, 2000; Legaspi et al., 1987; Rydén et al., 2008; Shaw e Wolfe, 1987; Zuijdgeest-van et al., 2000).

A idéia de que um aumento na lipólise contribui decisivamente para a caquexia foi inicialmente embasada pelo aumento na concentração plasmática de ácidos graxos livres e glicerol em pacientes caquéticos (Agustsson et al., 2007; Drott et al., 1989; Rydén et al., 2008; Shaw e Wolfe, 1987). Zuijdgeest-van et al. (2000), utilizando técnicas mais sofisticadas mostraram ainda um aumento na lipólise in vivo em pacientes com caquexia associada ao câncer. Em acordo com essas evidências, nossos resultados mostram que a concentração plasmática de ácidos graxos livres está mais de duas vezes aumentada tanto nos animais portadores de tumor no estágio final da progressão da caquexia (TB14) (Tabela 5), quanto nos pacientes portadores de tumor com caquexia (Tabela 2), sugerindo um aumento na lipólise nestes grupos.

Nos últimos 10 anos houve um expressivo progresso em relação ao conhecimento da regulação do processo lipolítico. Atualmente, sabe-se que a lipólise é controlada por interações complexas entre proteínas que recobrem a gotícula lipídica e lipases, além de proteínas adicionais que atuam como cofatores enzimáticos. De acordo com o modelo recentemente estabelecido, a enzima ATGL inicia a lipólise por remover especificamente o primeiro ácido graxo do triacilglicerol. Então, o diacilglicerol resultante é hidrolisado pela 
reação catalisada pela LHS, gerando monoacilglicerol. Finalmente, a hidrólise do monoacilglicerol é catalisada pela lipase de monoacilglicerol, a qual é abundante e não regulada (Jaworski et al., 2007).

Já há alguns anos vem sendo descrito um aumento na expressão da LHS no tecido adiposo de pacientes com caquexia associada ao câncer (Agustsson et al., 2007; Cao et al., 2010; Thompson et al., 1993). Contudo, são escassas na literatura informações a respeito da contribuição das demais enzimas/proteínas relacionadas à lipólise para a atrofia do tecido adiposo na caquexia. Sendo assim, foi objetivo do presente estudo analisar a expressão das principais proteínas envolvidas no processo lipolítico, a fim de verificarmos a contribuição das mesmas no estabelecimento e progressão do estado caquético. Para melhor compreensão dos parâmetros investigados foram realizados experimentos tanto com seres humanos, quanto com animais.

Neste contexto, o principal achado de nosso estudo foi o incremento na expressão protéica de ATGL, concomitante à redução do conteúdo de perilipina 1 no tecido adiposo subcutâneo de pacientes caquéticos. É digno de nota que ambos os resultados nunca foram descritos anteriormente na literatura.

Como esperado, nossos resultados demontram um aumento bastante pronunciado na expressão gênica (Figura 7-A), bem como no conteúdo protéico da LHS (Figura 8-A) nos pacientes do grupo TBC. Em 1993, um estudo realizado por Thompson e col. mostrou pela primeira vez um aumento na expressão gênica de LHS no tecido adiposo de pacientes caquéticos. Desde então outros autores têm relatado aumento no RNAm (Agustsson et al., 2007; Cao et al., 2010) e expressão protéica desta enzima (Agustsson et al., 2007; Cao et al., 2010). A fim de verificarmos a existência de um padrão temporal na modulação da expressão da LHS induzida pela caquexia, verificamos também a expressão gênica e protéica desta enzima em nosso modelo experimental. Nossos resultados mostram um aumento na expressão gênica da LHS nos animais do grupo TB7 e uma intrigante redução nos animais do grupo TB14 (Figura 16-A), sem alteração, entretanto, no conteúdo protéico em nenhum dos grupos (Figura 17-A).

Como a LHS era considerada até pouco tempo a enzima-chave da lipólise, postulouse que o aumento no seu conteúdo e na sua atividade eram diretamente responsáveis pelo aumento da lipólise na caquexia. Essa hipótese tomou ainda mais força com o resultado relatado no estudo de Agustsson et al. (2007). Estes autores inibiram a LHS em adipócitos provenientes do tecido adiposo subcutâneo de pacientes caquéticos e verificaram a existência de uma atividade lipolítica residual muito pequena (inferior a 10 \%). Este resultado é sugestivo de um papel determinante da LHS na regulação da lipólise na 
caquexia, enquanto a ATGL teria apenas um papel secundário neste processo. É importante notar que estes experimentos foram realizados com adipócitos isolados e, dessa forma, os resultados devem ser analisados com cautela. Macrófagos infiltrantes no tecido adiposo podem interagir de forma direta ou indireta com os adipócitos, afetando inúmeras vias de sinalização celular (Xie et al., 2010). Portanto, na caquexia, onde há a presença de um considerável infiltrado celular, experimentos realizados com adipócitos isolados podem não refletir a real condição metabólica do tecido.

Ainda neste contexto, resultados de um recente estudo confrontam a idéia de que a ATGL possua apenas um papel secundário na lipólise na caquexia. Das et al. (2011) verificaram inicialmente que camundongos portadores de carcinoma de pulmão ou de melanoma apresentavam taxas aumentadas de lipólise, perda de gordura corporal e redução da musculatura esquelética. Interessantemente, os autores inocularam os mesmos tipos tumorais em animais knockout para ATGL ou LHS e verificaram que estes camundongos foram resistentes aos efeitos da caquexia, sendo que o efeito protetor foi mais forte nos animais deficientes em ATGL.

A ATGL realiza seletivamente o primeiro passo da hidrólise do triacilglicerol (Zimmermann et al., 2004) e está bastante expressa no tecido adiposo branco (Watt e Steinberg, 2008). Utilizando linhagem de adipócitos de camundongos, Kershaw et al. (2006) demonstraram que a superexpressão de ATGL estimula a lipólise basal e a lipólise induzida por catecolaminas, enquanto que a ablação do seu gene induz o efeito inverso.

Nossos resultados mostram um aumento de quase duas vezes no conteúdo protéico da ATGL nos pacientes do grupo TBC (Figura 8-B), apesar de não termos encontrado mudanças na expressão gênica desta enzima (Figura 7-B). De modo distinto, em nosso modelo experimental verificamos nos animais do grupo TB7 a ausência de modulação desta lipase, tanto em relação ao RNAm quanto em relação ao conteúdo protéico (Figura 16B e Figura 17-B, respectivamente). Por outro lado, no estágio final da progressão da caquexia (TB14) observamos uma redução tanto na expressão gênica (Figura 16-B), quanto protéica (Figura 17-B) da ATGL.

Encontramos na literatura apenas dois estudos nos quais a expressão da ATGL na caquexia foi investigada. Similarmente ao resultado por nós obtido em humanos e nos animais do grupo TB7, Agustsson et al. (2007) não encontraram alteração na expressão gênica de ATGL no tecido adiposo subcutâneo de pacientes com caquexia na vigência de câncer. Entretanto, o conteúdo protéico da ATGL não foi analisado neste estudo. Já o estudo de Das et al. (2011) relata um aumento na atividade da ATGL no tecido adiposo visceral de pacientes com caquexia associada ao câncer, quando comparados a pacientes com tumor e 
peso estável. Além disso, demontrou-se relação inversa entre a atividade da ATGL e o IMC dos pacientes com câncer, sugerindo que o aumento na atividade desta enzima se correlaciona fortemente com a caquexia.

Com base na literatura, podemos especular que um dos fatores responsáveis pela modulação da ATGL observada em nosso estudo é a alterada sinalização da insulina na caquexia. De acordo com Chakrabarti e Kandror (2011) a função fisiológica primária da insulina no tecido adiposo é a supressão da lipólise, a qual ocorre através da inibição da sinalização $\beta$-adrenérgica. Contudo, estudos recentes mostram ainda que a insulina suprime a lipólise também por regular negativamente a expressão da ATGL (Kershaw et al., 2006; Kralisch et al., 2005).

Diversos autores descrevem um quadro de resistência à insulina em animais caquéticos (Copeland et al., 1987; Gambardella et al., 1993; Lundholm et al., 1978) e especula-se que este fato contribua para o estabelecimento da caquexia (Asp et al., 2010). A ligação da insulina ao seu receptor inicia uma cascata de fosforilação, que começa com a autofosforilação de múltiplos resíduos de tirosina quinase da subunidade $\beta$ do receptor de insulina e subsequente fosforilação dos substratos celulares, como o IRS-1 (Kasuga, 1993; White et al., 1985). O IRS-1 é essencial para muitos dos efeitos biológicos da insulina, incluindo a translocação do transportador de glicose do tipo 4 (GLUT4) estimulada por este hormônio (White e Kahn, 1994). Em adipócitos de animais caquéticos há significante redução na fosforilação do IRS-1, levando a menor disponibilidade de GLUT4 na membrana plasmática, caracterizando o quadro de resistência à insulina (Yoshikawa et al., 1999). Estudos in vivo com dois modelos de ação alterada da insulina, deficiência sistêmica de insulina induzida pela administração de estreptozotocina e camundongos knockout para o receptor de insulina específico no tecido adiposo, mostram uma aumento na expressão gênica de ATGL. Com base nestes resultados, especulamos que a sinalização inadequada da insulina no tecido adiposo induzida pela caquexia possa ter relação direta com a modulação da expressão da ATGL por nós verificada.

Ainda neste contexto, pode-se discutir o possível papel dos glicocorticóides na modulação da ATGL. Pacientes caquéticos possuem elevadas concentrações de glicocorticóides (Drott et al., 1988; Tisdale, 2009), relacionadas com aumento na lipólise através da regulação positiva da LHS (Djurhuus et al., 2002; Slavin et al., 1994). Estudos recentes mostram que os glicocorticóides aumentam a expressão gênica e protéica da ATGL (Serr et al., 2011; Villena et al., 2004). Tisdale (2005) sugere ainda um possível mediador da ação lipolítica dos glicocorticóides na caquexia, a ZAG, glicoproteína que está superexpressa no tecido adiposo de animais (Bing et al., 2004) e pacientes caquéticos (Mracek et al., 
2011). A ZAG induz o aumento da lipólise através da interação com receptores $\beta-3$ adrenérgicos e também através do aumento na expressão protéica de LHS e ATGL (Russell e Tisdale, 2011). Um estudo verificou que ao utilizar-se um antagonista do receptor de glicocorticóide é possível bloquear o aumento da expressão de ZAG no tecido adiposo, indicando a interação entre estes fatores.

Os glicocorticóides relacionam-se também com o quadro de resistência à insulina, resultante da elevada concentração de ácidos graxos livres induzida pelo estímulo lipolítico (Gao et al., 2004). Desta forma, além de afetar diretamente a expressão das principais lipases, é possível que os glicocorticóides possuam um efeito indireto na ATGL, decorrente do prejuízo na via de sinalização da insulina.

A atividade da ATGL é altamente dependente da associação com uma proteína coativadora demoninada CGI-58. A ATGL em camundongos este até 20 vezes mais ativa na presença de CGI-58. Já em seres humanos a CGI-58 ativa a ATGL de forma menos pronunciada (aproximadamente 5 vezes) (Zimmermann et al., 2009). Apesar de estar estabelecida a importância da CGI-58 para a ação da ATGL, ainda não está claro se a ligação com a CGI-58 afeta a conformação da ATGL ou facilita a apresentação do substrato (Zimmermann et al., 2009).

No presente estudo, verificamos a expressão gênica da CGI-58, quando encontramos um aumento de 4 vezes no conteúdo de RNAm nos pacientes portadores de tumor caquéticos (Figura 7-C). Novamente nossos resultados em animais mostraram resultados diferentes daqueles observados em seres humanos: no início da progressão da caquexia (TB7) não houve alteração na expressão gênica e protéica da CGI-58. Contudo, nos animais do grupo TB14 observamos uma redução nestes parâmetros (Figura 16-C e Figura 17-C). Não há dados na literatura a respeito da expressão desta proteína na caquexia.

A CGI-58 aumenta a atividade de hidrolase da ATGL, mas não da LHS (Lass et al., 2006). Diferentemente da ATGL, a atividade da LHS é regulada via fosforilação, embora estudos mostrem que há outros fatores importantes envolvidos neste processo.

A idéia de que a fosforilação não é o único fator determinante para a ativação da LHS originou-se de estudos que mostraram que a ativação da LHS pela PKA in vitro é de aproximadamente 2 vezes, quantidade muito inferior aos grandes aumentos na lipólise (30 a 100 vezes) observados com a elevação da atividade da PKA em adipócitos de mamíferos. Nesse contexto foi proposto que a translocação da LHS do citossol para a gotícula lipídica após estímulo lipolítico, é determinante para a ativação lipolítica (Brasaemle et al., 1999; Egan et al., 1992; Londos et al., 1999). 
A importância do processo de translocação para a ativação da LHS foi evidenciada através da realização de análises da reação lipolítica em camundongos que não expressavam perilipina 1 (Tansey et al., 2001). Verificou-se que a ablação do gene da perilipina 1 levava à perda quase total da lipólise estimulada por receptor adrenérgico, mesmo com a presença de um conteúdo normal de LHS (Sztalryd et al., 2003; Tansey et al., 2001). Contudo, estudos posteriores relatam que a fosforilação da perilipina 1 não é necessária para a translocação da LHS (Miyoshi et al., 2006). Watt e Steinberg (2008) sugeriram que a fosforilação da perilipina 1 aumenta a atividade da LHS por fatores independentes da translocação, talvez por melhorar o remodelamento das gotículas lipídicas e permitir um melhor acesso para a LHS, ou indiretamente, por aumentar a colocalização com a ATGL, melhorando o fornecimento de substrato (diacilglicerol) para a LHS.

Nossos resultados mostram uma redução de aproximadamente $50 \%$ no conteúdo protéico de perilipina 1 no tecido adiposo de pacientes caquéticos portadores de tumor (Figura 7). No nosso modelo experimental também observamos uma redução semelhante nos animais do grupo TB14 (Figura 16-D e Figura 17-D). É interessante notar que, apesar da importância já bem descrita desta proteína no processo lipolítico, não encontramos na Literatura dados a respeito da expressão de perilipina 1 na caquexia.

Levando-se em consideração que a atividade da LHS é dependente da perilipina 1, questionamo-nos se a redução desta proteína observada na vigência da caquexia poderia implicar em prejuízo na atividade desta lipase. Desta forma, a lipólise estimulada por hormônios estaria prejudicada. Por outro lado, a redução do conteúdo de perilipina 1 está associada ao aumento na lipólise basal. Animais knockout para perilipina 1 exibem elevada taxa de lipólise basal, em decorrência da perda do efeito protetor da perilipina 1 contra a degradação do triacilglicerol sob condições quiescentes da PKA (Brasaemle et al., 2000; Souza et al., 1998; Tansey et al., 2003). Além disso, a redução do conteúdo de perilipina poderia implicar ainda em um aumento indireto da atividade da ATGL. Em recente estudo, Gandotra et al. (2011) descreveram que mutações específicas no término carboxil da perilipina 1, impedem a sua associação com a CGI-58, permitindo a coativação da ATGL e resultando em um aumento na lipólise basal.

Diante do exposto, poderíamos hipotetizar que o conteúdo reduzido de perilipina 1 , concomitante ao aumento na expressão protéica de ATGL e expressão gênica de CGI-58, são sugestivos do papel crucial da ATGL no processo lipolítico na caquexia associada ao câncer em humanos.

As enzimas LHS e ATGL são as principais reguladoras do processo lipolítico, entretanto, citocinas como o TNF-a e a IL-6 também estão implicadas na atrofia do tecido 
adiposo na caquexia (Bing, 2011). Em nosso estudo, pacientes caquéticos portadores de tumor apresentaram um aumento de aproximadamente sete vezes na concentração plasmática de TNF-a (Tabela 2). Este mesmo aumento tem sido descrito em modelos experimentais de caquexia (Byerley et al., 2010; Chen et al., 2011; Das et al., 2011). Verificamos no nosso modelo experimental a expressão protéica de TNF-a no tecido adiposo epididimal e observamos um aumento no grupo TB7, o qual foi ainda mais pronunciado nos animais do grupo TB14 (Figura 17-D).

Numerosos estudos mostraram que o TNF-a aumenta a taxa de lipólise em adipócitos (Green et al., 1994; Rydén et al., 2004; Souza et al., 2003; Yang et al., 2011; Zhang et al., 2002). Experimentos com linhagens de adipócitos murinos ou humanos mostram que o tratamento crônico com TNF-a reduz o conteúdo de perilipina 1 (Bézaire et al., 2009; Rydén et al., 2004) e propõem-se que a regulação negativa desta proteína possa ser o principal mecanismo da lipólise induzida pelo TNF-a em humanos (Rydén et al., 2004).

Rydén et al. (2004) demonstraram que a redução do conteúdo de perilipina 1 mediada pelo TNF-a ocorre paralelamente ao aumento na lipólise basal, indicando uma correlação direta entre esses dois achados.

Ainda em relação a este aspecto, foi demonstrado recentemente que o tratamento de adipócitos humanos (hMADS) com TNF-a leva à redução da expressão gênica e protéica não só de perilipina 1, como também da ATGL e LHS (Bézaire et al., 2009). Ademais, 0 tratamento com TNF-a levou à redução na capacidade de hidrolase tanto da LHS quanto da ATGL. Entretanto, sob condições basais, a regulação negativa da perilipina 1 mostrou um efeito predominante sobre o conteúdo e atividade reduzida das lipases, resultando em lipólise aumentada. Por outro lado, o pré-tratamento com TNF-a prejudicou a lipólise estimulada e os autores sugerem que este fato pode ser decorrente de vários mecanismos, entre eles: redução na expressão das lipases, redução no conteúdo de perilipina 1 (e portanto da sua fosforilação) e diminuição da capacidade de hidrolase da LHS em condição estimulada (Bézaire et al., 2009).

Além do papel na modulação da perilipina 1, o aumento da lipólise basal induzido pelo TNF-a também é decorrente do bloqueio da ação anti-lipolítica exercida pela insulina. Inúmeros estudos descrevem que o TNF-a interfere diretamente na sinalização do receptor de insulina, prejudicando a sua ação no adipócito e induzindo o surgimento do quadro de resistência à insulina (Hotamisligil, 1999; Nieto-Vazquez et al., 2008; Sharma e Chetty, 2005).

Com base nestes indícios pode-se imaginar que a lipólise basal está aumentada na caquexia. Agustsson et al. (2007) observaram um aumento na atividade lipolítica in vivo em 
pacientes com caquexia na vigência de câncer. Contudo, ao analisar o tecido adiposo subcutâneo verificou-se que não havia diferenças na lipólise basal entre os pacientes caquéticos e controle. Da mesma forma, não foram encontradas diferenças nas concentrações plasmáticas de adrenalina, noradrenalina e peptídeo natriurético, importantes estimuladores da lipólise. Apesar disso, os autores verificaram que os adipócitos dos pacientes caquéticos são mais sensíveis ao estímulo lipolítico induzido por estes fatores. Os resultados deste estudo sugerem que o mecanismo celular para aumento da lipólise na caquexia tem base no aumento na sinalização lipolítica dos sistemas hormonais.

A hipótese supracitada é ratificada por um recente estudo que sugere o possível envolvimento dos receptores $\beta 1$-adrenérgicos (ADRB1) na lipólise na caquexia associada ao câncer. Cao et al. (2010) mostraram um aumento na expressão gênica e protéica do ADRB1 no tecido adiposo subcutâneo de pacientes com caquexia associada ao câncer. Observou-se ainda correlação positiva entre a expressão protéica de LHS, a qual estava aumentada na caquexia, e a expressão do ADRB1.

Buscando uma melhor compreensão de como seria a contribuição da lipólise basal e da lipólise estimulada para a atividade lipolítica total observada na caquexia, assim como possíveis variações temporais, realizamos o ensaio de lipólise. Nossos resultados mostraram que não houve alteração na capacidade lipolítica nos animais do grupo TB7 e, interessantemente, verificamos ainda uma redução na lipólise estimulada no grupo TB14.

O metabolismo do tecido adiposo apresenta regulações depósito-específicas e diferenças entre espécies (Giorgino et al., 2005; Palou et al., 2009) e embora vários hormônios mostrem ação lipolítica em roedores, apenas as catecolaminas e os peptídios natriuréticos estimulam a lipólise agudamente e marcadamente em seres humanos (Arner, 2005; Langin, 2006). Dessa forma, apesar dos estudos em adipócitos provenientes do tecido adiposo subcutâneo de pacientes caquéticos mostrarem uma maior sensibilidade ao estímulo adrenérgico é plausível que em ratos esta regulação seja distinta. Sendo assim, apesar dos adipócitos dos animais do grupo TB7 demonstrarem a mesma capacidade lipolítica que os animais controle, é possível que exista uma maior concentração circulante de catecolaminas e outros hormônios lipolíticos nos animais caquéticos, resultando em um aumento da lipólise in vivo. Ademais, não podemos descartar que a comunicação entre adipócitos e macrófagos pode exercer importante influência na via lipolítica através da secreção de fatores que podem atuar de modo parácrino e, ao realizarmos o ensaio com adipócitos isolados, a modulação decorrente desta interação é perdida.

No estágio final da progressão da caquexia (TB14) descrevemos a redução no conteúdo protéico de ATGL, CGI-58 e perilipina 1 (Figura 17). Este fato é coerente com a 
redução na capacidade lipolítica em condição estimulada observada neste grupo. Com a redução no conteúdo de importantes proteínas reguladoras do processo lipolítico, ainda que houvesse uma maior sensibilidade ao estímulo adrenérgico, estas células não seriam capazes de direcionar adequadamente o metabolismo para esta via.

Contudo, é importante ressaltar que apesar de redução na capacidade lipolítica observada neste grupo, a elevada concentração de ácidos graxos no plasma indica que a lipólise corporal está aumentada in vivo. Sendo assim, mesmo sem encontrarmos alterações no ensaio in vitro, é possível que a lipólise basal tenha um importante papel neste quadro.

\subsection{Expressão das adipocinas e seu papel na (des)regulação do metabolismo lipídico do tecido adiposo na caquexia}

Na última década o tecido adiposo tornou-se reconhecido como um importante órgão endócrino, capaz de sintetizar e secretar uma ampla gama de fatores, denominados adipocinas (revisão de Ahima, 2006). As adipocinas atuam localmente, de modo autócrino, parácrino e/ou como sinais endócrinos para regular o apetite, o gasto energético e uma série de outros processos fisiológicos como sensibilidade à insulina e inflamação (revisão de Ahima, 2006). A associação entre a caquexia e as alterações nas concentrações de adipocinas tem sido crescentemente compreendida (Nakajima et al., 2009; Smiechowska et al., 2010), porém está longe de ser completamente elucidada. Sugere-se que um prejuízo na resposta das adipocinas à perda de peso possa desempenhar um papel na patogênese da caquexia induzida pelo câncer (Nakajima et al., 2009). Adicionalmente, imaginamos que a modulação das adipocinas induzida pela caquexia possa ter ação direta nas vias de regulação do processo lipolítico.

A leptina é um indicador de adiposidade corporal e possui um papel essencial na regulação do comportamento alimentar e do metabolismo energético (Zhang et al., 1994). No presente estudo, apesar de não encontramos uma redução na concentração de leptina no plasma dos pacientes (Tabela 2), a expressão gênica desta adipocina foi reduzida no tecido adiposo dos pacientes caquéticos, quando comparados aos pacientes portadores de tumor com peso estável (Figura 6). Por outro lado, em nosso modelo experimental observamos redução na concentração de leptina no plasma (Tabela 5), assim como de sua expressão gênica e protéica já a partir do 70 dia após a inoculação do tumor (Figura 13 e 14, respectivamente). Diversos estudos mostram uma redução na concentração de leptina no plasma na caquexia (Bing et al., 2001; Brown et al., 2001; Lira et al., 2011; Machado et al., 2004; Mantovani et al., 2001; Smiechwska et al., 2010). Contudo já se descreveu uma 
concentração plasmática aumentada (Moses et al., 2001) ou inalterada (Wallace et al., 1998) nesta situação.

Estudos recentes mostram que a leptina é capaz de modular o metabolismo lipídico periférico através de ação parácrina ou autócrina (Li et al., 2008; 2010; Muller et al., 1997; Niang et al., 2011). Um dos seus principais efeitos é a indução da lipólise no tecido adiposo branco (Tajima et al., 2005). Após incubação de adipócitos com leptina verificou-se que esta adipocina é capaz de modular a expressão das principais proteínas envolvidas na via lipolítica (LHS, ATGL e perilipina 1), sendo o efeito em cada uma destas dependente do tempo de incubação e do tipo celular estudado (Li et al., 2008; 2010; Muller et al., 1997; Niang et al., 2011). Com base nas evidências poderia se imaginar que uma redução na concentração plasmática e tecidual de leptina favoreceria a redução da mobilização do triacilglicerol do tecido adiposo. Contudo, a ação parácrina e/ou autócrina da leptina na regulação do metabolismo lipídico sofre interferência de diversos fatores e os dados por nós obtidos são insuficientes para que possamos inferir qualquer tipo de relação entre esta adipocina e a via lipolítica.

Adicionalmente à sua ação parácrina e autócrina, a leptina atua centralmente na modulação da ingestão alimentar (Schwartz et al., 1999); este hormônio tem uma ação direta no sistema nervoso central, induzindo a expressão de neuropeptídeos anorexígenos e inibindo a expressão de neuropeptídeos orexígenos, resultando em redução na ingestão alimentar. Quando a concentração de leptina está baixa, ocorre o efeito inverso e há um estímulo da ingestão alimentar (Carvalheira et al., 2005; Inui, 1999; Laviano et al., 2008; Niswender et al., 2001; Plata-Salamán et al., 1998). Este balanço é perdido durante a caquexia, quando mesmo diante de uma marcante redução na concentração de leptina no plasma, a anorexia está presente (Lira et al., 2011; Mantovani et al., 2001; Smiechwska et al., 2010).

Estudos com modelos experimentais indicam que o aumento de citocinas próinflamatórias pode ser responsável pela redução no apetite e ingestão alimentar (Barton, 2001; Cahlin et al., 2000). Nosso grupo mostrou um elevado conteúdo de TNF-a e IL-1 $\beta$ no hipotálamo de animais caquéticos (Lira et al., 2011). Estas citocinas pró-inflamatórias são capazes de interferir na sinalização central da leptina, modulando a expressão e secreção de neuropeptídeos envolvidos no controle do comportamento alimentar (Carvalheira et al., 2005; Inui, 1999; Laviano et al., 2008; Niswender et al., 2001; Plata-Salamán et al., 1998). Além disso, as citocinas pró-inflamatórias podem ainda reduzir a expressão de leptina nos adipócitos (Wang e Trayhurn, 2006). 
Com base nestes dados, podemos especular que dificilmente uma simples desregulação da produção de leptina per se seja fundamental na etiologia da caquexia. Por outro lado, fica evidente que a inflamação do tecido adiposo contribui para a resistência aos efeitos orexígenos da leptina observada na caquexia.

Outra adipocina importante na regulação na composição corporal é a adiponectina, que é uma proteína secretada exclusivamente por adipócitos e possui efeito anti-inflamatório bem descrito (Ouchi et al., 2007). A concentração plasmática de adiponectina correlacionase inversamente com o peso corporal (Staiger et al., 2003; Yang et al., 2001). Assim, uma baixa concentração plasmática é encontrada em obesos (Heedman e Strang, 2001; Mathews et al., 1985) e elevados níveis são descritos na anorexia nervosa (Garcia et al., 2005) e durante a perda de peso (Nakajima et al., 2010).

Apesar da relação fisiológica inversa entre adiposidade corporal e adiponectina, nossos resultados não mostram aumento na concentração de adiponectina no plasma (Tabela 2). Contudo, verificamos um aumento na sua expressão gênica no tecido adiposo subcutâneo de pacientes do grupo TBC (Figura 6). Embora Kerem et al. (2008) e Smiechwska et al. (2010) descrevam um aumento na concentração plasmática de adiponectina em pacientes com caquexia associada ao câncer, outros autores relatam uma redução na concentração plasmática desta adipocina em pacientes caquéticos (Kemik et al., 2011; Nakajima et al., 2009; 2010).

Os resultados obtidos com o nosso modelo experimental mostram uma resposta diferente dos observados no modelo clínico. Em relação à concentração de adiponectina plasmática, verificamos uma redução no estágio final da progressão tumoral (Tabela 6). Entretanto, quando verificamos a sua expressão tecidual, percebemos que a caquexia foi capaz de modular esta adipocina já nos animais do grupo TB7, os quais apresentaram um aumento na sua expressão gênica (Figura 13-A). Todavia, a modulação da expressão gênica não refletiu em um conteúdo protéico aumentado, pelo contrário, esses animais apresentaram uma menor expressão protéica de adiponectina (Figura 14-A). Já nos animais do grupo TB14 observamos uma drástica redução tanto na expressão gênica quanto na expressão protéica desta adipocina.

Levando-se em consideração as propriedades anti-inflamatórias da adiponectina, é possível que o aumento da expressão gênica no tecido adiposo dos pacientes, assim como dos animais do grupo TB7, represente uma resposta compensatória do organismo na tentativa de controlar a progressão da caquexia. Neste aspecto, podemos especular que este aumento no RNAm de adiponectina poderia ser um mecanismo para atenuar o milieu inflamatório presente neste tecido. Entretanto, um aumento na concentração sistêmica de 
adiponectina pode não representar uma melhora na função fisiológica contra inflamação. Isto pode ser especulado com base em estudos que mostram que uma elevada concentração de adiponectina no plasma é um preditor de mortalidade em pacientes com falência cardíaca crônica (Kistorp et al., 2005). Um aumento local e/ou sistêmico na concentração de adiponectina também tem sido descrito em doenças crônicas inflamatórias e auto-imunes (Fantuzzi, 2008) e, desta forma, estas condições apresentam um aparente paradoxo caracterizado por elevada concentração de adiponectina na presença de inflamação. Autores descrevem um paradoxo semelhante envolvendo a IL-10, uma citocina que, apesar de ter ação anti-inflamatória, tem sido associada à mortalidade em pacientes com doenças cardíacas (Amir et al., 2010; Nishii et al., 2004; Yip et al., 2007).

Além da sua propriedade anti-inflamatória, a adiponectina apresenta uma importante ação sensibilizadora à insulina (Fasshauer et al., 2001). Estudos mostram que a adiponectina aumenta o transporte e a oxidação de ácidos graxos, evitando uma elevada concentração de ácidos graxos livres no plasma e consequente prejuízo na via de sinalização da insulina (Fruebis et al., 2001; Yamauchi et al., 2001). Com base neste fato, sugere-se que a redução na concentração de adiponectina possa contribuir de forma indireta para o aumento dos ácidos graxos livres no plasma, prejudicando a sinalização da insulina em tecidos sensíveis a este hormônio (Fasshauer et al., 2001; Lavoie et al., 2009).

Neste contexto, outro importante mecanismo de ação da adiponectina é a regulação recíproca entre esta adipocina e o TNF-a. A adiponectina reduz a expressão de TNF-a em adipócitos e, desta forma, reduz a interferência desta citocina na via sinalizadora da insulina. Interessantemente, a modulação inversa também ocorre, ou seja, o TNF-a induz a redução na expressão gênica e protéica de adiponectina, leva ao aumento da concentração de ácidos graxos livres e prejudica a sensibilidade à insulina (Hector et al., 2007; Li et al., 2009). A capacidade modulatória do TNF-a sobre a adiponectina sugere que a resistência à insulina promovida por esta citocina não decorre apenas da sua interferência direta na sinalização de insulina (Feinstein et al., 1993; Hotamisligil et al., 1994), mas também por reduzir a concentração de adiponectina (Berg et al., 2001; Combs et al., 2001; Yamauchi et al., 2001).

De acordo com essa regulação recíproca entre o TNF-a e a adiponectina, em nosso modelo experimental foi possível observar uma correlação inversa entre a concentração tecidual de adiponectina e TNF-a (Figura 15). Este fenômeno, associado ao aumento gradual na concentração plasmática de ácidos graxos livres (Tabela 5), é sugestivo de redução da sensibilidade à insulina no tecido estudado.

Com base nos resultados obtidos, especulamos que possa haver uma modulação temporal na expressão da adiponectina na caquexia. No início da progressão da caquexia é 
verossímil que a concentração de adiponectina aumente, mantendo a razão fisiológica com a perda de peso. Contudo, à medida que o estado caquético progride, concentrações crescentes de TNF-a poderiam modular a expressão de adiponectina, levando à sua redução.

Outro fato poderia ainda contribuir para a redução na concentração de adiponectina no estágio final da caquexia, a ação das catecolaminas. Fasshauer et al. (2001), mostraram que o estímulo $\beta$-adrenérgico diminui a expressão gênica de adiponectina em adipócitos 3T3L1. Como descrito anteriormente, na caquexia há aumento da expressão de receptores $\beta$ adrenérgicos no tecido adiposo (Cao et al., 2010), levando à maior sensibilidade dos adipócitos ao estímulo adrenérgico (Agustsson et al., 2007). É plausível que este estímulo aumentado acarrete em redução na expressão gênica de adiponectina. Evidências sugerem que as catecolaminas e o aumento na atividade do sistema nervoso prejudiquem a sensibilidade à insulina (Facchini et al. 1996; Reaven et al., 1996; Hoiggen et al., 2000; Maison et al., 2000). Além disso, sabe-se que o estímulo $\beta$-adrenérgico induz um aumento na concentração de ácidos graxos livres no plasma, os quais inibem moléculas sinalizadoras da insulina (Klein et al., 1999; Fasshauer et al., 2001; Schiffelers et al., 2001). Tendo em vista que a redução na adiponectina prejudica a tolerância dos tecidos aos ácidos graxos livres (Lavoie et al., 2009), podemos hipotetizar que esta seja uma via com interações complexas, onde a adiponectina poderia ter um papel central na regulação dos processos que culminam na resistência à insulina.

Outra adipocina por nós analisada, a visfatina, é uma proteína associada com anormalidades metabólicas na obesidade e diabetes (Wang et al., 2010). Todavia, recentes evidências indicam que a visfatina pode atuar como uma citocina pró-inflamatória (Bessa et al., 2010; Chang et al., 2010; McGee et al., 2011). Estudos sugerem ainda que esta adipocina possa atuar como um biomarcador do estágio de progressão de câncer gástrico (Nakajima et al., 2010) e da severidade de doenças inflamatórias (Huang et al., 2011).

Nossos resultados mostram um grande aumento na expressão gênica de visfatina no tecido adiposo subcutâneo de pacientes caquéticos (Figura 6-C). Recentemente, Chang et al. (2010) verificaram que o RNAm de visfatina é expresso de forma similar no tecido adiposo subcutâneo e visceral de adultos não-diabéticos e que a sua expressão correlaciona-se com o conteúdo de RNAm de genes pró-inflamatórios, como TNF-a, e resistência à insulina. Neste contexto, Moschen et al. (2007) mostraram que a visfatina regula positivamente a atividade de ligação do NFkB p65 ao DNA em leucócitos humanos. O NF-kB desempenha um papel importante no desencadeamento e coordenação da resposta imune, incluindo regulação de citocinas como IL-1, IL-6 e TNF-a (Baker et al., 2011). Tendo em vista que há infiltração de macrófagos no tecido adiposo branco de animais caquéticos (Machado et al., 2004), o 
aumento na expressão gênica de visfatina nos adipócitos e sua provável ação parácrina, poderia ter um importante papel na progressão da inflamação do tecido adiposo na caquexia associada ao câncer. Vale ressaltar que as citocinas inflamatórias, por sua vez, podem aumentar a expressão gênica de visfatina no tecido adiposo visceral (Hector et al., 2007), gerando um ciclo vicioso.

De modo similar ao observado nos pacientes, em nosso modelo experimental verificamos um aumento na expressão gênica de visfatina nos animais do grupo TB7 (Figura 13). Todavia, a aumentada expressão de visfatina não refletiu em elevação do seu conteúdo protéico (Figura 14) ou da sua concentração plasmática (Tabela 5). Embora estudos mostrem relação direta entre a concentração de visfatina com citocinas inflamatórias (Hector et al., 2007; Chang et al., 2010; Olszanecka-Glinianowicz et al., 2011), nos animais do grupo TB14, encontramos redução no RNAm (Figura 13), no conteúdo protéico (Figura 14) e na concentração plasmática desta adipocina (Tabela 5). A redução de visfatina no estágio final da caquexia é similar à redução das demais adipocinas estudadas.

\subsection{Considerações finais}

Observamos no nosso modelo experimental os principais sinais relacionados à caquexia (perda de peso, anorexia, dislipidemia), contudo nossos experimentos em animais não reproduziram de modo idêntico os resultados observados nos seres humanos, em decorrência das características específicas à espécie e à localização anatômica do depósito. Para minimizar estas diferenças, buscou-se inicialmente trabalhar com o tecido adiposo subcutâneo dos animais, porém em virtude da grande depleção deste depósito nos ratos caquéticos, esta conduta tornou-se inviável.

Apesar das limitações impostas pelas diferenças nos depósitos e espécies estudados, de acordo com o padrão dos resultados obtidos, podemos inferir que os efeitos observados nos pacientes caquéticos assemelham-se àqueles encontrados nos animais do grupo TB7. Além disso, hipotetizamos que as alterações observadas nos animais do grupo TB14 seriam condizentes com o que ocorre em pacientes com caquexia refratária (último estágio da progressão do estado caquético em seres humanos).

Ao realizarmos uma análise conjunta dos resultados aqui expostos torna-se evidente a existência de uma modulação temporal na expressão das adipocinas, assim como das proteínas relacionadas à via lipolítica. Em um estágio intermediário da síndrome, quando já se detecta a redução de massa gorda, verifica-se um desequilíbrio na secreção de fatores anti e pró-inflamatórios, como por exemplo, a redução da adiponectina e o aumento do TNF- 
a. Ocorre ainda um aumento da lipólise, não apenas pela atividade aumentada da LHS, mas também pelo aumento da expressão da ATGL e redução do conteúdo de perilipina 1.

No estágio final da caquexia observamos alterações morfológicas e humorais ainda mais profundas. Nesta fase, percebe-se a redução na expressão de quase todas as proteínas analisadas. Esta marcante redução na expressão de adipocinas e proteínas relacionadas à lipólise, associada à alteração na matriz extra-celular e formato dos adipócitos, sugere que no estágio final do estado caquético há um comprometimento da função celular como um todo. 


\section{CONCLUSÃO}

No presente estudo verificamos que a caquexia induz importantes alterações morfológicas e moleculares no tecido adiposo branco. Em um estágio intermediário da síndrome, a modulação das duas principais lipases (ATGL e LHS) e da perilipina 1 contribui para o aumento da lipólise nos pacientes caquéticos. Concomitantemente, há um desequilíbrio na secreção tecidual de fatores pró e anti-inflamatórios, que pode agravar ainda mais o quadro inflamatório sistêmico característico desta condição. No estágio terminal da caquexia, as alterações teciduais são mais pronunciadas e ocorre uma redução na expressão de quase todas as proteínas estudadas, sugerindo um prejuízo na funcionalidade

dos adipócitos. Desta forma, concluímos que as alterações no tecido adiposo podem ser utilizadas como marcadores indicativos de progressão da caquexia. 


\section{REFERÊNCIAS*}

Agustsson T, Rydén M, Hoffstedt J, van Harmelen V, Dicker A, Laurencikiene J, Isaksson B, Permert J, Arner P. Mechanism of increased lipolysis in cancer cachexia. Cancer Res. 2007;67:5531-5537.

Ahima RS. Adipose tissue as na edocrine organ. Obesity, 2006;5:242S-249S.

Albertus DL, Seder CW, Chen G, Wang X, Hartojo W, Lin L, Silvers A, Thomas DG, Giordano TJ, Chang AC, Orringer MB,Bigbee WL, Chinnaiyan AM, Beer DG. AZGP1 autoantibody predicts survival and histone deacetylase inhibitors increase expression in lung adenocarcinoma. J Thorac Oncol. 2008;3:1236-1244.

Alemán MR, Santolaria F, Batista N, de La Vega M, González-Reimers E, Milena A, Llanos M, Gómez-Sirvent JL. Leptin role in advanced lung cancer. A mediator of the acute phase response or a marker of the status of nutrition? Cytokine. 2002;19:21-26.

Aller R, de Luis DA, Izaola O, Sagrado MG, Conde R, Velasco MC, Alvarez T, Pacheco D, González JM. Influence of visfatin on histopathological changes of non-alcoholic fatty liver disease. Dig Dis Sci. 2009;54:1772-1777.

Alves MJ. Efeito da caquexia associada ao câncer em componentes da matriz extracelular do tecido adiposo. [dissertação (Mestrado em Biologia Celular e Tecidual)] - Instituto de Ciências Biomédicas, Universidade de São Paulo, São Paulo, 2011.

Amir O, Rogowski O, David M, Lahat N, Wolff R, Lewis BS. Circulating interleukin-10: association with higher mortality in systolic heart failure patients with elevated tumor necrosis factor-alpha. Isr Med Assoc J. 2010;12:158-162.

Anthonsen MW, Ronnstrand L, Wernstedt C, Degerman E, Holm C. Identification of novel phosphorylation sites in hormone-sensitive lipase that are phosphorylated in response to isoproterenol and govern activation properties in vitro. J Biol Chem. 1998;273:215-221.

Argilés JM, Alvarez B, López-Soriano FJ. The metabolic basis of cancer cachexia. Med Res Rev. 1997; 17:477-498.

Argilés JM, Alvarez B, Carbó N, Busquets S, Van Royen M, López-Soriano FJ. The divergent effects of tumour necrosis factor-alpha on skeletal muscle: implications in wasting. Eur Cytokine Netw. 2000;11:552-559.

Argilés JM, Busquets S, Felipe A, López-Soriano FJ. Muscle wasting in cancer and ageing: cachexia versus sarcopenia. Adv Gerontol. 2006;18:39-54.

Arnalich F, López J, Codoceo R, Jiménez M, Madero R, Montiel C. Relationship of plasma leptin to plasma cytokines and human survivalin sepsis and septic shock. J Infect Dis. 1999;180:908-911.

Arner P. Human fat cell lipolysis: biochemistry, regulation and clinical role. Best Pract Res Clin Endocrinol Metab. 2005;19:471-482.

\footnotetext{
* De acordo com: International Committe of Medical Journal Editors. Uniform requeriments for manuscripts submitted to Biomedical Journal: sample references. Available from: http://www.icmje.org [2007 May 22].
} 
Asp ML, Tian M, Wendel AA, Belury MA. Evidence for the contribution of insulin resistance to the development of cachexia in tumor-bearing mice. Int J Cancer. 2010;126:756-763.

Associação Brasileira de Cuidados Paliativos. Consenso Brasileiro de Caquexia/Anorexia. Rev Bras Cuidados Paliativos. 2011;3:suplemento 1.

Bachmann J, Heiligensetzer M, Krakowski-Roosen $\mathrm{H}$, Buchler MW, Friess $\mathrm{H}$, Martignoni ME. Cachexia worsens prognosis in patients with resectable pancreatic cancer. J Gastrointest Surg. 2008;12:1193-1201.

Baker RG, Hayden MS, Ghosh S. NF-kB, inflammation, and metabolic disease. Cell Metab. 2011;13:11-22.

Baratta M. Leptin-from a signal of adiposity to a hormone mediator in peripheral tissues. Med Sci Monit. 2002;8:282-292.

Barber MD, McMillan DC, Wallace AM, Ross JA, Preston T, Fearon KC. The response of leptin, interleukin- 6 and fat oxidation to feeding in weight-losing patients with pancreatic cancer. $\mathrm{Br}$ J Cancer. 2004;90:1129-1132.

Barton BE. IL-6-like cytokines and cancer cachexia: consequences of chronic inflammation. Immunol Res. 2001;23:41-58.

Ben-Noun LL. The disease that caused weight loss in King David the Great. J Gerontol A Biol Sci Med Sci. 2004;59:143-145.

Bennani-Baiti N, Walsh D. What is cancer anorexia-cachexia syndrome? A historical perspective. J R Coll Physicians Edinb. 2009;39:257-262.

Berg AH, Combs TP, Du X, Brownlee M, Scherer PE. The adipocyte-secreted protein Acrp30 enhances hepatic insulin action. Nat Med. 2001;7:947-953.

Berg $\mathrm{AH}$, Combs TP, Scherer PE. ACRP30/adiponectin: an adipokine regulating glucose and lipid metabolism. Trends Endocrinol Metab. 2002;13:84-89.

Bertevello PS, Seelaender MC. Heterogeneous response of adipose tissue to cancer cachexia. Braz J Med Biol Res. 2001;34:1161-1167.

Bessa SS, Hamdy SM, El-Sheikh RG. Serum visfatin as a non-traditional biomarker of endothelial dysfunction in chronic kidney disease: an Egyptian study. Eur J Intern Med. 2010;21:530-535.

Bézaire V, Langin D. Regulation of adipose tissue lipolysis revisited. Proc Nutr Soc. 2009;68:350-360.

Bezaire V, Mairal A, Ribet C, Lefort C, Girousse A, Jocken J, Laurencikiene J, Anesia R, Rodriguez AM, Ryden M, Stenson BM,Dani C, Ailhaud G, Arner P, Langin D. Contribution of adipose triglyceride lipase and hormone-sensitive lipase to lipolysis in hMADS adipocytes. J Biol Chem. 2009;284:18282-18291.

Bhogal AS, Lorite ML, Tisdale MJ. Changes in nucleic acid and protein levels in atrophying skeletal muscle in cancer cachexia. Anticancer Res. 2006;26:4149-4154. 
Bing C. Lipid mobilization in cachexia: mechanisms and mediators. Curr Opin Support Palliat Care, 2011;5:356-360.

Bing C, Bao Y, Jenkins J, Sanders P, Manieri M, Cinti S, Tisdale MJ, Trayhurn P. Zinc-alpha2glycoprotein, a lipid mobilizing factor, is expressed in adipocytes and is up-regulated in mice with cancer cachexia. Proc Natl Acad Sci U S A. 2004;101:2500-2505.

Bing C, Taylor S, Tisdale MJ, Williams G. Cachexia in MAC16 adenocarcinoma: supression of hunger despite normal regulation of leptin, insulin and hypothalamic neuropeptide $Y . \mathrm{J}$ Neurochem. 2001;79:1004-1012.

Bing C, Trayhurn P. New insights into adipose tissue atrophy in cancer cachexia. Proc Nutr Soc. 2009;68:385-392.

Blum D, Omlin A, Fearon K, Baracos V, Radbruch L, Kaasa S, Strasser F. Evolving classification systems for cancer cachexia: ready for clinical practice? Support Care Cancer, 2010;18:273-279.

Böni-Schnetzler M, Boller S, Debray S, Bouzakri K, Meier DT, Prazak R, Kerr-Conte J, Pattou $F$, Ehses JA, Schuit FC, Donath MY. Free fatty acids induce a proinflammatory response in islets via the abundantly expressed interleukin-1 receptor I. Endocrinology, 2009;150:52185229.

Borges-Silva CN, Fonseca-Alaniz MH, Alonso-Vale MI, Takada J, Andreotti S, Peres SB, Cipolla-Neto J, Pithon-Curi TC, Lima FB. Reduced lipolysis and increased lipogenesis in adipose tissue from pinealectomized rats adapted to training. J Pineal Res. 2005;39:178-184.

Boucher J, Castan-Laurell I, Daviaud D, Guigne C, Buleon M, Carpene C, Saulnier-Blache JS, Valet $P$. Adipokine expression profile in adipocytes of different mouse models of obesity. Horm Metab Res. 2005; 37: 761-767.

Brasaemle DL. Thematic review series: adipocyte biology. The perilipin family of structural lipid droplet proteins: stabilization of lipid droplets and control of lipolysis. J Lipid Res. 2007;48:2547-2559.

Brasaemle DL, Rubin B, Harten IA, Gruia-Gray J, Kimmel AR, Londos C. Perilipin A increases triacylglycerol storage by decreasing the rate of triacylglycerol hydrolysis. J Biol Chem. 2000;275:38486-38493.

Brasaemle DL, Subramanian V, Garcia A, Marcinkiewicz A, Rothenberg A. Perilipin A and the control of triacylglycerol metabolism. Mol Cell Biochem. 2009;326:15-21.

Brink M, Anwar A, Delafontaine P. Neurohormonal factors in the development of catabolic/anabolic imbalance and cachexia. Int J Cardiol. 2002;85:111-121.

Brown DR, Berkowitz DE, Breslow MJ. Weight loss is not associated with hyperleptinemia in humans with pancreatic cancer. J Clin Endocrinol Metab. 2001;86:162-166.

Brown J M, Chung S, Das A, Shelness GS, Rudel LL, Yu L. CGI-58 facilitates the mobilization of cytoplasmic triglyceride for lipoprotein secretion in hepatoma cells. J. Lipid Res. 2007;48:2295-2305. 
Bruera E. Anorexia, cachexia and nutrition. Br Med J. 1997;315:1219-1222.

Bulló M, Salas-Salvadó, García-Lorda P. Adiponectin expression and adipose tissue lipolytic activity in lean and obese women. Obes Surg. 2005;15:382-386.

Byerley LO, Lee SH, Redmann S, Culberson C, Clemens M, Lively MO. Evidence for a novel serum factor distinct from zinc alpha-2 glycoprotein that promotes body fat loss early in the development of cachexia. Nutr Cancer, 2010;62:484-94.

Cahlin C, Körner A, Axelsson H, Wang W, Lundholm K, Svanberg E. Experimental cancer cachexia: the role of host-derived cytokines interleukin (IL)-6, IL-12, interferon-gamma, and tumor necrosis factor alpha evaluated in gene knockout, tumor-bearing mice on C57 Bl background and eicosanoid-dependent cachexia. Cancer Res. 2000;60:5488-5493.

Campfield LA, Smith FJ, Guisez Y, Devos R, Burn P. Recombinant mouse OB protein: evidence for a peripheral signal linking adiposity and central neural networks. Science, 1995;269:546-549.

Cao DX, Wu GH, Yang ZA, Zhang B, Jiang Y, Han YS, He GD, Zhuang QL, Wang YF, Huang $\mathrm{ZL}, \mathrm{Xi} \mathrm{QL}$. Role of beta1-adrenoceptor in increased lipolysis in cancer cachexia. Cancer Sci. 2010;101:1639-1645.

Carlson GL, Saeed M, Little RA, Irving MH. Serum leptin concentrations and their relation to metabolic abnormalities in human sepsis. Am J Physiol. 1999;276:658-662.

Carmen GY, Victor SM. Signalling mechanisms regulating lipolysis. Cell Signal. 2006;18:401408.

Carvalheira JB, Torsoni MA, Ueno M, Amaral ME, Araújo EP, Velloso LA. Cross-talk between the insulin and leptin signaling systems in rat hypothalamus. Obes Res. 2005;13:48-57.

Chakrabarti P, Kandror KV. Adipose triglyceride lipase: a new target in the regulation of lipolysis by insulin. Curr Diabetes Rev. 2011;7:270-277.

Chandran M, Phillips SA, Ciaraldi T, Henry RR. Adiponectin: more than just another fat cell hormone? Diab Care, 2003;26:2442-2450.

Chang YC, Chang TJ, Lee WJ, Chuang LM. The relationship of visfatin/pre-B-cell colonyenhancing factor/nicotinamide phosphoribosyltransferase in adipose tissue with inflammation, insulin resistance, and plasma lipids. Metabolism, 2010;59:93-99.

Chen SZ, Qiu ZG. Combined treatment with GH, insulin, and indomethacin alleviates cancer cachexia in a mouse model. J Endocrinol. 2011;208:131-136.

Coleman DL. Effects of parabiosis of obese with diabetes and normal mice. Diabetologia, 1973;9:294-298.

Collins S, Cao W, Robidoux J. Learning new tricks from old dogs: beta-adrenergic receptors teach new lessons on firing up adipose tissue metabolism. Mol Endocrinol. 2004;18:21232131. 
Combs TP, Berg AH, Obici S, Scherer PE, Rossetti L. Endogenous glucose production is inhibited by the adipose-derived protein Acrp30. J Clin Invest. 2001;108:1875-1881.

Considine RV, Sinha MK, Heiman ML, Kriauciunas A, Stephens TW, Nyce MR, Ohannesian JP, Marco CC, McKee LJ, Bauer TL, Caro JF. Serum immunoreactive-leptin concentrations in normal-weight and obese humans. N Engl J Med. 1996; 334:292-295.

Coppack SW. Pro-inflammatory cytokines and adipose tissue. Proc Nutr Soc. 2001;60:349356.

Copeland GP, Leinster SJ, Davis JC, Hipkin LJ. Insulin resistance in patients with colorectal cancer. Br J Surg. 1987;74:1031-1035.

Costelli P, Muscaritoli M, Bossola M, Penna F, Reffo P, Bonetto A, Busquets $S$, Bonelli G, Lopez-Soriano FJ, Doglietto GB, Argilés JM, Baccino FM, Rossi Fanelli F. IGF-1 is downregulated in experimental cancer cachexia. Am J Physiol Regul Integr Comp Physiol. 2006;291:R674-R683.

Das SK, Eder S, Schauer S, Diwoky C, Temmel H, Guertl B, Gorkiewicz G, Tamilarasan KP, Kumari P, Trauner M, Zimmermann R, Vesely P, Haemmerle G, Zechner R, Hoefler G. Adipose triglyceride lipase contributes to cancer-associated cachexia. Science, 2011;333:233238.

Dasu MR, Jialal I. Free fatty acids in the presence of high glucose amplify monocyte inflammation via Toll-like receptors. Am J Physiol Endocrinol Metab. 2011;300:E145-54.

de Luis DA, Ballesteros $M$, Ruiz $E$, Muñoz $C$, Penacho A, Iglesias $P$, Guzmán AL, Abreu C, Maldonado A, Delgado M, Martín LS,Puigdevall V, Romero E, Sagrado MG, Izaola O, Conde R. Visfatin in obese patients, relation with cardiovascular risk factors, a cross sectional study. Med Clin. 2011;137:199-203.

Deans C, Wigmore SJ. Systemic inflammation, cachexia and prognosis in patients with cancer. Curr Opin Clin Nutr Metab Care. 2005;8:265-269.

Deans DA, Wigmore SJ, Gilmour H, Paterson-Brown S, Ross JA, Fearon KC. Elevated tumour interleukin-1beta is associated with systemic inflammation: a marker of reduced survival in gastro-oesophageal cancer. Br J Cancer, 2006;95:1568-1575.

Dewys WD, Begg C, Lavin PT, Band PR, Bennett JM, Bertino JR, Cohen MH, Douglass HO Jr, Engstrom PF, Ezdinli EZ, Horton J, Johnson GJ, Moertel CG, Oken MM, Perlia C, Rosenbaum C, Silverstein MN, Skeel RT, Sponzo RW, Tormey DC. Prognostic effect of weight loss prior to chemotherapy in cancer patients. Eastern Cooperative Oncology Group. Am J Med. 1980; 69:491-497.

Di Girolamo M, Medlinger S, Fertig JW. A simple method to determine cell size and number in four mammalian species. Am J Physiol. 1971;221:850-858.

Díez-Itza I, Sánchez LM, Allende MT, Vizoso F, Ruibal A, López-Otín C. Zn-alpha 2glycoprotein levels in breast cancer cytosols and correlation with clinical, histological and biochemical parameters. Eur J Cancer, 1993;29A:1256-1260. 
Divoux A, Clément K. Architecture and the extracellular matrix: the still unappreciated components of theadipose tissue. Obes Rev. 2011;12:e494-503.

Djurhuus CB, Gravholt CH, Nielsen S, Mengel A, Christiansen JS, Schmitz OE, Møller N. Effects of cortisol on lipolysis and regional interstitial glycerol levels in humans. Am J Physiol Endocrinol Metab. 2002;283:E172-E177.

Do MS, Nam SY, Hong SE, Kim KW, Duncan JS, Beattie JH, Trayhurn P.Metallothionein gene expression in human adipose tissue from lean and obese subjects. Horm Metab Res. 2002; 34: 348-351.

Doehner W, Anker SD. Cardiac cachexia in early literature: a review of research prior to Medline. Int J Cardiol. 2002;85:7-14.

Drott C, Svaninger G, Lundholm K. Increased urinary excretion of cortisol and catecholamines in malnourished cancer patients. Ann Surg. 1988;208:645-650.

Drott C, Persson $\mathrm{H}$, Lundholm K. Cardiovascular and metabolic response to adrenaline infusion in weight-losing patients with and without cancer. Clin Physiol. 1989;9:427-439.

Ducharme NA, Bickel PE. Lipid droplets in lipogenesis and lipolysis. Endocrinology, 2008;149:942-949.

Egan JJ, Greenberg AS, Chang MK, Wek SA, Moos MC Jr, Londos C. Mechanism of hormonestimulated lipolysis in adipocytes: translocation of hormone-sensitive lipase to the lipid storage droplet. Proc Natl Acad Sci U S A. 1992;89:8537-8541.

Engelman, JA, Berg, AH, Lewis, RY. Tumor necrosis factor alpha-mediated insulin resistance, but not dedifferentiation, is abrogated by MEK1/2 inhibitors in 3T3-L1 adipocytes. Mol Endocrinol. 2000;14:1557-1569.

Evans WJ, Morley JE, Argilés J, Bales C, Baracos V, Guttridge D, Jatoi A, Kalantar-Zadeh K, Lochs H, Mantovani G, Marks D, Mitch WE, Muscaritoli M, Najand A, Ponikowski P, Rossi Fanelli F, Schambelan M, Schols A, Schuster M, Thomas D, Wolfe R, Anker SD. Cachexia: a new definition. Clin Nutr. 2008;27:793-799.

Facchini FS, Stoohs RA, Reaven GM. Enhanced sympathetic nervous system activity. The linchpin between insulin resistance, hyperinsulinemia, and heart rate. Am J Hypertens. 1996;9:1013-1017.

Fantuzzi G. Adipose tissue, adipokines, and inflammation. J Allergy Clin Immunol. 2005;115:911-919.

Fantuzzi G. Adiponectin and inflammation: consensus and controversy. J Allergy Clin Immunol. 2008;121:326-330.

Fasshauer M, Klein J, Neumann S, Eszlinger M, Paschke R. Adiponectin gene expression is inhibited by beta-adrenergic stimulation via protein kinase A in 3T3-L1 adipocytes. FEBS Lett. 2001;507:142-146. 
Fasshauer M, Klein J, Lossner U, Paschke R. Interleukin (IL)-6 mRNA expression is stimulated by insulin, isoproterenol, tumour necrosis factor alpha, growth hormone, and IL-6 in 3T3-L1 adipocytes. Horm Metab Res. 2003;35:147-152.

Fearon K, Strasser F, Anker SD, Bosaeus I, Bruera E, Fainsinger RL, Jatoi A, Loprinzi C, MacDonald N, Mantovani G, Davis M,Muscaritoli M, Ottery F, Radbruch L, Ravasco P, Walsh D, Wilcock A, Kaasa S, Baracos VE. Definition and classification of cancer cachexia: an international consensus. Lancet Oncol. 2011;12:489-495.

Fearon KC, Preston T. Body composition in cancer cachexia. Infusionstherapie. 1990;3:6366.

Fearon KC, Moses AG. Cancer cachexia. Int J Cardiol. 2002;85:73-81.

Fearon $\mathrm{KCH}$, Voss AC, Hustead DS. Definition of cancer cachexia: effect of weight loss, reduced food intake and systemic inflammation on functional status and prognosis. Am J Clin Nutr. 2006;83:1345-1350.

Feinstein R, Kanety H, Papa MZ, Lunenfeld B, Karasik A. Tumor necrosis factor-alpha suppresses insulin-induced tyrosine phosphorylation of insulin receptor and its substrates. J Biol Chem. 1993;268:26055-26058.

Fischer-Posovszky P, Wabitsch M, Hochberg Z. Endocrinology of adipose tissue - an update. Horm Metab Res. 2007;39:314-321.

Fouladiun M, Körner U, Bosaeus I, Daneryd P, Hyltander $\quad$ A, Lundholm KG. Body composition and time course changes in regional distribution of fat and lean tissuein un selected cancer patients on palliative care correlations with food intake, metabolism, exercise capacity, and hormones. Cancer, 2005;103:2189-2198.

Fox KM, Brooks JM, Gandra SR, Markus R, Chiou CF. Estimation of Cachexia among Cancer Patients Based on Four Definitions. J Oncol. 2009;2009:1-7.

Fredrikson G, Stralfors P, Nilsson NO, Belfrage P. Hormone-sensitive lipase from rat adipose tissue. Purification and some properties. J Biol Chem. 1981;256:6311-6320.

Friedewald WT, Levy RI, Fredrickson DS. Estimation of the concentration of low-density lipoprotein cholesterol in plasma, without use of the preparative ultracentrifuge. Clin Chem. 1972;18:499-502.

Fruebis J, Tsao TS, Javorschi S, Ebbets-Reed D, Erickson MR, Yen FT, Bihain BE, Lodish HF. Proteolytic cleavage product of 30-kDa adipocyte complement-related protein increases fatty acid oxidation in muscle and causes weight loss in mice. Proc Natl Acad Sci U S A. $2001 ; 98: 2005-2010$.

Fujishiro $M$, Gotoh $Y$, Katagiri $H$, Sakoda $H$, Ogihara $T$, Anai $M$, Onishi $Y$, Ono $H$, Abe M, Shojima N, Fukushima Y, Kikuchi M,Oka Y, Asano T. Three mitogen-activated protein kinases inhibit insulin signaling by different mechanisms in 3T3-L1 adipocytes. Mol Endocrinol. 2003;17:487-497. 
Fukuhara A, Matsuda M, Nishizawa M, Segawa K, Tanaka M, Kishimoto K, Matsuki Y, Murakami M, Ichisaka T, Murakami H,Watanabe E, Takagi T, Akiyoshi M, Ohtsubo T, Kihara S, Yamashita S, Makishima M, Funahashi T, Yamanaka S, Hiramatsu R,Matsuzawa $Y$, Shimomura I. Visfatin: a protein secreted by visceral fat that mimics the effects of insulin. Science, 2005;307:426-430.

Galic S, Oakhill JS, Steinberg GR. Adipose tissue as an endocrine organ. Mol Cell Endocrinol. 2010;316:129-139.

Gambardella A, Paolisso G, D'Amore A, Granato M, Verza M, Varricchio M. Different contribution of substrates oxidation to insulin resistance in malnourished elderly patients with cancer. Cancer, 1993;72:3106-3113.

Gandotra S, Lim K, Girousse A, Saudek V, O'Rahilly S, Savage DB. Human frame shift mutations affecting the carboxyl terminus of perilipin increase lipolysisby failing to sequester the adipose triglyceride lipase (ATGL) coactivator AB-hydrolase-containing 5 (ABHD5). J Biol Chem. 2011;286:34998-35006.

Gao Z, Zhang X, Zuberi A, Hwang D, Quon MJ, Lefevre M, Ye J. Inhibition of insulin sensitivity by free fatty acids requires activation of multiple serine kinases in 3T3-L1 adipocytes. Mol Endocrinol. 2004;18:2024-2034.

Garcia JM, Garcia-Touza M, Hijazi RA, Taffet G, Epner D, Mann D, Smith RG, Cunningham GR, Marcelli M. Active ghrelin levels and active to total ghrelin ratio in cancer-induced cachexia. J Clin Endocrinol Metab. 2005;90:2920-2926.

Garton AJ, Campbell DG, Cohen P, Yeaman SJ. Primary structure of the site on bovine hormone-sensitive lipase phosphorylated by cyclic AMP-dependent protein kinase. FEBS Lett. 1988;229: 68-72.

Garton AJ, Yeaman SJ. Identification and role of the basal phosphorylation site on hormonesensitive lipase. Eur J Biochem. 1990;191:245-250.

Giorgino F, Laviola L, Eriksson JW. Regional differences of insulin action in adipose tissue: insights from in vivo and in vitro studies. Acta Physiol Scand. 2005;183:13-30.

Goodman JM. Demonstrated and inferred metabolism associated with cytosolic lipid droplets. J Lipid Res. 2009;50:2148-2156.

Green A, Dobias SB, Walters DJ, Brasier AR. Endocrinology, 1994;134:2581-2588.

Halaas JL, Gajiwala KS, Maffei M, Cohen SL, Chait BT, Rabinowitz D, Lallone RL, Burley SK, Friedman JM. Weight-reducing effects of the plasma protein encoded by the obese gene. Science, 1995;269:543-546.

Hale LP, Price DT, Sanchez LM, Demark-Wahnefried W, Madden JF. Zinc alpha-2glycoprotein is expressed by malignant prostatic epithelium and may serve as a potential serum marker for prostate cancer. Clin Cancer Res. 2001;7:846-853.

Hamlin JÁ, Kahn AM. Herniography in symptomatic patients following inguinal hernia repair. West J Med. 1995;162:28-31. 
Hawkins C, Waterfield K, Hildreth AJ, Kirkpatrick G, Andrew IM. Quantifying the impact of standardized assessment and symptom management tools on symptoms associated with cancer-induced anorexia cachexia syndrome. Palliat Med. 2009;23:680-688.

Hector J, Schwarzloh B, Goehring J, Strate TG, Hess UF, Deuretzbacher G, HansenAlgenstaedt N, Beil FU, Algenstaedt P. TNF-alpha alters visfatin and adiponectin levels in human fat. Horm Metab Res. 2007;39:250-255.

Heedman PA, Strang P. Symptom assessment in advanced palliative home care for cancer patients using the ESAS: clinical aspects. Anticancer Res. 2001;21:4077-4082.

Henry BA, Clarke IJ. Adipose tissue hormones and the regulation of food intake. J Neuroendocrinol. 2008;20:842-849.

Heymsfield SB, McManus CB. Tissue components of weight loss in cancer patients. A new method of study and preliminary observations. Cancer, 1985;55:238-249.

Hoieggen A, Fossum E, Nesbitt SD, Palmieri V, Kjeldsen SE. Blood viscosity, plasma adrenaline and fasting insulin in hypertensive patients with left ventricular hypertrophy. ICARUS, a LIFE Substudy. Insulin Carotids US Scandinavica Blood Press, 2000;9:83-90.

Holm C, Osterlund $\mathrm{T}$, Laurell $\mathrm{H}$, Contreras JA. Molecular mechanisms regulating hormonesensitive lipase and lipolysis. Annu Rev Nutr. 2000;20:365-393.

Holm, C. Molecular mechanisms regulating hormone-sensitive lipase and lipolysis. Biochem. Soc. Trans. 2003;31:1120-1124.

Hotamisligil GS, Shargill NS, Spiegelman BM. Adipose expression of tumor necrosis factoralpha: direct role in obesity-linked insulin resistance. Science, 1993;259:87-91.

Hotamisligil GS, Murray DL, Choy LN, Spiegelman BM. Tumor necrosis factor alpha inhibits signaling from the insulin receptor. Proc Natl Acad Sci U S A. 1994;91:4854-4858.

Hotamisligil GS. Mechanisms of TNF-alpha-induced insulin resistance. Exp Clin Endocrinol Diabetes, 1999;107:119-125.

Hu E, Liang P, Spiegelman BM. AdipoQ is a novel adipose-specific gene dysregulated in obesity. J Biol Chem. 1996;271:10697-10703.

Hu Z, Wang H, Lee IH, Du J, Mitch WE. Endogenous glucocorticoids and impaired insulin signaling are both require to stimulate muscle wasting under pathophysiological conditions in mice. J Clin Invest. 2009;119:3059-3069.

Huang JF, Huang CF, Yu ML, Dai CY, Huang CI, Yeh ML, Hsieh MH, Yang JF, Hsieh MY, Lin ZY, Chen SC, Chuang WL. Serum visfatin is correlated with disease severity and metabolic syndrome in chronic hepatitis C infection. J Gastroenterol Hepatol. 2011;26:530-535.

Hyltander A, Daneryd P, Sandstrom R, Korner U, Lundholm K. Beta-adrenoceptor activity and resting energy metabolism in weight losing cancer patients. Eur J Cancer, 2000; 36:330-334.

Inui A. Cancer anorexia-cachexia syndrome: are neuropeptides the key? Cancer Res. 1999;59:4493-4501. 
Inui A. Cancer anorexia-cachexia syndrome: current issues in research and management. CA Cancer J Clin. 2002;52:72-91.

Ishiko O, Nishimura S, Yasui T, Sumi T, Hirai K, Honda K, Ogita S. Metabolic and morphologic characteristics of adipose tissue associated with the growth of malignant tumors. Jpn J Cancer Res. 1999;90: 655-659.

Jamieson NB, Brown DJ, Michael Wallace A, McMillan DC. Adiponectin and the systemic inflammatory response in weight-losing patients with non-small cell lung cancer. Cytokine, 2004;27:90-92.

Jaworski K, Sarkadi-Nagy E, Duncan RE, Ahmadian M, Sul HS. Regulation of triglyceride metabolism. IV. Hormonal regulation of lipolysis in adipose tissue. Am J Physiol Gastrointest Liver Physiol. 2007;293:G1-G4.

Jeevanandam M, Horowitz GD, Lowry SF, Brennan MF. Cancer cachexia and the rate of whole body lipolysis in man. Metabolism, 1986;35:304-310.

Jenkins CM, Mancuso DJ, Yan W, Sims HF, Gibson B, Gross RW. Identification, cloning, expression, and purification of three novel human calcium-independent phospholipase A2 family members possessing triacylglycerol lipase and acylglycerol transacylase activities. J Biol Chem. 2004;279:48968-48975.

Ji LL, Gomez-Cabrera MC, Steinhafel N, Vina J. Acute exercise activates nuclear factor (NF)kappa B signaling pathway in rat skeletal muscle. FASEB J. 2004;18:1499-1506.

Kadowaki T, Yamauchi T. Adiponectin and adiponectin receptors. Endocr Rev. 2005;26:439 451.

Kalra PR, Tigas S. Regulation of lipolysis: natriuretic peptides and the development of cachexia. Int J Cardiol. 2002;85:125-132.

Kasuga. Mechanism of insulin action-signal transductions after binding to insulin receptor. Nihon Naibunpi Gakkai Zasshi. 1993;69:1029-1034.

Katch VL, Campaigne B, Freedson P, Sady S, Katch FI, Behnke AR. Contribution of breast volume and weight to body fat distribution in females. Am J Phys Anthropol. 1980;53:93100.

Kawanishi $\mathrm{N}$, Yano $\mathrm{H}$, Yokogawa $\mathrm{Y}$, Suzuki $\mathrm{K}$. Exercise training inhibits inflammation in adipose tissue via both suppression of macrophage infiltration and acceleration of phenotypic switching from M1 to M2macrophages in high-fat-diet-induced obese mice. Exerc Immunol Rev. 2010;16:105-18.

Kazantzis M, Seelaender MC. Cancer cachexia modifies the zonal distribution of lipid metabolism-related proteins in rat liver. Cell Tissue Res. 2005;321:419-427.

Kemik O, Kemik AS, Begenik H, Erdur FM, Emre H, Sumer A, Purisa S, Tuzun S, Kotan C. The relationship among acute-phase responce proteins, cytokines, and hormones in various gastrointestinal cancer types patients with cachectic. Hum Exp Toxicol. In press 2011. 
Kennedy GC. The Role of Depot Fat in the Hypothalamic Control of Food Intake in the Rat. Proc R Soc Lond B Biol Sci. 1953;140:578-592.

Kerem M, Ferahkose Z, Yilmaz UT, Pasaoglu $H$, Ofluoglu E, Bedirli A, Salman B, Sahin TT, Akin $M$. Adipokines and ghrelin in gastric cancer cachexia. World J Gastroenterol. 2008;14:3633-3641.

Kershaw EE, Hamm JK, Verhagen LA, Peroni O, Katic M, Flier JS. Adipose triglyceride lipase: function, regulation by insulin, and comparison with adiponutrin. Diabetes, 2006;55:148-157.

Kimmel AR, Brasaemle DL, McAndrews-Hill M, Sztalryd C, Londos C. Adoption of PERILIPIN as a unifying nomenclature for the mammalian PAT-family of intracellular lipid storage droplet proteins. J Lipid Res. 2010;51:468-471.

Kilgour RD, Vigano A, Trutschnigg B, Hornby L, Lucar E, Bacon SL, Morais JA. Cancer-related fatigue: the impact of skeletal muscle mass and strength in patients with advanced cancer. J Cachexia Sarcopenia Muscle, 2010;1:177-185.

Kistorp C, Faber J, Galatius S, Gustafsson F, Frystyk J, Flyvbjerg A, Hildebrandt P. Plasma adiponectin, body mass index, and mortality in patients with chronic heart failure. Circulation, 2005;112:1756-1762.

Klein J, Fasshauer M, Ito M, Lowell BB, Benito M, Kahn CR. beta(3)-adrenergic stimulation differentially inhibits insulin signaling and decreases insulin-induced glucose uptake in brown adipocytes. J Biol Chem. 1999;274:34795-34802.

Klein S, Wolfe RR. Whole-body lipolysis and triglyceridefatty acid cycling in cachectic patients with esophageal cancer. J Clin Invest. 1990;86:1403-1408.

Klempel MC, Varady KA. Reliability of leptin, but not adiponectin, as a biomarker for dietinduced weight loss in humans. Nutr Rev. 2011;69:145-154.

Kralisch S, Klein J, Lossner U, Bluher M, Paschke R, Stumvoll M, Fasshauer M. Isoproterenol, TNFalpha, and insulin downregulate adipose triglyceride lipase in 3T3-L1 adipocytes. Mol Cell Endocrinol. 2005;240:43-49.

Kubota N, Yano W, Kubota T, Yamauchi T, Itoh S, Kumagai H, Kozono H, Takamoto I, Okamoto S, Shiuchi T, Suzuki R, Satoh H, Tsuchida A, Moroi M, Sugi K, Noda T, Ebinuma H, Ueta Y, Kondo T, Araki E, Ezaki O, Nagai R, Tobe K, Terauchi Y, Ueki K, Minokoshi Y, Kadowaki T. Adiponectin stimulates AMP-activated protein kinase in the hypothalamus and increases food intake. Cell Metab. 2007;6:55-68.

Kurth AH, Wang C, Hayes WC, Shea M. The evaluation of a rat model for the analysis of densitometric and biomechanical properties of tumor-induced osteolysis. J Orthop Res. 2001;19:200-205.

Lago F, Gómez R, Gómez-Reino JJ, Dieguez C, Gualillo O. Adipokines as novel modulators of lipid metabolism. Trends Biochem Sci. 2009;34:500-510.

Lampidonis AD, Rogdakis E, Voutsinas GE, Stravopodis DJ. The resurgence of HormoneSensitive Lipase (HSL) in mammalian lipolysis. Gene, 2011;477:1-11. 
Langin D. Control of fatty acid and glycerol release in adipose tissue lipolysis. C R Biol. 2006;329:598-607.

Langin D. Adipose tissue lipolysis as a metabolic pathway to define pharmacological strategies against obesity and the metabolic syndrome. Pharmacol Res. 2006a;53:482-491.

Langin D, Arner P. Importance of TNFalpha and neutral lipases in human adipose tissue lipolysis. Trends Endocrinol Metab. 2006b;17:314-320.

Large V, Reynisdottir S, Eleborg L, van Harmelen V, Strommer L, Arner P. Lipolysis in human fat cells obtained under local and general anesthesia. Int J Obes Relat Metab Disord. 1997; 21:78-82.

Lass A, Zimmermann R, Haemmerle G, Riederer $M$, Schoiswohl $G$, Schweiger $M$, Kienesberger P, Strauss JG, Gorkiewicz G, Zechner R. Adipose triglyceride lipase-mediated lipolysis of cellular fat stores is activated by CGI-58 and defective in Chanarin-Dorfman Syndrome. Cell Metab. 2006;3:309-319.

Laurell, H., Grober, J., Vindis, C., Lacombe, T., Dauzats, M., Holm, C. and Langin, D. Species-specific alternative splicing generates a catalytically inactive form of human hormone-sensitive lipase. Biochem J. 1997;328:137-143.

Laviano A, Inui A, Marks DL, Meguid MM, Pichard C, Rossi Fanelli F. Neural control of the anorexia-cachexia syndrome. Am J Physiol Endocrinol Metab. 2008; 295:1000-1008.

Lavoie F, Frisch F, Brassard P, Normand-Lauzière F, Cyr D, Gagnon R, Drouin R, Baillargeon JP, Carpentier AC. Relationship between total and high molecular weight adiponectin levels and plasma nonesterified fatty acid tolerance during enhanced intravascular triacylglycerol lipolysis in men. J Clin Endocrinol Metab. 2009;94:998-1004.

Lefèvre C, Jobard F, Caux F, Bouadjar B, Karaduman A, Heilig R, Lakhdar H, Wollenberg A, Verret JL, Weissenbach J, Ozgüc M, Lathrop M, Prud'homme JF, Fischer J. Mutations in CGI58 , the gene encoding a new protein of the esterase/lipase/thioesterase subfamily, in Chanarin-Dorfman syndrome. Am J Hum Genet. 2001;69:1002-1012.

Legaspi A, Jeevanandam M, Starnes HF Jr, Brennan MF. Whole body lipid and energy metabolism in the cancer patient. Metabolism, 1987;36:958-963.

Lenk K, Schuler G, Adams V. Skeletal muscle wasting in cachexia and sarcopenia: molecular pathophysiology and impact of exercise training. J Cachexia Sarcopenia Muscle, 2010;1:9-21.

Li L, Yang G, Shi S, Yang M, Liu H, Boden G. The adipose triglyceride lipase, adiponectin and visfatin are downregulated by tumor necrosis factor-alpha (TNF-alpha) in vivo. Cytokine, 2009;45:12-9.

Li Y, Zheng X, Yang G. Effects of leptin on porcine primary adiocytes lipolysis and mRNA expression of key lipolytic enzymes. Sheng Wu Gong Cheng Xue Bao. 2008;24:1613-1619.

Li YC, Zheng XL, Liu BT, Yang GS. Regulation of ATGL expression mediated by leptin in vitro in porcine adipocyte lipolysis. Mol Cell Biochem. 2010;333:121-128. 
Lihn AS, Bruun JM, He G, Pedersen SB, Jensen PF, Richelsen B. Mol Cell Endocrinol. 2004;219:9-15.

Lima FB, Thies RS, Garvey WT. Glucose and insulin regulate insulin sensitivity in primary cultured adipocytes without affecting insulin receptor kinase activity. Endocrinology, 1991;128:2415-2426.

Lira FS, Tavares FL, Yamashita AS, Koyama CH, Alves MJ, Caperuto EC, Batista ML Jr, Seelaender M. Effect of endurance training upon lipid metabolism in the liver of cachectic tumour-bearing rats. Cell Biochem Funct. 2008;26:701-708.

Lira FS, Rosa JC, Zanchi NE, Yamashita AS, Lopes RD, Lopes AC, Batista ML Jr, Seelaender M. Regulation of inflammation in the adipose tissue in cancer cachexia: effect of exercise. Cell Biochem Funct. 2009;27:71-75.

Lira FS, Yamashita AS, Rosa JC, Tavares FL, Caperuto E, Carnevali Jr LC, Pimentel GD, Santos RV, Batista Jr ML, Laviano A, Rossi-Fanelli F, Seelaender M. Hypothalamic inflammation is reversed by endurance training in anorectic-cachectic rats. Nutr Metab. 2011;8:60.

Liu M, Liu F. Transcriptional and post-translational regulation of adiponectin. Biochem J. 2009;425:41-52.

Loberg RD, Bradley DA, Tomlins SA, Chinnaiyan AM, Pienta KJ. The lethal phenotype of cancer: the molecular basis of death due to malignancy. CA Cancer J Clin. 2007;57:225241.

Lofti CFP, Machado-Santelli GM. Comparative analysis of colchicine induced micronuclei in different cell types in vitro. Mutat Res. 1996;349:77-83.

Londos C, Brasaemle DL, Schultz CJ, Adler-Wailes DC, Levin DM, Kimmel AR, Rondinone CM. On the control of lipolysis in adipocytes. Ann N Y Acad Sci. 1999;892:155-168.

Lu X, Yang X, Liu J. Differential control of ATGL-mediated lipid droplet degradation by CGI58 and G0S2. Cell Cycle, 2010;9:2719-2725.

Lumeng CN, Deyoung SM, Saltiel AR. Macrophages block insulin action in adipocytes by altering expression of signaling and glucose transport proteins. Am J Physiol Endocrinol Metab. 2007;292:E166-174.

Lundholm K, Holm G, Scherstén T. Insulin resistance in patients with cancer. Cancer Res. $1978 ; 38: 4665-4670$.

Machado AP, Costa Rosa LF, Seelaender MC. Adipose tissue in Walker 256 tumour-induced cachexia: possible association between decreased leptin concentration and mononuclear cell infiltration. Cell Tissue Res. 2004;318:503-514.

Magni P. Hormonal control of the neuropeptide Y system. Curr Protein Pept Sci. 2003;4:4557. 
Maison $\mathrm{P}$, Byrne CD, Hales CN, Wareham NJ. Hypertension and its treatment influence changes in fasting nonesterified fatty acid concentrations: a link between the sympathetic nervous system and the metabolic syndrome? Metabolism, 2000;49:81-87.

Mantovani G, Madeddu C, Macciò A, Gramignano G, Lusso MR, Massa E, Astara G, Serpe R. Cancer-related anorexia/cachexia syndrome and oxidative stress: an innovative approach beyond current treatment. Cancer Epidemiol Biomarkers Prev. 2004;13:1651-1659.

Matsubara M, Maruoka S, Katayose S. Inverse relationship between plasma adiponectin and leptin concentrations in normal-weight and obese women. Eur J Endocrinol. 2002;147:173180.

Mattheus DR, Hosker JP, Rudenski AS, Naylor BA, Treacher DF, Turner RC. Homeostasis model assessment: insulin resistance and beta-cell function from fasting plasma glucose and insulin concentrations in man. Diabetologia, 1985;28:412-419.

McGee KC, Harte AL, da Silva NF, Al-Daghri N, Creely SJ, Kusminski CM, Tripathi G, Levick PL, Khanolkar M, Evans M, Chittari MV, Patel V, Kumar S, McTernan PG. Visfatin is regulated by rosiglitazone in type 2 diabetes mellitus and influenced by NFKB and JNK in human abdominal subcutaneous adipocytes. PLoS One, 2011;6:e20287.

McMillan DC, Preston T, Fearon KC, Burns HJ, Slater C, Shenkin A. Protein synthesis in cancer patients with inflammatory response: investigations with [15N]glycine. Nutrition, 1994;10:232-240.

Miyoshi H, Souza SC, Zhang HH, Strissel KJ, Christoffolete MA, Kovsan J, Rudich A, Kraemer FB, Bianco AC, Obin MS, Greenberg AS. Perilipin promotes hormone-sensitive lipasemediated adipocyte lipolysis via phosphorylation-dependent and -independent mechanisms. J Biol Chem. 2006;281:15837-15844.

Morley JE, Thomas DR, Wilson MM. Cachexia: pathophysiology and clinical relevance. Am J Clin Nutr. 2006;83:735-743.

Moschen AR, Kaser A, Enrich B, Mosheimer B, Theurl M, Niederegger H, Tilg H. Visfatin, an adipocytokine with proinflammatory and immunomodulating properties. J Immunol. 2007;178:1748-1758.

Moses AWG, Slater C, Preston T, Barber MD, Fearon $\mathrm{KCH}$. Reduced total energy expenditure and physical activity in cachectic patients with pancreatic cancer can be modulated by an energy and protein dense oral supplement enriched with n-3 fatty acids. Br J Cancer, 2004; 90:996-1002.

Moses AG, Dowidar N, Holloway B, Waddell I, Fearon KC, Ross JA. Leptin and its relation to weight loss, ob gene expression and the acute-phase response in surgical patients. $\mathrm{Br}]$ Surg. 2001;88:588-593.

Mracek T, Stephens NA, Gao D, Bao Y, Ross JA, Rydén $M$, Arner $P$, Trayhurn $P$, Fearon KC, Bing C. Enhanced ZAG production by subcutaneous adipose tissue is linked to weight loss in gastrointestinal cancer patients. Br J Cancer, 2011;104:441-447. 
Mu J, Feng B, Ye Z, Yuan F, Zeng W, Luo Z, Qi W. Visfatin is related to lipid dysregulation, endothelial dysfunction and atherosclerosis in patients with chronic kidney disease. J Nephrol. 2011;24:177-184.

Muller G, Ertl J, Gerl M, Preibisch G. Leptin impairs metabolic actions of insulin in isolated rat adipocytes. J Biol Chem. 1997; 272:10585-10593.

Murphy RA, Wike MS, Perrine M, Pawlowicz M, Mourtzakis M, Lieffers JR, Maneshgar M, Bruera E, Clandinin MT, Barracos VE, Mazurak VC. Loss of adipose tissue and plasma phospholipids: relationship to survival in advanced cancer patients. Clin Nutr. 2010;29:482487.

Muscaritoli M, Anker SD, Argilés J, Aversa Z, Bauer JM, Biolo G, Boirie Y, Bosaeus I, Cederholm T, Costelli P, Fearon KC, Laviano A, Maggio M, Rossi Fanelli F, Schneider SM, Schols A, Sieber CC. Consensus definition of sarcopenia, cachexia and pre-cachexia: joint document elaborated by Special Interest Groups (SIG) "cachexia-anorexia in chronic wasting diseases" and "nutrition in geriatrics". Clin Nutr. 2010;29:154-159.

Nakajima TE, Yamada Y, Hamano T, Furuta K, Gotoda T, Katai H, Kato K, Hamaguchi T, Shimada Y. Adipocytokine levels in gastric cancer patients: resistin and visfatin as biomarkers ofgastric cancer. J Gastroenterol. 2009;44:685-690.

Nakajima TE, Yamada Y, Hamano T, Furuta K, Oda I, Kato H, Kato K, Hamaguchi T, Shimada Y. Adipocytokines and squamous cell carcinoma of the esophagus. J Cancer Res Clin Oncol. 2010;136:261-266.

Niang F, Benelli C, Ribière C, Collinet M, Mehebik-Mojaat N, Penot G, Forest C, Jaubert AM. Leptin induces nitric oxide-mediated inhibition of lipolysis and glyceroneogenesis in rat white adipose tissue. J Nutr. 2011;141:4-9.

Nieto-Vazquez I, Fernández-Veledo S, Krämer DK, Vila-Bedmar R, Garcia-Guerra L, Lorenzo $M$. Insulin resistance associated to obesity: the link TNF-alpha. Arch Physiol Biochem. 2008;114:183-194.

Nishii M, Inomata T, Takehana H, Takeuchi I, Nakano H, Koitabashi T, Nakahata J, Aoyama $\mathrm{N}$, Izumi T. Serum levels of interleukin-10 on admission as a prognostic predictor of human fulminant myocarditis. J Am Coll Cardiol. 2004;44:1292-1297.

Niswender KD, Morton GJ, Stearns WH, Rhodes CJ, Myers MG Jr, Schwartz MW. Intracellular signalling. Key enzyme in leptin-induced anorexia. Nature, 2001;413:794-795.

Olsson $\mathrm{H}$, Belfrage $\mathrm{P}$. The regulatory and basal phosphorylation sites of hormone-sensitive lipase are dephosphorylated by protein phosphatase-1, $2 \mathrm{~A}$ and $2 \mathrm{C}$ but not by protein phosphatase-2B. Eur. J. Biochem. 1987;168:399-405.

Olszanecka-Glinianowicz M, Kocełak P, Janowska J, Skorupa A, Nylec M, ZahorskaMarkiewicz B. Plasma visfatin and tumor necrosis factor-alpha (TNF-a) levels in metabolic syndrome. Kardiol Pol. 2011;69:802-807.

Ouchi N, Kihara S, Arita Y, Maeda K, Kuriyama H, Okamoto Y, Hotta K, Nishida M, Takahashi M, Nakamura T, Yamashita S, Funahashi T, Matsuzawa Y. Novel modulator for endothelial 
adhesion molecules: adipocyte-dericed plasma protein adiponectin. Circulation, 1999;100:2473-2476.

Palou M, Priego T, Sánchez J, Rodríguez AM, Palou A, Picó C. Gene expression patterns in visceral and subcutaneous adipose depots in rats are linked to their morphologic features. Cell Physiol Biochem. 2009;24:547-556.

Pal'tsev MA. Cytokines and their role in intercellular interactions. Arkh Patol. 1996;58:3-7.

Papathanassoglou ED, Moynihan JA, Ackerman MH, Mantzoros CS. Serum leptin levels are higher but are not independently associated with severity or mortality in the multiple organ dysfunction/systemic inflammatory response syndrome: a matched case control and a longitudinal study. Clin Endocrinol. 2001;54:225-233.

Pelleymounter MA, Cullen MJ, Baker MB, Hecht R, Winters D, Boone T, Collins F. Effects of the obese gene product on body weight regulation in ob/ob mice. Science, 1995;269:540543.

Peluso G, Nicolai R, Reda E, Benatti P, Barbarisi A, Calvani M. Cancer and anticancer therapyinduced modifications on metabolism mediated by carnitine system. J Cell Physiol. 2000;182:339-350.

Piffar PM, Fernandez R, Tchaikovski O, Hirabara SM, Folador A, Pinto GJ, Jakobi S, GobboBordon D, Rohn TV, Fabrício VE,Moretto KD, Tosta E, Curi R, Fernandes LC. Naproxen, clenbuterol and insulin administration ameliorates cancer cachexia and reduce tumor growth in Walker 256 tumor-bearing rats. Cancer Lett. 2003;201:139-48.

Plata-Salamán CR, Ilyin SE, Gayle D. Brain cytokine mRNAs in anorectic rats bearing prostate adenocarcinoma tumour cells. Am J Physiol. 1998;275:566-573.

Qi L, Doria A, Manson JE, Meigs JB, Hunter D, Mantzoros CS, Hu FB. Adiponectin genetic variability, plasma adiponectin, and cardiovascular risk in patients with type 2 diabetes. Diabetes, 2006;55:1512-1516.

Reaven GM, Lithell H, Landsberg L. Hypertension and associated metabolic abnormalities-the role of insulin resistance and the sympathoadrenal system. N Engl J Med. 1996;334:374381.

Reid J, McKenna HP, Fitzsimons D, McCance TV. An exploration of the experience of cancer cachexia: what patients and their families want from healthcare professionals.Eur J Cancer Care, 2010;19: 682-689.

Reyna SM, Ghosh S, Tantiwong P, Meka CS, Eagan P, Jenkinson CP, Cersosimo E, Defonzo RA, Coletta DK, Sriwijitkamol A, Musi N. Elevated toll-like receptor 4 expression and signaling in muscle from insulin-resistant subjects. Diabetes, 2008;57:2595-2602.

Rodbell M. Metabolism of isolated fat cells. Effects of hormones on glucose metabolism and lipids. J Biol Chem. 1964;239:357-380.

Rydén $M$, Arvidsson E, Blomqvist L, Perbeck L, Dicker A, Arner P. Targets for TNF-alphainduced lipolysis in human adipocytes. Biochem Biophys Res Commun. 2004;318:168-175. 
Rydén M, Agustsson T, Laurencikiene J, Britton T, Sjölin E, Isaksson B, Permert J, Arner P. Lipolysis--not inflammation, cell death, or lipogenesis--is involved in adipose tissue loss in cancer cachexia. Cancer, 2008;113:1695-1704.

Russell ST, Tisdale MJ. The role of glucocorticoids in the induction of zinc-a2-glycoprotein expression in adipose tissue in cancer cachexia. Br J Cancer, 2005;92:876-881.

Samaan MC. The macrophage at the intersection of immunity and metabolism in obesity. Diabetol Metab Syndr. 2011;3:29.

Schiffelers SL, Saris $W H$, van Baak MA. The effect of an increased free fatty acid concentration on thermogenesis and substrate oxidation in obese and lean men. Int J Obes Relat Metab Disord. 2001;25:33-38.

Schwartz MW, Baskin DG, Kaiyala KJ, Woods SC. Model for the regulation of energy balance and adiposity by the central nervous system. Am J Clin Nut. 1999;69:584-596.

Seelaender MC, Nascimento CM, Curi R, Williams JF. Studies on the lipid metabolism of Walker 256 tumour-bearing rats during the development of cancer cachexia. Biochem Mol Biol Int. 1996;39:1037-1047.

Seelaender M, Batista Jr M. Heterogeneous response of rat and human adipose tissue in cancer cachexia. J Cachexia Sarcopenia Muscle, 2010;1:61-62 [5 $5^{\text {th }}$ Cachexia Conference; 2009; Barcelona].

Serr J, Suh Y, Oh SA, Shin S, Kim M, Latshaw JD, Lee K. Acute up-regulation of adipose triglyceride lipase and release of non-esterified fatty acids by dexamethasone in chicken adipose tissue. Lipids. 2011;46:813-820.

Sharma A M, Chetty V T. Obesity, hypertension and insulin resistance. Acta Diabetol. 2005; 42:S3-S8.

Shaw JH, Wolfe RR. Fatty acid and glycerol kinetics in septic patients and in patients with gastrointestinal cancer. The response to glucose infusion and parenteral feeding. Ann Surg. $1987 ; 205: 368-376$.

Shen WJ, Patel S, Natu V, Kraemer FB. Mutational analysis of structural features of rat hormone-sensitive lipase. Biochemistry 1998;37:8973-8979.

Shoelson SE, Lee J, Goldfine AB. Inflammation and insulin resistance. J Clin Invest. 2006;116:1793-1801.

Silva FM, de Almeida JC, Feoli AM. Effect of diet on adiponectin levels in blood. Nutr Rev. 2011;69:599-612.

Silvério R. A modulação da lipase de triacilglicerol do adipócito (ATGL) e da perilipina 1 contribui para o aumento da lipólise em pacientes caquéticos. [tese (Doutorado em Biologia Celular e Tecidual)]. São Paulo: Instituto de Ciências Biomédicas, Universidade de São Paulo; 2011.

Silverio R, Laviano A, Fanelli FR, Seelaender M. L: -Carnitine induces recovery of liver lipid metabolism in cancer cachexia. Amino Acids, in press 2011. 
Skipworth RJ, Stewart GD, Dejong CH, Preston T, Fearon KC. Pathophysiology of cancer cachexia: much more than host-tumour interaction? Clin Nutr. 2007;26:667-676.

Skoog T, Eriksson P, Hoffstedt J, Ryden M, Hamsten A, Armer P. Tumour necrosis factoralpha (TNF-alpha) polymorphisms -857C/A and -863C/A are associated with TNF-alpha secretion from human adipose tissue. Diabetologia, 2001;44:654-655.

Slavin BG, Ong JM, Kern PA. Hormonal regulation of hormone-sensitive lipase activity and mRNA levels in isolated ratadipocytes. J Lipid Res. 1994;35:1535-1541.

Smiechowska J, Utech A, Taffet G, Hayes T, Marcelli M, Garcia JM. Adipokines in patients with cancer anorexia and cachexia. J Investig Med. 2010;58:554-559.

Smith AJ, Sanders MA, Thompson BR, Londos C, Kraemer FB. Physical association between the adipocyte fatty acid-binding protein and hormone-sensitive lipase: a fluorescence resonance energy transfer analysis. J Biol Chem 2004;279:52399-52405.

Sobin LH ,Wittekind C. TNM Classification of Malignant Tumors. 6th ed. New York: John Wiley \& Sons; 2002.254p.

Sommer G, Garten A, Petzold S, Beck-Sickinger AG, Blüher M, Stumvoll M, Fasshauer M. Visfatin/PBEF/Nampt: structure, regulation and potential function of a novel adipokine. Clin Sci (Lond). 2008;115:13-23.

Souza, SC, Vargas, LMd, Yamamoto, MT, Lien P, Franciosa MD, Moss LG. Overexpression of perilipin A and B blocks the ability of tumor necrosis factor-a to increase lipolysis in 3T3-L1 adipocytes. J Biol Chem. 1998;273:24665-24669.

Souza SC, Palmer HJ, Kang YH, Yamamoto MT, Muliro KV, Paulson KE, Greenberg AS. TNFalpha induction of lipolysis is mediated through activation of the extracellular signal related kinase pathway in 3T3-L1 adipocytes. J Cell Biochem. 2003;89:1077-1086.

Springer J, von Haehling S, Anker SD. The need for a standardized definition for cachexia in chronic illness. Nat Clin Pract Endocrinol Metab. 2006;2:6-7.

Staiger H, Tschritter O, Machann J, Thamer C, Fritsche A, Maerker E, Schick F, Häring $\mathrm{HU}$, Stumvoll M. Relationship of serum adiponectin and leptin concentrations with body fat distribution in humans. Obes Res. 2003;11:368-372.

Stralfors P, Belfrage P. Phosphorylation of hormone-sensitive lipase by cyclic AMP-dependent protein kinase. J Biol Chem. 1983;258:15146-15152.

Stralfors $\mathrm{P}$, Bjorgell $\mathrm{P}$, Belfrage P. Hormonal regulation of hormone-sensitive lipase in intact adipocytes: identification of phosphorylated sites and effects on the phosphorylation by lipolytic hormones and insulin. Proc Natl Acad Sci. 1984;81:3317-3321.

Strasser F, Bruera ED. Update on anorexia and cachexia. Hematol Oncol Clin North Am. 2002;16:589-617.

Subramanian V, Rothenberg A, Gomez C, Cohen AW, Garcia A, Bhattacharyya S, Shapiro L, Dolios G, Wang R, Lisanti MP, Brasaemle DL. Perilipin A mediates the reversible binding of CGI-58 to lipid droplets in 3T3-L1 adipocytes. J Biol Chem. 2004;279:42062-42071. 
Suganami T, Nishida J, Ogawa Y. A paracrine loop between adipocytes and macrophages aggravates inflammatory changes: role of free fatty acids and tumor necrosis factor alpha. Arterioscler Thromb Vasc Biol. 2005;25:2062-2068.

Suganami T, Tanimoto-Koyama K, Nishida J, Itoh M, Yuan X, Mizuarai S, Kotani H, Yamaoka S, Miyake K, Aoe S, Kamei Y, Ogawa Y. Role of the Toll-like receptor 4/NF-kappaB pathway in saturated fatty acid-induced inflammatory changes in the interaction between adipocytes and macrophages. Arterioscler Thromb Vasc Biol. 2007;27:84-91.

Sztalryd C., Xu G, Dorward H, Tansey JT, Contreras JA, Kimmel AR, Londos C. Perilipin A is essential for the translocation of hormone-sensitive lipase during lipolytic activation. J Cell Biol. 2003;161:1093-1103.

Tada T, Ohkubo I, Niwa M, Sasaki M, Tateyama H, Eimoto T. Immunohistochemical localization of Zn-alpha 2-glycoprotein in normal human tissues. J Histochem Cytochem. 1991;39:1221-1226.

Tajima D, Masaki T, Hidaka S, Kakuma T, Sakata T, Yoshimatsu H. Acute central infusion of leptin modulates fatty acid mobilization by affecting lipolysis and mRNA expression for uncoupling proteins. Exp Biol Med. 2005;230:200-206.

Takahashi M, Terashima M, Takagane A, Oyama K, Fujiwara H, Wakabayashi G. Ghrelin and leptin levels in cachectic patients with cancer of the digestive organs. Int J Clin Oncol. 2009;14:315-320.

Tansey JT, Sztalryd C, Gruia-Gray J, Roush DL, Zee JV, Gavrilova O, Reitman ML, Deng CX, Li C, Kimmel AR, Londos C. Perilipin ablation results in a lean mouse with aberrant adipocyte lipolysis, enhanced leptin production, and resistance to diet-induced obesity. Proc Natl Acad Sci U S A. 2001;98:6494-6499.

Thompson MP, Cooper ST, Parry BR, Tuckey JA. Increased expression of the mRNA for hormone-sensitive lipase in adipose tissue of cancer patients. Biochim Biophys Acta. 1993; $1180,236-242$.

Tisdale MJ. Molecular pathways leading to cancer cachexia. Physiology, 2005;20:340-348.

Tisdale MJ. Mechanisms of cancer cachexia. Physiol Rev. 2009;89:381-410.

Tisdale MJ. Are tumoral factors responsible for host tissue wasting in cancer cachexia? Future Oncol. 2010;6:503-513.

Titos E, Rius B, González-Périz A, López-Vicario C, Morán-Salvador E, Martínez-Clemente M, Arroyo V, Clària J. Resolvin D1 and Its Precursor Docosahexaenoic Acid Promote Resolution of Adipose Tissue Inflammation by Eliciting Macrophage Polarization toward an M2-Like Phenotype. J Immunol. 2011;187:5408-54018.

Trayhurn P, Beattie JH. Physiological role of adipose tissue: white adipose tissue as an endocrine and secretory organ. Proc Nutr Soc. 2001;60:329-339.

Trayhurn P. Endocrine and signalling role of adipose tissue: new perspectives on fat. Acta Physiol Scand. 2005;184:285-293. 
Trotta PP. Cytokines: an overview. Am J Reprod Immunol. 1991;25:137-141.

Trujillo ME, Scherer PE. Adiponectin-journey from an adipocyte secretory protein to biomarker of the metabolic syndrome. J Intern Med. 2005;257:167-175.

Villena JA, Roy S, Sarkadi-Nagy E, Kim KH, Sul HS. Desnutrin, na adipocyte gene encoding a novel patatin domain-containing protein, is induced by fasting and glucocorticoids: ectopic expression of desnutrin increases triglyceride hydrolysis. J Biol Chem. 2004;279:4706647075.

Wallace AM, Sattar N, McMillan DC. Effect of weight loss and the inflammatory response on leptin concentrations in gastrointestinal cancer patients. Clin Cancer Res. 1998;4:29772979.

Wang B, Trayhurn P. Acute and prolonged effects of TNF-alpha on the expression and secretion of inflammation-related adipokines by human adipocytes differentiated in culture. Pflugers Arch. 2006;452:418-427.

Wang $\mathrm{H}$, Edens NK. mRNA expression and antilipolytic role of phisphodiesterase 4 in rat adipocytes in vitro. J Lipid Res. 2007;48:1099-1107.

Wang P, Bai C, Xu QY, Xu TY, Su DF, Sassard J, Miao CY. Visfatin is associated with lipid metabolic abnormalities in Lyon hypertensive rats. Clin Exp Pharmacol Physiol. 2010;37:894899.

Wang SP, Laurin N, Himms-Hagen J, Rudnicki MA, Levy E, Robert MF, Pan L, Oligny L, Mitchell GA. The adipose tissue phenotype of hormone-sensitive lipase deficiency in mice. Obes Res. 2001;9:119-128.

Warren S. The immediate cause of death in cancer. Am J Med Sci. 1932;184:610-613.

Watt MJ, Steinberg GR. Regulation and function of triacylglycerol lipases in cellular metabolism. Biochem J. 2008;414:313-325.

Watt MJ, van Denderen BJ, Castelli LA, Bruce CR, Hoy AJ, Kraegen EW, Macaulay L, Kemp B E. Adipose triglyceride lipase regulation of skeletal muscle lipid metabolism and insulin responsiveness. Mol Endocrinol. 2008;22,1200-1212.

Watt MJ. Triglyceride lipases alter fuel metabolism and mitochondrial gene expression. Appl Physiol Nutr Metab. 2009;34:340-347.

Webber J. Energy balance in obesity. Proc Nutr Soc. 2003;62:539-543.

Weryńska B, Kosacka M, Gołecki M, Jankowska R. Leptin serum levels in cachectic and noncachectic lung cancer patients. Pneumonol Alergol Pol. 2009;77:500-506.

White $\mathrm{MF}$, Maron $\mathrm{R}$, Kahn CR. Insulin rapidly stimulates tyrosine phosphorylation of a Mr185,000 protein in intact cells. Nature, 1985;318:183-186.

White MF, Kahn CR. The insulin signaling system. J Biol Chem. 1994;269:1-4. 
Xie L, Ortega MT, Mora S, Chapes SK. Interactive changes between macrophages and adipocytes. Clin Vaccine Immunol. 2010;17:651-659.

Yamaguchi T, Omatsu N, Morimoto $\quad$ E, Nakashima $\quad H$, Ueno $\quad K$, Tanaka $\quad$, Satouchi K, Hirose F, Osumi T. CGI-58 facilitates lipolysis on lipid droplets but is not involved in the vesiculation of lipid droplets caused by hormonal stimulation. J Lipid Res. 2007;48:10781089.

Yamauchi T, Kamon J, Waki H, Terauchi Y, Kubota N, Hara K, Mori Y, Ide T, Murakami K, Tsuboyama-Kasaoka N, Ezaki O, Akanuma Y, Gavrilova O, Vinson C, Reitman ML, Kagechika H, Shudo K, Yoda M, Nakano Y, Tobe K, Nagai R, Kimura S, Tomita M, Froguel P, Kadowaki $\mathrm{T}$. The fat-derived hormone adiponectin reverses insulin resistance associated with both lipoatrophy and obesity. Nat Med. 2001;7:941-946.

Yang WS, Lee WJ, Funahashi T, Tanaka S, Matsuzawa Y, Chao CL, Chen CL, Tai TY, Chuang LM. Weight reduction increases plasma levels of an adipose-derived anti-inflammatory protein, adiponectin. J Clin Endocrinol Metab. 2001;86:3815-3819.

Yeaman SJ. Hormone-sensitive lipase-a multipurpose enzyme in lipid metabolism. Biochim Biophys Acta, 1990;1052:128-132.

Yeaman SJ. Hormone-sensitive lipase--new roles for an old enzyme. Biochem J. 2004;379:11-22.

Yip HK, Youssef AA, Chang LT, Yang CH, Sheu JJ, Chua S, Yeh KH, Lee FY, Wu CJ, Hang CL. Association of interleukin-10 level with increased 30-day mortality in patients with STsegment elevation acute myocardial infarction undergoing primary coronary intervention. Circ J. 2007;71:1086-1091.

Yoshikawa T, Noguchi Y, Satoh S. Inhibition of IRS-1 phosphorylation and the alterations of GLUT4 in isolated adipocytes from cachectic tumor-bearing rats. Biochem Biophys Res Commun. 1999;256:676-681.

Zechner R, Strauss JG, Haemmerle G, Lass A, Zimmermann R. Lipolysis: pathway under construction. Curr Opin Lipidol. 2005;16:333-340.

Zechner R, Kienesberger PC, Haemmerle G, Zimmermann R, Lass A. Adipose triglyceride lipase and the lipolytic catabolism of cellular fat stores. J Lipid Res. 2009;50:3-21.

Zelissen PM, Stenlof K, Lean ME, Fogteloo J, Keulen ET, Wilding J, Finer N, Rössner S, Lawrence E, Fletcher C, McCamish M. Effect of three treatment schedules of recombinant methionyl human leptin on body weight in obese adults: a randomized, placebo-controlled trial. Diabetes Obes Metab. 2005;7:755-761.

Zhang Y, Proenca R, Maffei M, Barone M, Leopold L, Friedman JM. Positional cloning of the mouse obese gene and its human homologue. Nature, 1994;372:425-432.

Zhang HH, Halbleib M, Ahmad F, Manganiello VC, Greenberg AS. Tumor necrosis factor-alpha stimulates lipolysis in differentiated human adipocytes through activation of extracellular signal-related kinase and elevation of intracellular cAMP. Diabetes, 2002;51:2929-2935. 
Zimmermann R, Strauss JG, Haemmerle G, Schoiswohl G, Birner-Gruenberger R, Riederer M, Lass A, Neuberger G, Eisenhaber F, Hermetter A, Zechner R. Fat mobilization in adipose tissue is promoted by adipose triglyceride lipase. Science, 2004;306:1383-1386.

Zimmermann R, Lass A, Haemmerle G, Zechner R. Fate of fat: the role of adipose triglyceride lipase in lipolysis. Biochim Biophys Acta, 2009;1791:494-500.

Zuijdgeest-van Leeuwen SD, van den Berg JW, Wattimena JL, van der Gaast A, Swart GR, Wilson JH, Dagnelie PC. Lipolysis and lipid oxidation in weight-losing cancer patients and healthy subjects. Metabolism, 2000;49:931-936. 
ANEXOS 


\section{Anexo A - Termo de Consentimento Livre e Esclarecido}

ESTUDO: Influência das Citocinas pró e anti-inflamatórias no tecido adiposo branco. Possível interação entre adipócito e infiltrado mononuclear.

Você está sendo convidado (a) a participar do projeto de pesquisa acima citado. O documento abaixo contém todas as informações necessárias sobre a pesquisa que estamos fazendo. Sua colaboração neste estudo será de muita importância para nós, mas se desistir a qualquer momento, isso não causará nenhum prejuízo a você.

$\mathrm{Eu}$,

profissão__

residente e domiciliado

na__ telefone___ portador da Cédula de

identidade, $\mathrm{RG}$

e inscrito no $\mathrm{CPF} / \mathrm{MF}$

nascido (a) em ___ _ _ _ _ abaixo assinado (a), concordo de livre e espontânea vontade em participar como voluntário (a) do estudo "Influência das Citocinas pró e anti-inflamatórias no tecido adiposo branco. Possível interação entre adipócito e infiltrado mononuclear". Declaro que obtive todas as informações necessárias, bem como todos os eventuais esclarecimentos quanto às dúvidas por mim apresentadas.

Estou ciente que:

1) O estudo se faz necessário para que se possam descobrir as possíveis causas da síndrome denominada caquexia (síndrome caracterizada pela grande perda de peso, força muscular e diminuição do apetite) associada ao câncer. Será utilizado o sangue e o tecido adiposo branco para as análises. Esses materiais coletados demonstram-se importantes para o entendimento da etiologia do processo de caquexia. A pesquisa terá duração total de quatro anos, sendo sua participação pontual, ou seja, apenas no ato cirúrgico;

2) Será feita uma coleta de $20 \mathrm{ml}$ de sangue, no momento da entrevista e consentimento da participação do projeto, por um profissional da saúde;

3) Essa coleta será feita apenas para este estudo, em nada influenciará o tratamento e não modificará o procedimento cirúrgico;

4) Durante o procedimento cirúrgico será retirado um fragmento de aproximadamente um grama de tecido adiposo branco subcutâneo de omento, com tempo total de coleta de aproximadamente 5 minutos. Esse procedimento possui um grau de risco mínimo, não interferindo nos procedimentos padrões da cirurgia;

5) Essa coleta será feira apenas para este estudo e em nada influenciará o tratamento; não vai me curar, não vai me causar nenhum problema, não haverá nenhum incômodo de dor no momento da coleta;

6) A participação neste projeto não tem objetivo de me submeter a um tratamento, bem como não me acarretará qualquer despesa pecuniário com relação aos procedimentos médicoclínico-terapêuticos efetuados com o estudo;

7) Tenho a liberdade de desistir ou de interromper a colaboração neste estudo no momento em que desejar, sem necessidade de qualquer explicação;

8) A desistência não causará nenhum prejuízo à minha saúde ou bem estar físico. Não virá interferir no atendimento ou tratamento médico; 
9) Os resultados obtidos durante este ensaio serão mantidos em sigilo, mas concordo que sejam divulgados em publicações científicas, desde que meus dados pessoais não sejam mensionados;

10) Casou eu desejar, poderei pessoalmente tomar conhecimentos dos resultados, ao final desta pesquisa.

( ) Desejo conhecer os resultados desta pesquisa.

( ) Não desejo conhecer os resultados desta pesquisa.

11) Concordo que o material poderá ser utilizado em outros projetos desde que autorizado pela Comissão de Ética deste Instituto e pelo responsável por esta pesquisa.

( ) Sim ou ( ) Não

"DECLARO QUE, APÓS CONVENIENTEMENTE ESCLARECIDO PELO PESQUISADOR E TER ENTENDIDO O QUE ME FOI EXPLICADO, CONSINTO EM PARTICIPAR DA PRESENTE PESQUISA".

São Paulo, de de 2011.

( ) Paciente / ( ) Responsável:

Testemunha 1:

Nome / RG / Telefone

Testemunha 2:

Nome / RG / Telefone

Responsável pelo Projeto:

Prof. Dra. Marília Cerqueira Leite Seelaender Instituto de Ciências Biomédicas I

Telefone para contato: 30917225

Identificação do CEP-HU: Endereço: Av. Prof. Lineu Preste, 2565 - Cidade Universitária

CEP: 05508-900 São Paulo-SP

Telefone: $3039-9457$ ou 3039-9479

e-mail: CEP@hu.usp.br 